\title{
PREVALÊNCIA DA HIPERTENSÃO ARTERIAL REFERIDA, PERCEPÇÃO DE SUA ORIGEM E FORMAS DE CONTROLE EM ÁREA DA METROPOLITANA DE SÃO PAULO - SP (1989-1990)
}

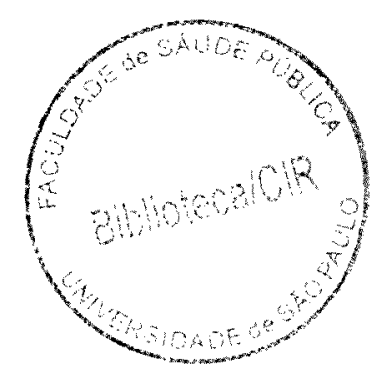

ANA LUIZA LIMA SOUSA

Tese de Doutorado apresentada ao Departamento de Epidemiologia da Faculdade de Saúde Pública da Universidade de São Paulo para obtenção do Grau de Doutor. Área de concentração: Epidemiologia

ORIENTADOR: PROF. DR . CHESTER LUIZ GALVÃO CESAR

São Paulo - SP 1999 


\title{
PREVALÊNCIA DA HIPERTENSÃO ARTERIAL REFERIDA, PERCEPÇÃO DE SUA ORIGEM E FORMAS DE CONTROLE EM ÁREA DA METROPOLITANA DE SÃO PAULO - SP (1989-1990)
}

\begin{abstract}
ANA LUIZA LIMA SOUSA
Tese de Doutorado apresentada ao Departamento de Epidemiologia da Faculdade de Saúde Pública da Universidade de São Paulo para obtenção do Grau de Doutor. Área de concentração: Epidemiologia
\end{abstract}

ORIENTADOR: PROF. DR . CHESTER LUIZ GALVÃO CESAR

São Paulo - SP 1999 
Autorizo, exclusivamente para fins acadêmicos e científicos, a reprodução total ou parcial desta tese, por processos fotocopiadores.

Assinatura:

Data:

$39069 / 99(d 0 c)$ 


\section{DEDICATÓRIA}

aos meus pais, pelo exemplo de vida,

pelo estímulo e principalmente,

pela presença constante em todos os momentos. 


\section{AGRADECIMENTOS}

Ao Prof. Dr. CHESTER LUIZ GALVÃO CESAR pela orientação deste trabalho.

À amiga ESTELAMARIS TRONCO MONEGO por ser um ponto de apoio e por toda cooperação.

À Fundação Aperfeiçoamento de Pessoal de Nível Superior (CAPES) que viabilizou esta qualificação concedendo-me bolsa de pós-graduação (PICD).

À Pró-Reitoria de Pesquisa e Pós-Graduação da Universidade Federal de Goiás.

À todos que, de alguma forma, participaram para tornar possivel esta realização. 


\section{RESUMO}

Sousa ALL. Prevalência da Hipertensão Arterial referida, percepção de sua origem e formas de controle em área da metropolitana de São Paulo - SP (1989 - 1990). [Tese de Doutorado - Faculdade de Saúde Pública da USP].

Objetivo. Estudar a prevalência da hipertensão arterial, a percepção de sua origem pela população segundo os modelos etiológicos, as formas de controle e a correlação entre os modelos e formas de controle. Material e Métodos. Utilizou-se banco de dados primário gerado por inquérito domiciliar de saúde (1989-1990), com 10199 entrevistas. Foi analisada a prevalência da morbidade referida, os modelos etiológicos, uso dos serviços e de medicação, e a correlação entre o modelo de percepção e estas formas de controle. $\mathrm{Na}$ análise estatística foi utilizado o teste qui-quadrado, regressão logística e freqüências absolutas e relativas. Resultados. A população de hipertensos maiores de 20 anos foi constituida de 1681 individuos. A prevalência da hipertensão foi de $18,0 \%$. Foi maior no sexo feminino e indivíduos com menor escolaridade. Prevaleceu o modelo de percepção endógeno. As mulheres apresentaram mais este modelo ( $p<$ $0,00001)$. A maioria não usava os serviços de saúde $(63,8 \%)$ e $44,0 \%$ não usavam medicação. As mulheres procuraram mais pela assistência ( $p=$ $0,00002)$ e apresentavam mais uso de medicamentos $(p=0,00006)$. $O$ modelo de percepção esteve associado com o uso de serviços, mas não ao de medicamentos. Conclusões. A prevalência referida reflete a taxa de deteç̧ão de casos e subestima o valor real. $O$ modelo de percepção endógeno prevaleceu na população $e$ isto deve ser usado para o planejamento e para estratégias de abordagem terapêutica.

Descritores: Hipertensão arterial, modelos etiológicos. 


\section{SUMMARY}

Sousa ALL. Prevalence rates of referred Hypertension, the perception of its origin and its control forms in the Metropolitan Area / São Paulo, 1989 1990, SP, Brazil. [USP Public Health Faculty].

Objective. The objective was to study the prevalence rates of referred Hypertension, the perception of its origin by the population according to etiological models, the forms of control and the correlation between the models and the forms of control. Material and methods. A primary database was generated from a household health survey $(1989$ - 1990) when 10199 families were interviewed. This data base was used to analyse referred morbidity prevalence, the etiological models, service and medication uses and, the association between the perception model and these forms of control. Chi Square tests, logistic regression and absolute and relative frequency were the statistical methods used. Results. The hypertensive population over 20 years of age was composed of 1681 persons. The prevalence of hypertension was $18 \%$. It was greater within the female group and people with less formal education. The endogenous perception model predominated. Woman presented this model more then man $(p=0,00002)$ and used more drugs $(p=0,00006)$. The perception model was associated to the use of services, but not to the use of drugs.

Conclusions. The referred prevalence reflects the rate of case detection but underestimates its actual value. The endogenous perception model prevailed in the population and this ought to be used in planning and for strategic therapeutic approach.

Index terms: Arterial Hypertension, etiological models. 


\title{
ÍNDICE
}

\author{
Lista de Figuras \\ Lista de Quadros \\ Lista de Tabelas \\ Resumo \\ Summary
}

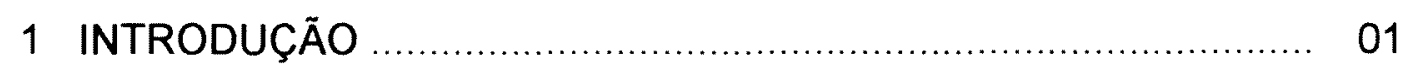

1.1 A Hipertensão Arterial ................................................ 01

1.2 A Hipertensão como Fator de Risco ................................ 04

1.3 Definição de Hipertensão Arterial ..................................... 07

1.40 Desafio do Diagnóstico ............................................ 09

1.5 A Hipertensão Arterial como Morbidade Referida ................. 13

1.6 Percepção da Origem da Doença .................................... 21

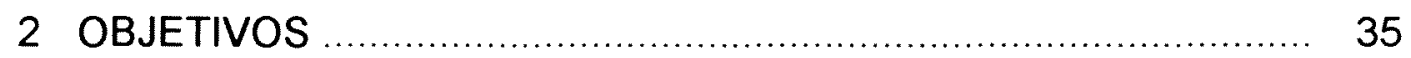

2.1 Objetivo Geral ..................................................... 35

2.2 Objetivos Específicos .............................................. 35

3 MATERIAL E MÉTODOS .................................................... 36

3.1 Área de Estudo .......................................................... 36

3.2 Fonte dos Dados ............................................... 41

3.3 População de Estudo................................................. 42

3.4 Amostragem ....................................................... 42

3.5 Coleta dos Dados ....................................................... 44

3.6 Definição das Variáveis.................................................. 45

3.6.1 Variáveis Sócio-Demográficas ..................................... 45

3.6.2 Categorização para Estudo da Percepção sobre a Doença .. 47

3.6.3 Questões Usadas para Estudo do Controle da Doença........ 50 


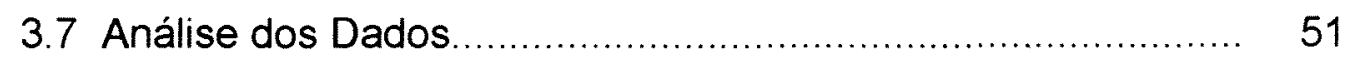

3.7.1 Análise da Prevalência da Hipertensão Arterial Referida ..... 51

3.7.2 Análise do Modelo Etiológico da Hipertensão Arterial........... 52

3.7.3 Análise sobre o Uso dos Serviços de Saúde e Uso de 53 Medicação Especifica como Formas de Controle sobre a Doença 3.7.4. Regressão Logística Múltipla

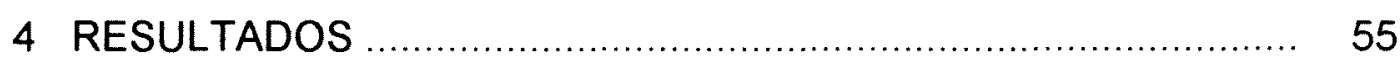

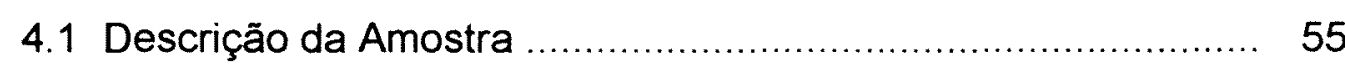

4.2 A Prevalência da Hipertensão Arterial Referida .................... 56

4.2.1 A Prevalência da Hipertensão Arterial e sua Associação com as Variáveis

4.3 Os modelos Etiológicos e suas Associações com as Variáveis 61

4.3.1 As Categorias e Respostas da Percepção e suas Associações com o sexo e idade....................................... 69

4.4 As Formas de Controle sobre a Hipertensão Arterial ............ $\quad 79$

4.4.1 O Uso dos Serviços de Saúde ............................................ 79

4.4.2 O Uso de Medicamentos Específicos ….............................. 84

4.4.3 O Uso dos Serviços Associado Uso da Medicação Especifica 90

4.5 A Influência do Modelo Etiológico sobre Formas de Controle da Morbidade

4.5.1 O Modelo Etiológico e o Uso dos Serviços de Saúde ........... 91

4.5.2 O Modelo Etiológico e o Uso de Medicamentos Específicos .. 93

5 DISCUSSÃO

5.1 A Prevalência da Hipertensão Arterial Referida .................... 99

5.2 Os Modelos Etiológicos ................................................... 107

5.3 As Formas de Controle sobre a Hipertensão Arterial ............ 117

5.3.1 O Uso dos Serviços de Saúde como Forma de Controle da Doença 
5.3.2 O Uso de Medicamentos Específicos como Forma de Controle da Doença

5.4 Os Modelos Etiológicos e as Formas de Controle da Hipertensão Arterial

6 CONCLUSÕES

7 REFERÊNCIAS BIBLIOGRÁFICAS ANEXO

Anexo 1 - Instrumento de coleta dos dados no Inquérito 


\section{LISTA DE FIGURAS}

Figura

Título

$\mathrm{pg}$

1 Mapa da região metropolitana de São Paulo.

2 Pirâmide populacional Região Sudoeste da Grande São Paulo, 1989 90.

3 Coeficiente de prevalência (\%) da hipertensão arterial referida segundo nivel de escolaridade. Região Sudoeste da Grande São Paulo - SP, 1989 -90 .

4 Distribuição da porcentagem de hipertensos referidos segundo os modelos etiológicos relacionados à hipertensão arterial. Região Sudoeste da Grande São Paulo - SP, 1989 - 90

5 Distribuição do número de hipertensos referidos segundo os municipios de residência e os modelos etiológicos sobre hipertensão arterial. Região Sudoeste da Grande São Paulo - SP , 1989 - 90.

6 Distribuição do número de hipertensos referidos segundo sexo e os modelos etiológicos sobre a hipertensão arterial. Região Sudoeste da Grande São Paulo - SP , 1989 - 90.

7 Distribuição do número de hipertensos referidos segundo a idade e os modelos etiológicos sobre a hipertensão arterial. Região Sudoeste da Grande São Paulo - SP , 1989 - 90.

8 Distribuição do número de hipertenso referidos segundo nível de escolaridade e os modelos etiológicos sobre a hipertensão arterial. Região Sudoeste da Grande São Paulo - SP , 1989 - 90

9 Distribuição do número de hipertensos referidos segundo a condição de classe e os modelos etiológicos sobre a hipertensão arterial. Região Sudoeste da Grande São Paulo - SP, 1989 - 90.

10 Distribuição do número de hipertensos referidos segundo as categorias dos modelos etiológicos e o sexo. Região Sudoeste da Grande São Paulo - SP, $1989-90$

11 Distribuição do número de hipertensos referidos segundo as respostas da categoria A - condições ambientais e causas sócio-econômicas e o sexo. Região Sudoeste da Grande São Paulo - SP, 1989 - 90. 
12 Distribuição do número de hipertensos referidos segundo as respostas da categoria B - situações comportamentais e de hábitos de vida e o sexo. Região Sudoeste da Grande São Paulo - SP, 1989 - 90.

13 Distribuição do número de hipertensos referidos segundo as respostas da categoria C - causas psicossociais e o sexo. Região Sudoeste da Grande São Paulo - SP, $1989-90$.

14 Distribuição do número de hipertensos referidos segundo as respostas da categoria D - causas naturais e o sexo. Região Sudoeste da Grande São Paulo - SP, 1989 - 90 .

15 Distribuição do número de hipertensos referidos segundo as categorias e faixas etárias. Região Sudoeste da Grande São Paulo - SP, 1989 - 90....

16 Distribuição do número de hipertensos referidos segundo as respostas da categoria A - condições ambientais e causas sócio-econômicas e faixa etária. Região Sudoeste da Grande São Paulo - SP, 1989 - 90.

17 Distribuição do número de hipertensos referidos segundo as respostas da categoria B - situações comportamentais e de hábitos de vida e faixa etária. Região Sudoeste da Grande São Paulo - SP, 1989 - 90.

18 Distribuição do número de hipertensos referidos segundo as respostas da categoria C - causas psicossociais e faixa etária. Região Sudoeste da Grande São Paulo - SP, 1989 - 90

19 Distribuição do número de hipertensos referidos segundo as respostas da categoria D - causas naturais e faixa etária. Região Sudoeste da Grande São Paulo - SP, 1989 - 90.

20 Distribuição dos número de hipertensos referidos segundo $\circ$ uso dos serviços de saúde e sexo. Região Sudoeste da Grande São Paulo - SP, $1989-90$.

21 Distribuição do número de hipertensos referidos segundo o uso dos serviços e faixa etária. Região Sudoeste da Grande São Paulo - SP, $1989-90$

22 Distribuição do número de hipertensos referidos segundo o uso dos serviços e a condição de classe. Região Sudoeste da Grande São Paulo - SP, $1989-90$.

23 Distribuição do número de hipertensos referidos segundo o uso de medicamentos específicos e sexo. Região Sudoeste da Grande São Paulo - SP, 1989 - 90 
24 Distribuição do número de hipertensos referidos segundo o uso de medicamentos específicos e faixa etária. Região Sudoeste da Grande São Paulo - SP, 1989 - 90

25 Distribuição do número de hipertensos referidos segundo 0 uso de medicamentos específicos e a condição de classe. Região Sudoeste da Grande São Paulo - SP, 1989 - 90.

26 Distribuição do número de hipertensos referidos segundo o uso dos serviços de saúde e uso de medicamentos especificos. Região Sudoeste da Grande São Paulo - SP, 1989 - 90.

27 Distribuição do número de hipertensos referidos segundo os modelos etiológicos e a procura por assistência. Região Sudoeste da Grande São Paulo - SP, $1989-90$.

28 Distribuição do número de hipertensos referidos segundo os modelos etiológicos e o uso de medicamentos específicos. Região Sudoeste da Grande São Paulo - SP, 1989 - 90. 


\section{LISTA DE QUADROS}

Quadro

Título

pg

1 Síntese dos modelos etiológicos segundo seus pares

2 Categorização das respostas quanto à percepção da população sobre a origem da Hipertensão Arterial.

3 Resumo dos resultados encontrados. Região Sudoeste da Grande São Paulo - SP, 1989 - 90 


\section{LISTA DE TABELAS}

1 Taxas populacionais de conhecimento, tratamento e controle da pressão arterial alta em adultos. Estados Unidos, 1976 - 94

2 Taxas de prevalência, conhecimento, tratamento e controle da pressão arterial alta em adultos

3 Distribuição dos municípios segundo área e população. Região Sudoeste da Grande São Paulo - SP. 1989 - 1990.

4 Número de habitantes por domicilio e densidade demográfica (hab/ $\mathrm{Km}^{2}$ ) por municípios. Região Sudoeste da Grande São Paulo - SP. 1980-1991.

5 Distribuição dos municípios do ERSA - 12, segundo taxa de crescimento urbano. Região Sudoeste da Grande São Paulo - SP, 1980 - 1991.

6 Distribuição da população ( $\geq 20$ anos) segundo sexo. Região Sudoeste da Grande São Paulo, 1989-1990.

7 Distribuição da população hipertensa ( $\geq 20$ anos), segundo sexo e idade. Região Sudoeste da Grande São Paulo, 1989 -1990

8 Distribuição dos coeficientes de prevalência da Hipertensão Arterial referida segundo o município de residência. Região Sudoeste da Grande São Paulo, 1989-1990

9 Intervalos com 95\% de Confiança dos coeficientes de prevalência (\%) da Hipertensão Arterial referida ( $\geq 20$ anos) segundo o municipio de residência. Região Sudoeste da Grande São Paulo, 1989-1990

10 Distribuição do número de casos e coeficientes de prevalência de Hipertensão Arterial referida na população segundo faixa etária. Região Sudoeste da Grande São Paulo - SP, 1989 - 1990

11 Número e coeficiente de prevalência (\%) de Hipertensão Arterial na população ( $\geq 20$ anos)segundo condição de classe. Região Sudoeste da Grande São Paulo - SP, 1989 - 1990

12 Número e porcentagem de hipertensos referidos segundo as categorias de percepção sobre a origem da Hipertensão Arterial. Região Sudoeste da Grande São Paulo, 1989 - 1990. 
13 Número e porcentagem de hipertensos referidos segundo os modelos etiológicos. Região Sudoeste da Grande São Paulo, 1989 - 1990.

14 Distribuição do número e porcentagens dos hipertensos referidos que usam os serviços de saúde. Região Sudoeste da Grande São Paulo SP, $1989-90$.

15 Distribuição da freqüência e porcentagem dos hipertensos referidos segundo as respostas justificando a falta da procura por assistência. Região Sudoeste da Grande São Paulo - SP, 1989 - 90

16 Distribuição da freqüência e porcentagem de hipertensos referidos segundo as justificativas da falta de procura por assistência e o sexo. Região Sudoeste da Grande São Paulo - SP, 1989 - 90.

17 Distribuição dos indivíduos hipertensos que não fazem uso de medicamento segundo a justificativa. Região Sudoeste da Grande São Paulo - SP, 1989 - 90

18 Distribuição das justificativas do não uso de medicação específica segundo o sexo. Região Sudoeste da Grande São Paulo - SP, 1989 - 90

19 Distribuição das variáveis segundo o uso dos serviços de saúde em hipertensos ( $\geq 20$ anos). Região sudoeste da Grande São Paulo - SP, $1989-1990$

20 Distribuição das variáveis segundo o uso de medicação por hipertensos ( $\geq 20$ anos). Região sudoeste da Grande São Paulo - SP, 1989 1990

21 Análise multivariada do uso dos serviços de saúde segundo as variáveis do estudo. Região sudoeste da Grande São Paulo - SP, 1989 - 1990

22 Análise multivariada do uso de medicamentos segundo as variáveis do estudo. Região sudoeste da Grande São Paulo - SP, 1989 - 1990

23 Prevalências (\%) da hipertensão em alguns estudos. Brasil - 1999 


\section{INTRODUÇÃO}

\section{1 - A Hipertensão Arterial}

A hipertensão arterial é uma entidade clínica multifatorial, conceituada atualmente como uma síndrome, associada a alterações metabólicas e hormonais e a fenômenos tróficos (hipertrofia cardiaca e vascular), não devendo ser caracterizada somente pela elevação da pressão arterial acima de determinados níveis adotados para normalidade. A existência de uma definição operacional, traduzida em números, serve apenas para facilitar o diagnóstico, comportando, por outro lado, uma comparação com um "padrão ouro" (III CONSENSO BRASILEIRO DE HIPERTENSÃO, 1998).

De acordo com a Organização Mundial de Saúde as taxas de mortalidade por doença coronariana e doença cerebrovascular estão aumentando rapidamente em paises em desenvolvimento e nas antigas repúblicas socialistas. Isto ao ponto de se falar em uma segunda onda de epidemia das doenças cardiovasculares. Estima-se que, até o ano 2020 , estas doenças ocuparão o primeiro e quarto lugar respectivamente como causas de morte no mundo. Diante disso o controle da hipertensão arterial apresenta-se como um desafio para as autoridades de saúde pública e profissionais de saúde, pois esta morbidade tem um papel central na patogênese tanto das doenças cerebrovasculares quanto das coronarianas (WORLD HEALTH ORGANIZATION, 1999).

A Organização Mundial de Saúde estimava que, em 1997, havia 691 milhões de pessoas hipertensas em todo o mundo (WORLD HEALTH ORGANIZATION, 1997). Só nos Estados Unidos da América do Norte, segundo os critérios do $\mathrm{V}$ Report of The Joint National Committee on Detection, Evaluation and Treatment of High Blood Pressure, esse número seria de 40 milhões (VJOINT NATIONAL COMMITTEE, 1993). 
A prevalência da Hipertensão Arterial é extremamente variável, segundo o país e também em função dos diferentes critérios de diagnóstico. Existem comunidades tribais onde a prevalência praticamente é nula ou então é muito baixa, como por exemplo populações de Ilhas do Pacífico, indios Yanomami e Xavantes no Brasil e comunidades isoladas como os Kalungas, também no Brasil (LOWENSTEIN, 1961; MADDOCKS, 1961; SUAREZ, 1985; LÓLIO, 1990b; JARDIM e col., 1992a; BLOCH e col., 1993; CARNEIRO e JARDIM, 1993). Outros países e regiōes apresentam valores que variam desde 9,3\% na Nigéria a 39,8\% em Buenos Aires, 32,7\% na Espanha e 27,9\% em Barbados (FREEMAN e col., 1996a; KAUFAMN e col., 1996; PURAS e col., 1998).

Nos Estados Unidos, para os anos de 1971 a 1975 (NHANES I), considerando o critério do Joint National Committee for the Detection, Evaluation and Treatment of High Blood Pressure (V JNC), a taxa de prevalência encontrada foi de $36.3 \%$. No segundo inquérito realizado de 1976 a 1980 (NHANES II), esta taxa foi igual a $26,4 \%$. Os resultados do último National Health and Nutrition Examination Surveys (NHANES III 1988 a 1991) revelaram uma taxa de $24,2 \%$ (WORLD HEALTH ORGANIZATION, 1978; ROBERTS e ROWLAND, 1981; DRIZD e col., 1986; BURT e col., 1995b).

Segundo a Sociedade Interamericana de Hipertensão essa é hoje uma enfermidade generalizada na América Latina com mais de 30 milhões de hipertensos, com pequenas variações de país para país: México - 22,0\% dos adultos; Equador - 22,0\%; Uruguai - 20,0\%; Chile - 18,8\% das pessoas acima de 15 anos; Costa Rica - 14,4\% (SOCIEDADE INTEAMERICANA DE HIPERTENSÃO, 1996) .

No Brasil, o impacto sócio-econômico da Hipertensão Arterial isoladamente também é significativo. COSTA, em 1983, apresentou dados da Secretaria de Serviços Previdenciários de 1978, que informavam que o tempo médio de trabalho perdido por pessoa, que esteve em benefício de saúde e retornou a atividade, foi de 370 dias, mais do que o dobro de afastamento por outras razões. Trata-se de doença que mais determina 
afastamento do trabalho e de mais longa duração. É também a primeira causa de aposentadoria precoce, tanto em termos de incidência como de prevalência de incapacidade definitiva. As doenças cardiovasculares, incluindo a Hipertensão Arterial , representaram a terceira causa de auxíliodoença em 1986 com mais de cem mil licenciados (MINISTÉRIO DA SAÜDE, 1993).

A maioria dos dados disponiveis sobre hipertensão arterial no Brasil são de mortalidade, portanto não deixam claro se as mudanças são ligadas à incidência de casos ou à letalidade dos mesmos. Deve-se considerar que atestados de óbitos não são os melhores instrumentos de registro desse agravo, pois devido às disposições internacionais de codificação das declarações de óbito, a hipertensão foi substituída como causa básica de morte pelas suas mais freqüentes complicações (doenças coronariana e cerebrovasculares). Estudos de mortalidade podem ser usados para determinar a influência da hipertensão arterial, desde que sejam utilizados os dados de mortalidade com causas múltiplas e não por causa básica (LÓLIO, 1990a; LESSA, 1998). Daí a dificuldade de estudar essa doença, dentre as cardiovasculares, pois mesmo as taxas de mortalidade só permitem análises indiretas sobre a sua presença.

Muitos estudos sobre prevalência e aspectos epidemiológicos da hipertensão no Brasil têm sido feitos, desde a década de 40 . Geralmente são estudos regionais com abrangência local (municípios, empresas). A maioria dos estudos que tem apresentado valores de prevalência utilizam-se da medida convencional da pressão arterial e diferentes metodologias para a amostragem e critérios de normalidade. Alguns estudos nacionais apresentam taxas de prevalência variando de $7,8 \%$ a $37,9 \%$ na dependência dos critérios adotados e da população investigada (LESSA, 1998). Apesar das limitações, são estudos que têm possibilitado um pouco mais de conhecimento sobre como se distribui essa morbidade em nosso país e o desenho de seu perfil epidemiológico na população brasileira (KLEIN, 1981, 1985; LÓLIO, 1990a; CARNEIRO e JARDIM, 1993; MOURA e col., 1995). 


\section{2 - A Hipertensão como Fator de Risco}

A Hipertensão Arterial é o fator de risco mais comum para doenças do coração e doenças renais, representando altos índices de incapacidade e mortes, independente da associação com outros fatores preditivos dessas doenças. Estima-se que aproximadamente $35,0 \%$ dos eventos cardiovasculares ateroscleróticos possam ser atribuídos a Hipertensão Arterial. Trata-se de um fator de risco para todas as formas de doenças cardiovasculares ateroscleróticas incluindo insuficiência cardíaca, acidente vascular cerebral, doença coronariana e doença arterial periférica. Manifestações clínicas de doença coronariana, tais como angina, infarto do miocárdio e morte súbita estão aumentadas em pessoas com Hipertensão e o risco é proporcional à gravidade da Hipertensão prévia (LAURENTI e FONSECA, 1976; LÓLIO e LAURENTTI, 1986; KANNEL, 1993, 1996; LOTUFO e LÓLIO, 1995).

O desenvolvimento da hipertensão tem um forte componente de fatores ambientais e de comportamento. A forma de conduzir a vida e os hábitos adquiridos quanto a alimentação podem ser responsabilizados pela presença desta morbidade em grande número dos casos. Diversos estudos epidemiológicos tem associado os níveis de pressão arterial com a obesidade, alta ingesta de sódio, consumo excessivo de álcool e inatividade física. Existem outros fatores de risco que interagem com a pressão arterial para aumentar o risco de doenças cardiovasculares, tais como: tabagismo e dislipidemias (PAGE, 1976; COSTA e col., 1990; V JOINT NATIONAL COMMITTEE, 1993; KANNEL, 1993, 1996; STAMLER, 1997).

A pressão arterial, particularmente a sistólica, tende a aumentar progressivamente com a idade. Estudos em populações primitivas não apresentam esse comportamento, como os índios Xavantes e Yanomami e descendentes de escravos na comunidade Kalunga (JARDIM e col., 1992b; CARNEIRO e col., 1993; BLOCH e col., 1993). O fator idade relacionado com a hipertensão está também associado ao modo de vida das civilizações. 
As mulheres apresentam pressões arteriais mais baixas até a meia idade, mas estas tendem a aumentar acentuadamente com o tempo, equiparando-se com a pressão arterial dos homens após a meia idade. As taxas de morbidade e mortalidade são mais altas nos homens $\mathrm{O}$ estudo de Framingham mostra uma elevação média de $20 \mathrm{mmHg}$ na pressão sistólica e de $10 \mathrm{mmHg}$ na diastólica dos 30 aos 65 anos, sendo que entre as mulheres continuou a subir até a oitava década e entre os homens até a sétima (KANNEL, 1996; KAPLAN, 1990; DUNCAN e col., 1993 ).

Maior prevalência da hipertensão é reconhecida entre a população de raça negra. Estudos que procuram identificar a variável raça têm esbarrado na dificuldade da própria classificação racial que difere largamente de um país para outro (AZEVEDO, 1996) Na América do Norte, alguns estudos apresentam a prevalência da hipertensão arterial mais alta entre negros e com maior número de complicações como doenças cerebrovasculares e insuficiência cardiaca nesta raça. A prevalência em alguns estudos chegou a ser duas vezes maior entre os negros (HYPERTENSION DETECTION AND FOLLOW-UP PROGRAM, 1977). Na população afro-americana residente nos Estados Unidos da América a alta prevalência de hipertensão e o fracasso do tratamento para alcançar o controle da doença, parecem estar associados ao baixo poder sócio-econômico e ao padrão de utilização dos serviços de saúde. No Brasil, estudos epidemiológicos também têm registrado maior prevalência da hipertensão arterial entre negros e mulatos do que entre os brancos (RIBEIRO e col., 1981; COSTA, 1983; KAPLAN, 1990; KANNEL, 1996; FANG e col., 1996).

Ainda há muita discussão sobre o grau de contribuição dos fatores genéticos e biológicos sobre a determinação e susceptibilidade para Hipertensão Arterial. Alguns pesquisadores preferem utilizar a idéia de raça como uma variável social mais relacionada com o ambiente. Dessa forma a raça estaria relacionada à Hipertensão através dos hábitos dietéticos e estresse psicológico. CARVALHO (1983) encontrou taxas de prevalência maiores entre grupos de presidiários, independente de raça e idade. A maioria das doenças crônicas que acometem mais os negros é mais comum 
entre indivíduos com nivel sócio-econômico mais baixo (LÓLIO, 1990b ; LOPES, 1996). CORDEIRO ( 1993) encontrou maiores prevalências entre os trabalhadores não especializados e com menores salários.

As condições sócio-econômicas da população também são fatores que têm merecido a atenção de diversos autores. A grande dificuldade de comparar os dados existentes sobre hipertensão arterial e classe social é devido a falta de padronização de metodologia dos estudos. Apesar disso, pode-se notar entre os estudos existentes uma relação inversa entre hipertensão arterial e escolaridade, ocupação e renda familiar. Sociedades mais privilegiadas apresentam menores prevalências. Acredita-se que são questões que devem ser elucidadas à luz das relações sociais e seus produtos: estresse, urbanização, acesso aos serviços públicos de saúde e educação e condições de moradia (ANTONOVSKY, 1968; RIBEIRO e col., 1981; KLEIN, 1981; COSTA, 1983; KOCHAR e WOODS, 1990; LÓLIO, 1990b; HE e col., 1991; TORMO e col., 1997).

Outros estudos apontam para a agregação familiar nos casos de Hipertensão, em parentes de primeiro grau. Há maior semelhança entre a pressão arterial de gêmeos monozigóticos que entre os dizigóticos. Filhos adotados não apresentam correlação entre seus níveis de pressão e de seus pais, o que pode mostrar a existência de um patrimônio genético na determinação da pressão arterial (EYER, 1975; LÓLIO, 1990b).

O consumo de álcool também está associado com maior prevalência de hipertensão. Já a associação entre o hábito de fumar e a hipertensão não tem sido consistente. No entanto, sabe-se que pessoas tabagistas desenvolvem mais formas malignas da doença e têm mais altas taxas de mortalidade por morte súbita e doença coronariana (PAGE, 1983; LANG e col., 1987; LEVINE e col., 1993; VALLES e col., 1997).

Correlaciona-se também a prevalência da hipertensão com a obesidade em uma relação direta entre o peso excedente ao ideal e uma maior prevalência dessa morbidade. Entre os mais obesos existe maior freqüência da hipertensão (LÓLIO, 1993). Resultados do Framingham Study sugerem que $78,0 \%$ dos homens hipertensos e $65 \%$ das mulheres podem 
ter sua hipertensão atribuída diretamente à obesidade. Existe também uma relação inversa entre os niveis de atividade física e o valor pressórico, independente da obesidade. Há evidências que aumentando a atividade física pode-se reduzir a pressão arterial (STAMLER e col., 1985; LEVINE e col., 1993; KANNEL, 1996).

A relação positiva entre o consumo de sódio e a prevalência da Hipertensão Arterial tem sido demonstrada em várias populações de diferentes partes do mundo. O consumo de sódio em paises industrializados tem estado muito acima das necessidades fisiológicas e há uma associação entre esta ingestão e o nível da pressão arterial. Por outro lado, em populações primitivas, com baixo conteúdo de sódio na dieta, mostram valores de pressão mais baixos e sem alteração com a idade. O VI Relatório do Joint National Committee recomenda a redução moderada de sódio a um nivel de aproximadamente 6 gramas de cloreto de sódio ou 24 gramas de sódio por dia (PAGE, 1976;LÓLIO, 1990; LEVINE e col., 1993; STAMLER, 1997; VI JOINT NATIONAL COMMITTEE, 1997).

\section{3 - Definição de Hipertensão Arterial}

O diagnóstico da hipertensão arterial está associado a necessidade da realização de uma medida, traduzida em números muito mais do que a sinais e sintomas, como na maioria de outras patologias.

A variável pressão arterial é uma constante fisiológica usualmente medida em $\mathrm{cm}$ ou $\mathrm{mmHg}$ ou em $\mathrm{kPa}$. Está sujeita a variações durante cada ciclo cardíaco, dependendo também de situações fisiológicas como mudança de posição, atividade física, alterações de temperatura, estresse emocional, situações de sono e vigilia ou em situações patológicas como choque hemorrágico, insuficiência cardíaca e infarto agudo do miocárdio (LÓLIO, 1990b).

Desde a década de 30 vários valores tem sido sugeridos para definir Hipertensão Arterial, variando de $120 / 80$ a $180 / 110$ mmHg (PICKERING, 
1990). Estabelecer números para limites de corte de normalidade da pressão arterial essencial na prática médica, pois são necessários critérios que sirvam como norteadores na sistematização do diagnóstico.

O Joint National Committee for Detection, Evaluation and Treatment of High Blood Pressure (VI JOINT NATIONAL COMMITTEE, 1997) estabelece que, para o diagnóstico da hipertensão, devem ser feitas medidas apropriadas e repetidas da pressão arterial. Deve-se proceder a medida de um modo padronizado e com equipamentos que atendam aos critérios recomendados.

A definição do diagnóstico, qualquer que seja o nível da pressão, envolve riscos e custos, tanto quanto benefícios. Para KAPLAN (1990) a hipertensão deveria ser definida a partir de niveis da pressão nos quais os benefícios (menos os riscos e custos) da ação ultrapassassem os riscos e custos (menos os benefícios) da falta de ação.

Os critérios adotados no III CONSENSO BRASILEIRO DE HIPERTENSÃO (1998) estabelece como normal 0 indivíduo adulto $(\geq 18$ anos) com cifras inferiores a $85 \mathrm{mmHg}$ de pressão diastólica e inferiores a $130 \mathrm{mmHg}$ de pressão sistólica. Valores de pressão entre 130-139 de sistólica ou 85-89 de diastólica, devem ser considerados no limite da normalidade ("normal - alta"). De acordo com este critério pode-se classificar a Hipertensão Arterial em Hipertensão Leve (ou estágio 1), Hipertensão moderada (ou estágio 2), Hipertensão grave (estágio 3) e Hipertensão sistólica isolada (III CONSENSO BRASILEIRO DE HIPERTENSÃO, 1998).

Outra forma de classificação dessa morbidade é segundo a etiologia. Estima-se que mais de $90 \%$ dos casos não têm causa orgânica evidente e, portanto, são identificadas como hipertensão primária ou essencial. Nas situações em que alguma causa possa ser associada (doença renal, uso de drogas, doença de cushing, coarctação da aorta, doença das glândulas supra-renais, uso de contraceptivos hormonais ou gravidez) a hipertensão é secundária (KAPLAN, 1990; LÓLIO, 1990;III CONSENSO BRASILEIRO DE HIPERTENSÃO, 1998; NOBRE, 1998). 
Como qualquer medida, a pressão arterial pode sofrer variações em função de estímulos fisiológicos intrínsecos (sono, febre), ou ambientais (frio, calor, ruído). As medidas ainda podem sofrer alterações relacionadas ao mal uso do equipamento e a distorções do observador. Essa variabilidade da medida tem sido responsável pelas maiores dificuldades metodológicas nos estudos epidemiológicos. Diante disso tais estudos procuram reduzir a ocorrência de erros e de vícios na aferição através de técnicas padronizadas para o treinamento do observador, emprego de equipamentos modificados e manutenção e calibração freqüentes dos esfigmomanômetro, durante os processos de coleta. Mesmo assim, vale lembrar que a pressão arterial sofre flutuações casuais podendo apresentar valores diferentes em medidas subsequentes no mesmo momento. Por isso discute-se qual o número de medidas deveria ser válido para que se possa considerar o diagnóstico da hipertensão arterial. Pesquisas populacionais, que fazem uso das medidas de pressão precisam ser cautelosas na afirmação das taxas de prevalência encontradas. O III Consenso Brasileiro recomenda que para a confirmação diagnóstica as medidas sejam repetidas no mínimo duas vezes em ocasiões diferentes, sob condições controladas (LÓLIO, 1990; III CONSENSO BRASILEIRO DE HIPERTENSÃO, 1998).

\section{5 - O Desafio do Diagnóstico:}

A detecção, tratamento e controle dos indivíduos hipertensos deveriam ser assinalados como alta prioridade diante do risco que a hipertensão arterial não tratada oferece e também considerando o valor da terapia anti-hipertensiva na redução deste risco,.

Mesmo em países desenvolvidos, onde a tecnologia está avançada e os sistemas de saúde apresentam boa resolutividade, ainda não se pode afirmar que todo paciente hipertenso esteja identificado e esteja sendo tratado adequadamente. Tornou-se uma realidade reconhecida o fato de que 
entre um terço e um quarto dos individuos hipertensos continuam sem diagnóstico (WHELTON, 1994; SOCIEDADE INTERAMERICA DE HIPERTENSÃO, 1996; KANNEL, 1996; HYPERTENSION DETECTION AND FOLLOW-UP PROGRAM, 1977).

Entre aqueles diagnosticados muitos desconhecem sobre sua situação a maioria não busca tratamento e entre aqueles que tratam, a metade não alcança controle. Existe uma regra construida ao longo do tempo e comumente aceita sobre a epidemiologia da hipertensão arterial. $E$ a chamada "The rule of halves". De todos os individuos hipertensos em uma comunidade, somente a metade conhece seu diagnóstico. Daqueles que conhecem, a metade está sob tratamento e daqueles que estão sob tratamento, a metade tem seus níveis pressóricos controlados satisfatoriamente (MARQUES-VIDAL e TUOMILETHO, 1997).

Nos Estados Unidos da América essa tendência tem sido alterada pelo Programa Nacional de Educação sobre Pressão Arterial Alta (NHBPEP), estabelecido desde 1972. Segundo o último relatório do Joint (VI JOINT NATIONAL COMMITTEE, 1997) o programa tem alcançado sucesso em seu objetivo de aumentar o conhecimento, prevenção, tratamento e controle da hipertensão arterial. De acordo com os dados das pesquisas nos últimos trinta anos, pode-se identificar uma tendência em direção ao crescimento do conhecimento, tratamento e controle da hipertensão na comunidade, independente do ponto de corte de definição para a doença. A porcentagem de americanos que está ciente de que tem hipertensão arterial passou de $51,0 \%$ no segundo National Health and Nutrition Examination Survey (II NHANES 1976 - 1980) para 73,0\% no III NHANES (1988 - 1991 fase 1). Esses dados ajudam a entender por que houve uma redução na morbi-mortalidade atribuiveis a pressão alta e com reflexo na redução dos custos nacionais de cuidados com a saúde naquele país No entanto, esta tendência de crescimento nestas taxas não têm se mantido e são hoje um motivo de preocupação, pois as taxas de controle da Hipertensão Arterial não continuaram a melhorar na década de 90 (WHELTON, 1994; VI JOINT NATIONAL COMMITTEE, 1997) (Tabela 1). 
Tabela 1 - Taxas populacionais de conhecimento, tratamento e controle da pressão arterial alta em adultos. Estados Unidos, 1976 - 94.

\begin{tabular}{l|c|c|c} 
Taxas & $\begin{array}{c}\text { NHANES II } \\
\text { especificas }\end{array}$ & $\begin{array}{c}\text { NHANES III } \\
\text { (fase 1) }\end{array}$ & $\begin{array}{c}\text { NHANES III } \\
\text { (fase 2) } \\
\end{array}$ \\
& $(\% 76-80$ & $\begin{array}{c}1988-91 \\
1991-94\end{array}$ & $(\%)$ \\
\hline Conhecimento & 51,0 & 73,0 & 68,4 \\
\hline Tratamento & 31,0 & 55,0 & 53,6 \\
\hline Controle & 10,0 & 29,0 & 27,4 \\
\hline
\end{tabular}

Fonte: VI JOINT NATIONAL COMMITTEE, 1997.

Em estudos epidemiológicos realizados em todo o mundo, a taxa de conhecimento sobre a hipertensão arterial tem variado de 9,7\% em Israel a $90,0 \%$ em Barbados, e aqueles que estão sob tratamento de $24,0 \%$ no Egito a $85,0 \%$ em Barbados; e destes os que conseguem o controle pressórico varia de 7,6\% em Buenos Aires a 72,0\% em Barbados (DE-LENA e col., 1995; IBRAHIM e col., 1995; FREEMAN e col., 1996b; AMAND e col., 1996; PAVLIK e col., 1997; TORMO e col., 1997; VALLES e col., 1997) (Tabela 02). 
Tabela 2 - Taxas de prevalência, conhecimento, tratamento e controle da pressão arterial alta em adultos.

\begin{tabular}{|c|c|c|c|c|}
\hline Populações & $\begin{array}{c}\text { Prevalência } \\
(\%)\end{array}$ & $\begin{array}{c}\text { Conhecimento } \\
(\%)\end{array}$ & $\begin{array}{c}\text { Tratamento } \\
(\%)\end{array}$ & $\begin{array}{c}\text { Controle } \\
(\%)\end{array}$ \\
\hline Profissionais de saúde (1) & 9,7 & 73,2 & 19,7 & 28,0 \\
\hline Egito (2) & 26,3 & 37,5 & 23,9 & 8,0 \\
\hline St Lúcia ${ }^{(3)}$ & $\overline{18,3}$ & 74,0 & 59,0 & 35,0 \\
\hline Barbados $^{(3)}$ & 21,5 & 90,0 & 85,0 & 72,0 \\
\hline China $^{(4)}$ & 6,6 & 25,0 & 15,0 & 3,0 \\
\hline Jordão ${ }^{(5)}$ & 17,1 & 48,6 & - & 36,5 \\
\hline $\mid$ Israel ${ }^{(6)}$ & 26,7 & 9,7 & - & - \\
\hline Afro-americanos $^{(7)}$ & 45,0 & 73,0 & 64,0 & 28,0 \\
\hline Espanha $^{(8)}$ & - & 80,8 & 61,5 & 33,7 \\
\hline Buenos Aires $^{(9)}$ & 39,8 & 47,0 & 34,0 & 7,6 \\
\hline
\end{tabular}

FONTES: (1) VALLES col., 1997; (2) IBRAHIM e col., 1995; (3) FREEMAN e col., 1996b; (4) TAO-S e col., 1995; (5) JADDOU e col., 1996; (6) AMAND e col. 1996; (7) PAVLIK e col., 1997; (8) TORMO e col., 1997; (9) DE-LENA e col., 1995.

Quando se procura identificar e tratar o indivíduo hipertenso 0 objetivo final é reduzir o risco de doença cardiovascular e as taxas de morbidade $e$ mortalidade associadas. Os dados apresentados ajudam a confirmar que não basta o primeiro passo do diagnóstico, mas nenhum impacto será notado sobre as condições de saúde de uma população, no que se refere às doenças cardiovasculares, caso não seja alcançado maior sucesso no controle sobre a morbidade hipertensão arterial.

A maior dificuldade em se alcançar maiores taxas de diagnóstico e de controle sobre a hipertensão advém da própria característica do agravo, que por apresentar uma sintomatologia pobre ou mesmo ausente, não leva à procura pela assistência. 


\section{5 - O Estudo da Hipertensão Arterial como Morbidade Referida}

Estudos epidemiológicos, que fazem uso de dados de mortalidade, são extremamente úteis para identificar a situação de saúde de uma população, principalmente quando os riscos de mortalidade são elevados. No entanto quando se percebe a redução desses riscos e se pretende conhecer as tendências ao declínio destas taxas, o que tem ocorrido por exemplo com as doenças cardiovasculares no ocidente, é mais pertinente julgar a situação de saúde em função da morbidade. $\mathrm{O}$ conhecimento sobre as taxas de morbidade de uma população é fundamental para que os serviços possam traçar suas metas e fazer o planejamento de cobertura populacional, dando início ao processo de demanda de atenção (MEDINA e col., 1987).

Situações de saúde de uma população têm sido descritas com base nas consultas realizadas, possíveis hospitalizações e, mesmo, dados de mortalidade. Essa descrição fica restrita a uma fração da morbidade total, pois a totalidade do conhecimento de uma doença só seria possível através de exames médicos e diagnósticos da população. No entanto isso tem sido impraticável devido aos elevados custos financeiros e dificuldades operacionais.

$\mathrm{Na}$ América Latina os registros ou notificaçōes de casos pelos serviços de saúde nem sempre são completos e adequados, do ponto de vista de qualidade e da quantidade, pois os recursos limitados determinam que somente uma fração da incidência da enfermidade aguda e da prevalência de enfermidades crônicas seja assistida por profissionais de saúde e tenha portanto consulta registrada. Além disso as informações obtidas diretamente dos serviços de saúde são referentes à demanda, e não ao total da comunidade e podem, portanto, levar a quadros de morbidade populacional distorcidos. Para LEBRÃO e col., (1991) o desenvolvimento das estatísticas de morbidade tem sido muito lento e isso pode ser explicado em parte pelas dificuldades próprias do sistema de coleta 
dos dados e também pela falta de padronização destas estatísticas e das diferentes definições dos casos de doença.

Diante do prejuizo social produzido pelas enfermidades e do alto custo da assistência, as informações exatas que as estatísticas de morbidade podem oferecer tornam-se de extrema utilidade no planejamento das medidas de prevenção. Uma alternativa que vem sendo cada vez mais usada para este fim são os inquéritos populacionais. Trata-se do método mais apropriado em tais situações, pois proporcionam informações sobre áreas habitualmente pouco conhecidas no processo de produção de uma determinada enfermidade e da atenção médica. Eles oferecem uma valiosa informação a respeito da dimensão da percepção que a população tem da existência de enfermidades e sua relação com a utilização de serviços de saúde. Através de tais inquéritos é possível conhecer as caracteristicas da morbidade, os motivos pelos quais uma pessoa consulta ou deixa de fazê-lo, os sistemas de serviços oficiais e tradicionais empregados, o nível de satisfação com a assistência, a freqüência da auto - medicação e os custos em geral (MECHANIC, 1976; MEDINA e col., 1987; MEDICI, 1990).

A forma do levantamento dos dados de morbidade em inquéritos populacionais pode ser definida de forma distinta. Existe a "morbidade medicamente definida" que é aquela definida pelos profissionais e a "morbidade referida" pelo próprio sujeito acometido. São formas de medidas diferentes e que apresentam dificuldades específicas na coleta dos dados (LEBRÃO, 1997).

No caso da morbidade identificada a partir de um diagnóstico profissional, a maior dificuldade nos estudos epidemiológicos é justamente a aferição dentro dos conceitos padronizados. Inquéritos epidemiológicos que se utilizam de coleta de dados como medidas de pressão arterial, dosagem sérica de colesterol, dosagem de eliminação de sódio, são altamente dispendiosos e muitas vezes inviabilizam os estudos. Deve-se lembrar, também que qualquer dado mensurável estará sempre sofrendo influências de variados fatores que podem interferir nos resultados. Esses fatores podem estar presentes no equipamento (necessidade de calibração), no 
observador com sua subjetividade e no próprio indivíduo alvo destas medidas (variabilidade interna).

No caso dos dados coletados a partir da morbidade referida pelo próprio sujeito a principal dificuldade é que somente serão levadas em conta aquelas doenças percebidas por esse sujeito. $E$ assim, indivíduos assintomáticos poderiam, em um inquérito de auto-percepção, deixar de registrar doenças como anemia e hipertensão arterial, por exemplo, ou referirem doenças que não estão presentes. No entanto, a preferência pelo uso de dados assim referidos é justamente porque são eles que expressam demanda aos serviços de saúde, pois são as doenças percebidas pelos sujeitos que os motivam a procurar assistência (LEBRÃO, 1997).

Outra dificuldade encontrada em estudos que fazem uso de dados referidos é a definição da morbidade. Devem ser construídos conceitos que estejam ao alcance do conhecimento da enfermidade por parte da população. Este conhecimento é variável, pois as populações têm uma construção própria e culturalmente aprendida. O problema é justamente conseguir definir a enfermidade de forma tal que possa ser entendida pelo sujeito alvo da percepção (CARVALHEIRO e col. ,1982; KROEGER, 1986; MEDINA e col.,1987; BOWLIN e col., 1993).

Algumas vantagens de estudos com dados referidos incluem: a relativa rapidez e facilidade na coleta dos dados, baixos custos (se comparado com inquéritos que utilizam exames), a possibilidade de uso de leigos como entrevistadores e de medidas de percepção da saúde na comunidade (KROEGER, 1983).

O uso de dados referidos pela população tem a vantagem de permitir um melhor conhecimento de como os fenômenos mórbidos e o desempenho dos serviços de saúde são vistos e, desta forma, valorizar a visão que a comunidade tem sobre o sistema de saúde e o processo saúde-doença.

A percepção toma aspectos diferentes conforme a própria situação de desigualdade das condições sociais, econômicas e de reprodução da força de trabalho. A forma como são ofertados os serviços de saúde em cada 
classe social ou região parece contribuir para o aprofundamento destas diferenças na percepção das enfermidades (OLIVEIRA e SIMOES, 1984).

Um dos objetivos da maioria dos estudos aplicados tem sido avaliar as condições de saúde da população, tentando descobrir o componente submerso do processo saúde-doença - "a morbidade percebida ou sentida", ou ainda a "demanda reprimida", sem acesso aos serviços e analisar, também, a determinação social deste processo, subsidiando o planejamento de cuidados à saúde, em diferentes níveis geográficos ou administrativos. Busca-se, também, avaliar a presença de doenças especificas, contribuir para as pesquisas no campo das doenças crônicas ou grupos específicos de doenças e avaliar o uso de diferentes tipos de serviços de saúde (KROEGER, 1983; LEBRÃO e col., 1991).

Os inquéritos domiciliares sobre morbidade referida pela população e sobre os serviços têm tido um uso sistemático desde os anos 20 (SYNDENTRICKER 1925). São vários os estudos que têm se valido dessa forma de coleta de dados com múltiplos objetivos. Os exemplos mais completos são o National Health Interview Survey, e o National Health and Nutritional Examination Survey (NHANES) que começaram nos Estados Unidos a partir da década de 60 , e que constam de levantamentos nacionais contínuos por amostra. São colhidos dados através da aferição com aparelhos e também dados referidos pela população. Dentre os estudos internacionais o mais abrangente é o "International Collaborative Study on Health Care" que foi realizado em 12 regiões de sete paises (KOHN e WHITE, 1976; ROBERTS e ROWLAND, 1981; KROEGER 1983; LEBRÃO, 1997)

No Brasil, o exemplo mais abrangente é a Pesquisa Nacional por Amostra de Domicilio (PNAD), implantada em 1967. A PNAD, a partir de 1981, adotou um suplemento especial objetivando a obtenção de informações sobre as condições de saúde da população brasileira e de acesso aos serviços de saúde. A partir deste ano cada volume suplementar, em cada ano, atende determinada área. (Fundação IBGE 1981, 1990). 
A maioria dos estudos realizados no Brasil foi com o objetivo de proceder o levantamento de condições de saúde de populações de determinadas regiões. Foi realizado por CARVALHEIRO e col. (1982) o "Levantamento de condições de saúde por entrevistas domiciliárias", em Ribeirão Preto . Em 1984 foi feita "Análise das condições de saúde e de vida da população urbana de Botucatu - SP" (CARANDINA e col., 1986; LEBRÃO e col., 1991). CARVALHO e cols., realizaram estudo no Estado da Bahia, em 1982 - 86, utilizando instrumento de coleta de dados semelhante ao da PNAD - 1981 (CARVALHO e col., 1988). Em Itapecirica da Serra - SP, nos anos de 1989 - 90 foram colhidos dados para estudo da "Morbidade referida e utilização de serviços de saúde em localidades urbanas brasileiras" (CÉSAR e col., 1996). Nestes estudos foram analisados dados de morbidade referida e não se utilizou de qualquer aferição ou método para diagnóstico.

No caso específico da hipertensão arterial, tem sido uma prática comum nos estudos internacionais, a coleta dos dados aferidos para a análise da tendência do agravo, da distribuição e prevalência e também para conhecer a porcentagem da população com hipertensão que tem conhecimento do diagnóstico, que esteja em tratamento, e que tenha alcançado o controle pressórico (conhecimento, tratamento e controle). Trata-se de um método que tem sido incorporado aos estudos brasileiros mais recentemente (BURT e col., 1995a; 1995b; VARGAS e col., 1997).

O National Health and Nutrition Examination Survey (NHANES), nos Estados Unidos, tem sido o responsável pela vigilância sobre a hipertensão e faz isto baseando-se no cálculo da prevalência através da medida da pressão arterial. Devido ao alto custo e complexidade destes inquéritos, eles têm sido feitos com intervalos de, aproximadamente, 10 anos. Entre eles, anualmente, são feitos levantamentos com o uso de dados referidos, como fonte alternativa de dados. Para usar os dados referidos com confiança é necessário conhecer sua validade, isto é, quanto reflete o diagnóstico da doença. A partir do NHANES III (1988 - 1991) alguns estudos têm sido feitos para conhecer a validade do uso de dados referidos, especialmente no caso 
da hipertensão arterial. O NHANES III incluiu entrevistas domiciliares, exame físico e análise de laboratório em uma amostra com adultos maiores de 25 anos. Na entrevista foram considerados os dados de pressão arterial, uso de drogas antihipertensivas e características sócio-demográficas. Os participantes respondiam a pergunta: "Alguma vez um médico ou outro profissional de saúde lhe disse que tem hipertensão arterial, também chamada de pressão alta ?" Aqueles que afirmavam serem hipertensos eram então questionados sobre o uso de medicamentos e sobre o tratamento não farmacológico (dieta hipossódica, exercício físico, restrição do álcool). A pressão arterial foi medida aproximadamente seis vezes em cada participante e entrevistadores e médicos seguiam um protocolo padrão para obter as medidas. VARGAS e col. (1997) consideraram a validade dos dados comparando o diagnóstico prévio referido de hipertensão, contra o diagnóstico de hipertensão construido pela medida da pressão arterial e relato de uso de drogas hipotensoras ou uso de outras formas de controle. A sensibilidade, neste estudo foi de $75,0 \%$ e correspondeu ao conhecimento sobre a doença. Os resultados possibilitaram concluir que os dados de hipertensão arterial colhidos em entrevistas individuais podem ser apropriados como indicadores da prevalência da doença. Os autores concluíram que o dado referido da hipertensão pode ser usado para avaliar a tendência do agravo e como indicador da prevalência na ausência de medidas da pressão (VARGAS e col., 1997).

BOWLIN e col. (1993) também estudaram a validade de dados de morbidade referida. Eles utilizaram dados colhidos pelo Behavioral Risk Factors Surveillance System (BRFSS) do Centers for Disease Control dos Estados Unidos (CDC) através de inquéritos por telefone e exames físicos e laboratoriais. A maioria dos participantes foi examinada um mês após a entrevista ter sido realizada. A pergunta feita pelo telefone sobre a hipertensão arterial foi a mesma usada pelo NHANES III. E a pressão arterial foi registrada após duas ou três medidas usando um Random-Zero Esfigmomanômetro. A sensibilidade encontrada neste estudo foi de $40,0 \%$ para os homens e $46,0 \%$ para as mulheres. A prevalência com os dados 
referidos foi de 21,0 e $22,0 \%$ para homens e mulheres e a prevalência "real" era de $37,0 \%$ e $36,0 \%$ respectivamente. Os autores concluem que inquéritos com dados referidos podem ser usados para estimar os valores de prevalência e que outros estudos devem ser feitos que possibilitem a validação de dados através da comparação com medidas objetivas.

No Brasil, em estudo realizado no município de Botucatu -SP (1983 1984), utilizando-se de informações sobre morbidade referida, a hipertensão arterial representou $5,3 \%$ do total de queixas referidas. Nessa mesma população foi realizado estudo posterior com medidas de pressão arterial e a prevalência foi de $12,3 \%$ na faixa etária acima de 16 anos. Esses dados permitem inferir que mais de $50 \%$ dos hipertensos estavam sem diagnóstico (HABERMANN, 199?; LEBRÃO e col., 1991).

Em estudo realizado por CHOR (1997), foi aferida a pressão arterial em 319 funcionários de um banco estatal, e a prevalência de hipertensão encontrada foi de $20,4 \%$. As estimativas de sensibilidade da pergunta em relação à medida variou segundo a idade da população (os mais velhos parecem conhecer melhor sobre seus niveis pressóricos), critérios de classificação adotados e também do tipo de coleta dos dados. A sensibilidade encontrada aproximou-se de resultados de outros estudos com métodos semelhantes (BOWLIN e col., 1993; VARGAS e col., 1997).

Um dos problemas na coleta de dados referidos sobre hipertensão é justamente o conceito admitido sobre esta enfermidade. Entre os próprios profissionais tem variado muito os critérios utilizados para se determinar a presença ou não de valores pressóricos altos. Niveis tensionais altos, mas próximos dos limites de normalidade, podem produzir confusão, pois a doença pode estar sendo diagnosticada por alguns, em consideração a diferenças mínimas acima do limite superior de normalidade e, refutada por outros, com base nos mesmos argumentos. Outra questão a ser considerada quanto aos critérios é a diferença entre o que é utilizado pelo clínico e o que se utiliza em pesquisa epidemiológica. Sabe-se que o diagnóstico clínico é baseado em diversas medidas da pressão, de preferência em diferentes ocasiões, enquanto em situações de coleta de 
dados as medidas são feitas no mesmo dia. Por isso deve-se ter muito cuidado ao comparar dados para não colocar como semelhantes coisas distintas, pois em uma situação o objetivo é o diagnóstico individual e na outra a classificação populacional (CHOR, 1997).

A classificação da população segundo o nivel pressórico não é uma tarefa de fácil execução, pois está associada à medida da pressão arterial, a qual depende de treinamento para padronização e, mesmo assim, não está isenta de erros. A medida de pressão utilizada é, na verdade, a situação possivel, onde segundo CARVALHEIRO e col. (1982) o "investigador substitui o que ele gostaria de medir pelo que ele pode medir", pois a pressão arterial verdadeira, aquela obtida pela medida direta intra-arterial, está inviabilizada em estudos populacionais. Alguns obstáculos precisam ser superados na coleta de dados em tais estudos, como por exemplo: a necessidade de equipamentos calibrados, equipamentos conferidos sistematicamente, pessoal com treinamento específico e manuseio e transporte adequado desse equipamento (CARVALHEIRO e col., 1982).

É evidente que somente a medida da pressão arterial pode servir como instrumento para coleta de dados dos valores pressóricos, em estudos de prevalência populacional desta morbidade. A possibilidade de inquéritos com dados de morbidade referida, em se tratando da Hipertensão Arterial, apresenta-se como uma alternativa para o conhecimento do nivel de diagnóstico na região. Este conhecimento reflete o uso dos serviços de saúde e a assistência que tem sido ofertada, consequentemente traduzido na cobertura da extensão da morbidade.

O que pode ser observado nos estudos já realizados com a presença da medida da pressão arterial, é que muitas vezes o valor pressórico ocupa espaço central nas análises e outras variáveis sobre o uso dos serviços de saúde e mesmo sobre a percepção da população sobre a doença deixam de ser exploradas.

Estudar a hipertensão arterial como morbidade referida, sem a exigência da medida da pressão, pode facilitar o acesso a novos ângulos de conhecimento sobre esta doença. 
Como já foi demonstrado, o uso de dados referidos está sendo cada vez mais utilizado em diversos estudos sem prejuízo na qualidade metodológica ou dos resultados. O fato de ser a hipertensão um agravo mensurável com instrumento específico e que pode ser interpretada dentro de uma escala numérica não deve obrigar o investigador a se limitar aos números no seu conhecimento. Existem situações, como das doenças sexualmente transmissíveis, hanseniase e AIDS, em que não há uma medida numérica especifica e nem por isso os estudos sobre estas doenças são inviabilizados. Estudar o perfil epidemiológico e o padrão do uso dos serviços de saúde pela população hipertensa, sob o ângulo de sua própria percepção da doença, pode ser uma nova possibilidade para conhecer mais sobre as desigualdades na assistência e nas suas necessidades.

Um banco de dados assim gerado pode servir como nova fonte de informações para o planejamento de ações de saúde voltadas para grupos definidos e de acordo com as necessidades apresentadas. O que, em última análise, poderia significar redução de custos nos serviços de saúde e incremento nos benefícios ofertados (CESAR e TANAKA, 1996; BORREL, 1997).

\section{6 - A Percepção da origem da Doença}

"A doença é o lado sombrio da vida, uma espécie de cidadania mais onerosa. Todas as pessoas vivas têm dupla cidadania, uma no reino da saúde e outra no reino da doença. Embora todos prefiramos usar somente o bom passaporte, mais cedo ou mais tarde cada um de nós será obrigado, pelo menos por um curto período, a identificar-se como cidadão do outro país." (SONTAG, 1984, p.7). 
Estar doente é um dos aspectos da vida, è um fenômeno vital e representa uma das maneiras pela qual os corpos organizados se manifestam. A enfermidade é proveniente do indivíduo, e de imediato não revela seu vínculo com o social. Ela deve ser entendida como um fenômeno social que faz parte do modo de organização da vida cotidiana e da história pessoal de cada um. Trata-se de um fenômeno que não é apenas físico, mas possui uma dimensão psicológica "que passa pelo vivenciar e pela emoção de cada indivíduo". A natureza social da doença se verifica na especificidade do processo de adoecer e morrer dos diferentes grupos humanos, isto é, na análise das condições coletivas de vida. Existe uma historicidade nas doenças, ligada a todos os acontecimentos do ser humano (BERLINGUER, 1988; VAITSMAN, 1992; MONEGO, 1995).

(....) "o social, o cultural e o econômico são a fonte de origem das cadeias de causalidade que conduzem à saúde ou à doença através de uma contradição dialética, porque são os mesmos fatores os que ao final atuam para produzir uma ou outra" (BREIHL, 1991, p.18).

Existem diferenças profundas, entre individuos e entre povos no modo de reagir às doenças. As representações das doenças estão relacionadas às categorias sócio - culturais. A saúde e a doença são distribuidas de maneira desigual entre os individuos, classes e povos. Segundo MINAYO (1988) as concepções de saúde-doença são construídas em referência ao lugar e à posição de classe e no conjunto das experiências dadas por um modo de vida particular. Cada sociedade faz uma representação própria da doença em cada tempo.

A doença se manifesta e é percebida individualmente. Geralmente a percepção individual sobre a doença está associada aos usos e representações sociais que a pessoa faz de seu corpo. A experiência da doença é o que há de mais individual no ser humano e ao mesmo tempo o que é mais repleto de social. As interpretações engendradas do meio social 
e cultural ultrapassam as razões do corpo individual. (MINAYO, 1988; BERLIINGUER, 1988; OLIVEIRA, 1998).

A forma como uma população percebe a doença pode ser o determinante do seu comportamento de cuidado com a saúde, assim como do conceito de causalidade construído social e culturalmente. A forma como a doença é entendida vai permear a relação que se estabelece entre o individuo e os sistemas de saúde. Através de um processo de definição e interpretação o conceito de doença torna-se cristalizado e a partir daí são formulados os planos de ação. A construção social da concepção de doença tem um efeito importante na determinação por busca de assistência e sobre o tipo de profissional que será consultado. O modo como o indivíduo se percebe doente vai determinar diretamente o seu discurso e mesmo como ele entende que deva ser feita a assistência. Geralmente os comportamentos das pessoas devem ser considerados como uma função dos motivos, conhecimentos e crenças pessoais (MINAYO, 1988; KROEGER, 1986; MECHANIC, 1978; BLUMHAGEN, 1980; OLIVEIRA, 1998).

Um modelo de crenças e a forma de perceber o mundo são construções individuais, com influência das características da personalidade e do status social, e que vão estar na gênese da determinação dos comportamentos. Doenças que são ricas em sintomatologia fornecem material suficiente para que a pessoa se preocupe e se motive a buscar assistência e uma definição da morbidade identificada e sentida. Em situações onde os sinais e sintomas são obscuros ou até mesmo ausentes, esta motivação está ausente e muitas vezes sinais são "inventados" e sintomas podem ser criados como forma de justificar a doença.

As percepções e atitudes em relação à doença variam muito. $\mathrm{O}$ que a população pensa a respeito das doenças não deve ser desvinculado da própria concepção que trazem sobre a saúde. O comportamento em saúde é determinado a partir da consideração que o individuo tem em relação à possibilidade de ter um problema de saúde e acreditar que poderá minimizar a ameaça com atitudes individuais. A crença individual sobre saúde, a 
percepção e motivação que se tem sobre a realidade, tem valor primordial na determinação do comportamento. Além das crenças em saúde, as características de personalidade e o status social são importantes fatores que têm implicações na tomada de ação (REZENDE, 1989; LESCURA, 1990).

Quando estão presentes as motivações é esperado que haja como conseqüência um comportamento em saúde. Os sintomas de doenças, a ameaça à vida ou o medo de incapacitações podem funcionar como motivações. A motivação é pois uma condição necessária para a ação, como também vai determinar a forma de percepção do meio ambiente. Por outro lado o comportamento pode existir mesmo na ausência deste agente motivador, caso esteja presente a ação do trabalhador em saúde (LESCURA, 1990).

O indivíduo, ao identificar a presença da doença, julga o seu estado por suas manifestações intrínsecas e seus efeitos e busca no profissional de saúde a legitimidade de sua situação através de uma definição. A busca por esta definição é precedida pela percepção do indivíduo da doença em seu corpo. A partir daí define comportamentos em relação a seu estado e define o poder estar doente, não só para si como para o outro e para a sociedade. Mais do que a opinião dos médicos, é a própria apreciação dos pacientes e das idéias dominantes do meio social que vão determinar o que chamar doença (CANGUILHEM,1982; BERLINGUER, 1988).

A doença, como um fato objetivo, está revestida de um juízo social pelas conseqüências que provoca na vida cotidiana. Estar doente ou estar bem de saúde são noções que transbordam de significações (econômicas, políticas, morais, religiosas, existenciais). $O$ sentir-se doente e a identificação da doença são parte do processo de adoecer e estão envolvidos tanto com a dimensão individual quanto social .

LAPLANTINE (1991) propõe a construção de modelos da doença e da cura identificados a partir da linguagem. Existe um número limitado de termos no processo de elaboração da interpretação da doença que vai possibilitar que o discurso seja usado para identificar estes modelos. A 
percepção dita espontânea da doença - e que de fato é sempre aprendida é eminentemente seletiva. Toda elaboração, seja erudita ou popular, de uma representação é o resultado da escolha ao mesmo tempo cultural e individual, lógica e afetiva. Essa elaboração sofre influencia do pensamento cientifico, mas não se fundamenta nele. Portanto os modelos propostos por LAPLANTINE (1991) tem o objetivo de dar conta teoricamente dessa exploração empírica limitada, construídos a partir da percepção individual, mas inseridos historicamente e socialmente. Não existe a predominância de um modelo sobre o outro. O que se observa é que, historicamente, há variações entre aceitar um ou outro modelo conforme o conhecimento científico da época e mais ainda com relação à construção social de cada representação. Ressalte-se ainda que não há uma derivação histórica entre eles. As diversas representações são explicadas através da construção de dois modelos gerais, o modelo etiológico, relativo às origens e causas das doenças, e o modelo terapêutico relativo às formas elementares de cura.

Os Modelos Etiológicos foram organizados em pares opostos assim identificados: Ontológico e Funcional, Exógeno e Endógeno, Aditivo e Subtrativo, Benéfico e Maléfico.

Modelo Ontológico: neste modelo prevalece a idéia que existe um ser da doença. A doença tem sempre uma causa precisa, o ser da doença está presente em alguma parte do corpo, provocando lesões e se traduzindo em sintomas. A primeira expressão científica desse modelo surge em uma das correntes da medicina hipocrática e irá afirmar-se na exploração da anatomia, culminando com as descobertas da microbiologia de Pasteur. $\mathrm{O}$ discurso da doença é o discurso sobre o corpo ou parte dele. Esse modelo oferece duas vantagens: a) as doenças são isoláveis: a causa é identificada como uma lesão provocada por um agente material em órgão ou tecido específico; b) as representações localizadoras tranqüilizam, pois retiram do individuo a culpa por estar doente. "É tranqüilizante saber que as doenças são realidades que, finalmente, têm pouco a ver com a pessoa do doente" (LAPLANTINE 1991, p. 52). A doença é representada como anônimo, como 
"não - eu". A origem da doença está fora do indivíduo, ele não carrega a culpa do adoecer. Mesmo hoje, até doenças discutidas dentro de outro modelo (endógeno), têm recebido atenção diferente, evidenciando uma persistência de um modo de pensar ontológico. A depressão, por exemplo, tem sido apresentada pelas associações psiquiátricas americanas como uma doença igual a qualquer outra, cuja cura só depende de mecanismos biológicos calibrados e reposições de substâncias. O paciente não deve vasculhar em seu íntimo as causas dessa depressão. Ele não tem nenhuma responsabilidade por isso. A responsabilidade é do sistema biológico. Isto reforça uma certa irresponsabilidade sobre os próprios conflitos.

Modelo Funcional (ou Relacional): o normal e o patológico passam a ser pensados em termos de equilibrio e desequilibrio, e a doença é considerada como um desarranjo, por excesso ou por falta. Ocorre uma ruptura com o modelo anterior que é de uma medicina dos agentes patogênicos para uma medicina de reações patológicas. Deve-se admitir que cada elemento e cada fenômeno natural, como cada condição da existência do homem pode igualmente transformar-se em fonte de doença. A doença é pois uma alteração da própria vida. E o elemento que pode ser a fonte da saúde pode também causar o mal. A vida tem aptidão de funcionar normalmente e também de se degenerar na doença e, ainda mais, de tender em direção a morte. A morbidez não é mais considerada como um ser independente do organismo, mas trata-se de um processo de reação. A doença se apresenta então como a "função físiológica desviada". Ela é a própria reação do organismo e que vai ser julgado, durante um certo tempo, como responsável pela maior parte, para não dizer totalidade, dos problemas patológicos. Ao passar de uma interpretação ontológica para o modelo relacional observa-se uma completa mudança de perspectiva e surge uma percepção não apenas anatômica, mas também fisiológica da doença. Não são mais partes isoladas do corpo que estão doentes, mas a pessoa do doente como um todo está envolvida (BERLINGUER 1988; LAPLANTINE 1991).

Moḍelo Exógeno: a doença aqui é vista como o resultado de uma intervenção exterior de elementos estranhos, que a partir de fora vem se 
abater sobre o indivíduo. Esta exterioridade pode ser identificada: a) na vontade má de um "poder antropomorfizado" que pode ser o diabo, o feiticeiro ou mesmo Deus; b) ou pode ser representada por agentes nocivos resultado das relações do ser humano com o meio físico como as influências mórbida dos planetas; influência geográfica, climática, meteorológica, condições ecológicas e sociais da existência; ou ainda a relação do ser humano com o meio químico e bioquímico: alimentos, odores, intoxicações. Pasteur, até 1875, apresentava um primeiro esquema onde a relação de causa e efeito era exclusiva do micróbio sobre o organismo. Existia uma primazia da etiologia exógena de natureza microbiana. A pesquisa etiológica pasteuriana dificilmente pode ser dissociada da noção de entidade mórbida independente. A causalidade totalmente exógena pode ser associada a representação ontológica. Existe uma imputação etiológica a partir da cultura, que atribui a origem de um número muito grande de doenças, tanto ao meio social quanto ao modo de vida, como: a poluição, o ruído, as más condições de moradia, o desemprego, problemas familiares; o sedentarismo, responsável pela obesidade e pelos riscos de problemas cardiovasculares, o trabalho; o acidente propriamente dito, exógenos; a alimentação, particularmente as "conservas"; o tabaco e o álcool. O alimento tem sido apontado como um adversário constante. Algumas vezes ele é reconhecido como fraco demais ou forte demais, outras vezes é visto como mal equilibrado, não natural, e aparece agindo como uma causa extrínseca sobre o organismo. Desta forma pode-se identificar e isolar os verdadeiros culpados da doença fora do individuo e o inimigo tem nome (HERZLICH 1968; LAPLANTINE 1991).

Modelo Endógeno: a doença é vista como uma conseqüência de desequilíbrio do interior do indivíduo e seu exterior e não mais uma entidade estranha. Ela parte do próprio interior do sujeito, sua origem está no próprio ser humano, que é o gerador do que the acontece. Esta compreensão se exprime nas noções de temperamento, tipo de caráter, de constituição, de disposição e predisposição, de natureza, de organismo, de hereditariedade. Existem algumas doenças para as quais uma etiologia endógena parece se 
impor como evidência: doenças da nutrição, desarranjos do metabolismo, as alergias, desequilibrios hormonais como o diabetes, distúrbios funcionais como a hipertensão essencial, câncer e doença mental. Há duas variantes neste modelo: a variante somática, mais precisamente genética, que atribui a etiologia aos ascendentes e a doença a um exterior temporal com relação ao sujeito, negligenciando a personalidade no que ela tem de singular e responsabilizando o destino e a fatalidade; e a psicológica que dá maior ênfase ao doente do que a doença e que tem forte relação com a personalidade (a história do sujeito), orientado-se a partir da liberdade e da culpabilidade. Uma doença pode ter sua origem no exterior do doente e no entanto ter sido provocada por ele que seria responsável em evitar aquele agravo.

Modelo Aditivo: a doença é determinada pela presença de algo e não pela sua ausência. Trata-se de um modelo que guarda estreita relação com as formas ontológica e exógena. As expressões usadas ajudam a atestar a adição, o acréscimo indesejável: tenho gripe, estou com AIDS, estou com dor de cabeça. Existe uma estreita ligação entre a natureza da imputação etiológica e as condições sociais e econômicas de existência em diferentes épocas na mesma sociedade. No século anterior as patologias geralmente eram devidas à falta, à carência, à ausência. Em nossa época vivemos a patologia do excesso.

Modelo Subtrativo: neste modelo a doença é uma ausência com uma précompreeensão negativa. Ela é o resultado de alguma coisa a menos que precisa ser restituida e que requer terapia aditiva. Os exemplos desta representação podem ser dados com a úlcera e o desmaio.

Modelo Maléfico: a doença é nociva, perniciosa, indesejável e completamente privadora $\mathrm{E}$ como um mal ela deve ser evitada e combatida. Trata-se de um desvio biológico e social. O doente torna-se aos olhos dos outros e aos seus próprios olhos como um ser sem valor social. Esta representação é presente de modo muito forte na cultura ocidental que 
"ensina a viver a doença como um não-sentido radical que nada revela $e$ que nada pode justificar" (LAPLANTINE 1991, p.103).

Modelo Benéfico: a doença é vista positivamente como uma tentativa para restaurar o equilíbrio perturbado. Ela tem um sentido, seus sintomas são mensagens a serem ouvidas e entendidas. a doença é vista positivamente como uma tentativa para restaurar o equilíbrio perturbado, permitindo um reconhecimento social que antes fazia falta ao indivíduo. $O$ papel que 0 doente representa na sociedade produz um sentimento de prazer, de gratificação. A afirmação de que a doença tem um sentido positivo, uma função insubstituível e que tem um valor em si mesma, remete-nos a uma interpretação totalizante produto de um pensamento religioso. "A doença que fere a carne, cura a alma" (BERLINGUER 1988). A legislação social é um exemplo de como a doença (prejuizo ou privilégio) pode produzir benefícios econômicos ou trabalhistas, que são assegurados aos operários atingidos por acidente ou doenças profissionais (LAPLANTINE, 1991).

Para BERLINGUER (1988) existem alguns significados básicos que a sociedade dá à doença: ela pode ser vista como sofrimento, anormalidade, perigo, sinal e mesmo como forma de alcançar estima. Portanto, a doença é um elemento de influência na vida individual e na sociedade, provocando conseqüências e atitudes. 
No Quadro 1 apresenta-se uma, sinopse dos modelos etiológicos propostos por LAPLANTINE (1991).

\section{Quadro 1}

Síntese dos modelos etiológicos segundo seus pares.

\begin{tabular}{|c|c|}
\hline O ONTOLÓGICO & LOO FUNCIONAL \\
\hline $\begin{array}{l}\text { Polo orgânico } \\
\text { Expressão científica = anatomia baseada } \\
\text { no estudo das lesões; geografia médica do } \\
\text { corpo }\end{array}$ & $\begin{array}{l}\text { Polo temporal } \\
\text { Expressão científica = fisiologia baseada no } \\
\text { modelo clínico apoiado na observação dos } \\
\text { sintomas. }\end{array}$ \\
\hline MO & MC \\
\hline $\begin{array}{l}\text { A doença é o resultado de uma intervenção } \\
\text { exterior. } \\
\text { O individuo não pode ser responsabilizado. } \\
\text { A causalidade totalmente exógena pode } \\
\text { ser associada a representação ontológica. }\end{array}$ & $\begin{array}{l}\text { A doença parte do próprio interior do sujeito. } \\
\text { O doente é responsável pela gênese de seu } \\
\text { estado mórbido. } \\
\text { A variante somática deste modelo pode ser } \\
\text { associada a representação funcional. }\end{array}$ \\
\hline MODEL & MODELO S \\
\hline $\begin{array}{l}\text { A doença é determinada pela presença de } \\
\text { algo. }\end{array}$ & ausência. \\
\hline MODELO I & MODELO BENÉFICO \\
\hline $\begin{array}{l}\text { A doença é nociva, perniciosa, indesejável } \\
\text { e privadora. }\end{array}$ & $\begin{array}{l}\text { A doença é vista positivamente como uma } \\
\text { tentativa para } \\
\text { perturbado. }\end{array}$ \\
\hline
\end{tabular}

Em estudo realizado por BLUMHAGEN (1980) sobre as causas da hipertensão arterial tentou-se identificar qual a percepção popular sobre esta doença e como as pessoas agiam em decorrência de seus sistemas de crenças. As respostas produziram categorias que foram agrupadas em duas causas principais: a psicossocial e a física.

Causa Psicossocial: o estado identificado com esta causa foi chamado pelos indivíduos de Hyper - Tension, diferenciando da Pressão Alta por ser um estado caracterizado por nervosismo, ansiedade, tensão, exaustão e/ou excitação e que pode ser responsável pela elevação da pressão arterial. Dentro das causas psicossociais surgiram distintas 
categorias que podem ser associadas ao par de modelo exógeno-endógeno conforme suas identificações:

a) Estresse Crônico externo: os estressores se originam fora dos indivíduos e foram divididos em três grupos; aqueles que são episódios agudos mas momentâneos; aqueles identificados no ambiente do trabalho (desemprego, ocupação estressante, work too hard) e o terceiro grupo é formado pelo estresse normal, mas acumulado, como falta de lazer, vida estressante, preocupação, ansiedade. Pode-se associar com facilidade estes resultados e o Modelo Exógeno proposto por LAPLANTINE (1991).

b) Estresse Crônico Interno: nesta categoria as causas são vistas como problemas psiquiátricos ou resultado da convivência com problemas familiares por longo tempo. Trata-se de uma característica do indivíduo que não é vista por ele como herança familiar. Aqui pode-se associar o Modelo Endógeno.

c) Estresse agudo: aqui a causa é vista como qualquer situação que esteja afetando temporariamente o indivíduo, como ficar zangado com alguém, ser parado pela polícia etc. As pessoas acreditam que algumas são mais propensas a se tornarem hipertensas em tais situações do que outras. A responsabilidade individual estaria associada aos agentes externos na causalidade da doença. A permanência dessas situações poderia resultar então na alteração do estado físico e mudar para estresse crônico externo.

Causa Física: aqui são agrupados uma variedade de fatores associados ao biológico que podem provocar alterações fisiológicas. Estes podem estar relacionadas com mecanismos hereditários, alimentação (sal, gorduras, comida em excesso), tabagismo, alcoolismo. A causa da doença, no caso especificamente a Hipertensão Arterial, surge como algo externo ao individuo. No entanto, esta exterioridade não é mencionada aqui como pretexto para eximir de culpa, pois, a responsabilidade por permitir o agravo ao corpo é também do indivíduo e da coletividade.

Os estudos apresentados mostram, sob perspectivas diferentes, que a construção de concepções sobre a doença são feitas a partir de pontos 
diversos mas que apresentam cruzamentos na historicidade dos fatos e da linguagem (HERZLICH, 1968; BLAUMHAGEN, 1980; BERLINGUER, 1988; LAPLANTINE, 1991).

Esses modelos podem ser reconhecidos a partir de investigações que têm utilizado diferentes métodos teóricos. A construção das representações sobre as doenças vai sofrer determinações da época, do local, do desenvolvimento da ciência e também da própria doença em questão. Um método que vem sendo utilizando em anos recentes foi o desenvolvido por KLEINMAN (1980), que busca descrever as doenças, a partir da crença individual. Trata-se do Modelo Explanatório de Doenças ("Explanatory Models of IIIness"). Sua construção consta de questões a serem respondidas pelos individuos:

a) O que causou esta doença?

b) Por que ela começou exatamente nesse tempo particular ?

c) Por que eu ? Por que comigo ?

d) Em que resultará esta doença ?

e) $\mathrm{O}$ que pode ser feito sobre isso?

Este método tem sua origem em três fontes principais:

a) idiossincrática: é derivado das próprias experiências e observações pessoais, portanto vai variar individualmente.

b) popular ou senso comum empírico: quando uma doença acontece ela ocorre não só para o indivíduo doente mas também para o meio social que o envolve. Portanto, essa experiência vivida coletivamente produz representações sobre as doenças que vão sendo historicamente construídas na medida em que se manifestam e interferem com a vida individual e coletiva dos povos. Ë senso comum que todos os excessos, sejam de alimentação, trabalho, emoções, são prejudiciais à saúde e sobrepõe a idéia de que a saúde esteja associada a manutenção do equilibrio e interrupção destes excessos (NGOKWEY, 1988). 
c) profissional: a fonte é alguém que tenha conhecimento científico sobre a doença.

E haveria ainda outra fonte para o conhecimento popular sobre causas de doenças, as crenças e práticas religiosas (NGOKWEY, 1988).

Pensar sobre a causalidade da hipertensão arterial e os possiveis modelos que podem ser construídos ao redor deste agravo, reconduz para a questão primária sobre como este agravo é visto pela população e se é identificada como doença entre o meio não científico.

A identificação da percepção de causalidade da hipertensão arterial entre a população vai estar contaminada pelos conceitos já existentes e pelo conceito de doença construido socialmente. A hipertensão só veio a se tornar um mal conhecido a partir do desenvolvimento tecnológico que possibilitou a aferição de medidas através das quais a doença pode ser traduzida dentro de determinados padrões. O que the confere a identidade, não são os sinais ou sintomas, ou qualquer característica identificada popularmente, mas o saber científico. Para a população os órgãos sadios são silenciosos, portanto a fonte do conhecimento profissional torna-se única para que os individuos construam suas percepções e possam explanar sobre suas condições de hipertensos.

A população procura os serviços de saúde quando é motivada por algum fator desencadeante de mal estar, de "não se sentir bem", e que costuma ser o reconhecimento de sintomas por parte dos indivíduos. Com relação à hipertensão arterial, a demanda não é formada por pessoas que suspeitam da morbidade, pois geralmente o diagnóstico é feito de forma inesperada, ao se buscar solução para outras queixas aparentes.

A falta de conhecimento sobre a doença, sua origem, causas, conseqüências e controle, têm sido responsabilizados pela baixa adesão dos hipertensos ao tratamento $e$, pelo baixo sucesso da terapêutica, com impactos insignificante sobre a população. Aqueles que abandonam o tratamento parecem conhecer menos sobre a hipertensão (CADLWELL e col., 1970; BLACKELL, 1973; DEGOULET e col., 1983; CURB e col., 1985; MION Jr., 1987; ZWEIFLER e KAUNISTO, 1989; JARDIM e col., 1992a). 
Este é o grande desafio dos serviços que atendem aos hipertensos: promover a remoção de todos os obstáculos que impeçam a melhor adesão do paciente. Segundo JARDIM (1998) o grau de conhecimento do indivíduo sobre o seu problema reflete em um comprometimento efetivo no auto cuidado e em maior chance de sucesso.

É necessário então buscar entender a percepção que os individuos trazem sobre a doença e as formas como isso pode motivar suas ações e comportamentos. Estudos com esse objetivo têm sido raros e de difícil execução. O uso dos dados referidos no caso específico da hipertensão arterial lança luz sobre questões do comportamento dos indivíduos hipertensos, principalmente naquilo que se relaciona ao conhecimento sobre a doença, o tratamento e as ações tomadas para o seu controle.

Estudar a prevalência referida de uma doença como a hipertensão, repleta de singularidades, é também conhecer como esta morbidade é percebida fora do âmbito técnico-profissional. Pois será justamente está forma como a doença é sentida que determinará as ações sobre seu controle e que devem também determinar as organizações dos serviços de saúde que assistem esta demanda. 


\section{OBJETIVOS}

\section{1 - Objetivo Geral}

Estudar a prevalência da hipertensão arterial referida, a percepção sobre a origem da doença e as formas de controle exercidas sobre o agravo, em adultos maiores de 20 anos, residentes em área da região metropolitana de São Paulo.

\section{2 - Objetivos específicos:}

- conhecer a prevalência da hipertensão arterial referida segundo variáveis sócio-demográficas: idade, sexo, município de residência, escolaridade e condição de classe.

- estudar a percepção que os indivíduos que referiram hipertensão arterial têm sobre a origem da doença, segundo as variáveis sócio-demográficas;

- estudar o uso dos serviços de saúde e o uso de medicação hipotensora como formas de controle sobre a morbidade, segundo as variáveis sóciodemográficas;

- analisar a associação entre a percepção sobre a origem da doença e as formas de controle. 


\section{MATERIAL E MÉTODOS}

\section{1 - Área de Estudo}

A região delimitada para este estudo compreende oito municípios da Grande São Paulo: ${ }^{(1)}$ Taboão da Serra, ${ }^{(2)}$ Embú, ${ }^{(3)}$ Cotia, ${ }^{(4)}$ Vargem Grande Paulista, ${ }^{(5)}$ Itapecirica da Serra, ${ }^{(6)}$ Embu-Guaçu, (7) Juquitiba e ${ }^{(8)}$ São Lourenço da Serra. Foram considerados seis municípios desta área, pois os dados de Vargem Grande Paulista e Cotia são apresentados juntos porque até o momento em que o inquérito foi aplicado eles possuiam um sistema de saúde em comum. São Lourenço da Serra na época da coleta ainda pertencia a Itapecirica. A região ocupa uma área de $1.491 \mathrm{Km}^{2}$, sendo que os municípios menores são Vargem Grande Paulista $\left(29 \mathrm{Km}^{2}\right)$ e Taboão da Serra $\left(20 \mathrm{Km}^{2}\right)$. E os maiores são Juquitiba $\left(550 \mathrm{Km}^{2}\right)$ e Cotia $\left(325 \mathrm{Km}^{2}\right)$ (Figura 1 e Tabela 3).

Figura 1

Mapa da Região Metropolitana de São Paulo - SP.

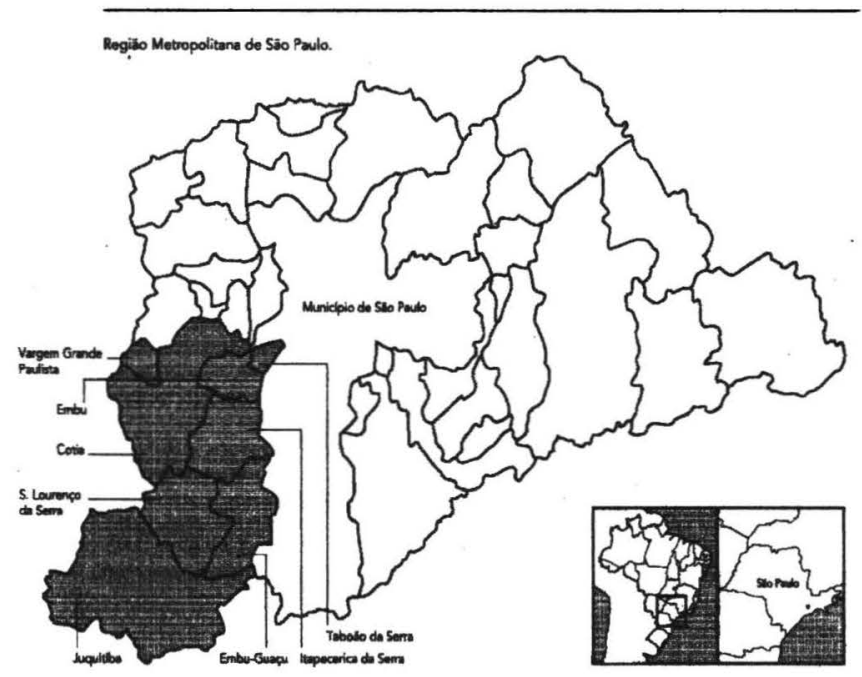


Tabela 3 - Distribuição dos municípios segundo área e população. Região Sudoeste da Grande São Paulo - SP.1989 - 1990.

\begin{tabular}{l|c|c}
\hline Municipio & \multicolumn{1}{c}{ área $\left(\mathrm{Km}^{2}\right)$} & População (censo 91) \\
Cotia & 325 & 106822 \\
\hline Embu & 68 & 155851 \\
\hline Embu-Guaçu & 171 & 35873 \\
\hline Itapecirica da Serra & 136 & 85372 \\
\hline Juquitiba & 550 & 19866 \\
\hline Taboão da Serra & 20 & 159894 \\
\hline S. Lourenço da Serra & 192 & 7482 \\
\hline Vargem Grande Paulista & 29 & 15840 \\
\hline Total & 1491 & 587000 \\
\hline
\end{tabular}

Fonte: Fundação SEADE 1993.

A população da área segundo o Censo Demográfico de 1991, realizado pelo IBGE, era de 588.700 pessoas, sendo que cerca de $50 \%$ eram do sexo feminino e $55 \%$, de 20 anos e mais (FUNDAÇÀO IBGE, 1994) (Figura 2). 
Figura 2

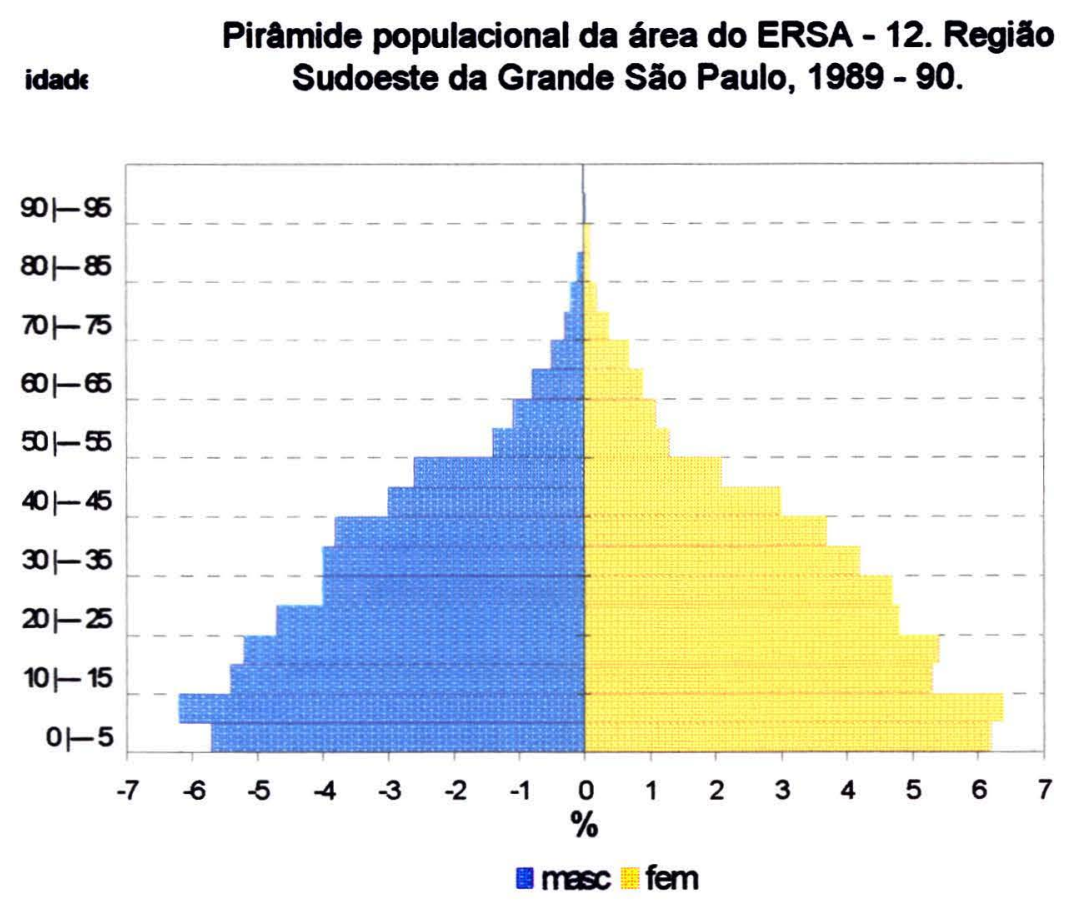

Mudanças nos padrōes de mortalidade, natalidade e migração de uma população podem ser refletidas na pirâmide populacional evidenciando a história passada naquela área. A região apresenta um desenho que se assemelha a forma piramidal tipo 2 , com uma base mais larga e diminuindo conforme avançam as idades (LAURENTI e col., 1987). A razão de dependência' é alta $(61,42 \%)$, e observa-se também que $35,33 \%$ da população tem menos de 15 anos, e 4,38\% tem mais de 60 anos. 0 que reflete uma população jovem com diminuição da mortalidade nessa faixa, diminuição da natalidade e também início de envelhecimento. A pirâmide da região estudada guarda o mesmo perfil da pirâmide desenhada para a população do Brasil.

Os municípios de Cotia e Embu-Guaçu apresentam a população com melhor nível sócio-econômico, com melhores condiçōes de moradia e têm densidade populacional média de 328,68 e $209,78 \mathrm{hab} / \mathrm{Km}^{2}$ respectivamente.

\footnotetext{
${ }^{1}$ Razão de dependência $=\underline{n}^{\circ}$ de habitantes $0 \mid-15+n^{\circ}$ de habitantes 65 e $+\quad \times 100$ habitantes $15 \mid-65$
} 
O crescimento em Cotia, deu-se às custas da instalação de moradias destinadas às populações de estratos sócio-econômicos mais elevados.

Cotia apresentou a menor razão de dependência $(55,1 \%)$. Neste município foi encontrada a maior proporção com nível superior de escolaridade $(13,0 \%)$ e, também a maior proporção de famílias pertencentes à burguesia $(2,6 \%)$.

Taboão da Serra, Embú e Itapecirica da Serra são municípios que apresentam características comuns. Eles possuem áreas pequenas, que fazem limite com a capital, apresentam as maiores populações e são densamente povoados. Taboão da Serra com 7.994,70hab/ $/ \mathrm{Km}^{2}$ e Embú com 2.291,43 hab/ $/ \mathrm{Km}^{2}$. Apresentaram nos últimos anos as maiores taxas de crescimento populacional às custas do crescente número de favelas, com condições precárias de moradia e saneamento. Geralmente a população destes municipios trabalha longe de suas residências, um padrão de emprego favorecido pela proximidade com São Paulo. Embú foi o município que apresentou a maior proporção de jovens, com 37,5\% menores de 15 anos (SUAREZ, 1996) (Tabela 3 e 4).

Juquitiba, com a menor taxa de crescimento urbano, é um município situado mais distante da capital e relativamente isolado dos demais. Talvez por isso ainda guarde muitas características rurais, tendo a maior parte de sua população trabalhando no próprio município. É O município que apresentou a menor densidade demográfica com $36.12 \mathrm{hab} / \mathrm{Km}^{2}$ e também a maior proporção de idosos ( $\geq 65$ anos) e uma alta razão de dependência $(70,2 \%)$. Juquitiba foi o município com a maior proporção de analfabetos $(16,1 \%)$ e a maior proporção de sub proletariado como condição de classe (13,3\%) (FUNDAÇÃO SEADE, 1993; SUAREZ, 1996). 
Tabela 4 - Número de habitantes por domicílio e densidade demográfica (hab/ $\mathrm{Km}^{2}$ ) por municípios. Região Sudoeste da Grande São Paulo - SP.1980-1991.

\begin{tabular}{l|c|c|c|c} 
Municipio & \multicolumn{3}{c}{ habitantes/domicilio } & $\begin{array}{r}\text { Densidade demográfica } \\
\text { hab/Km }\end{array}$ \\
& 1980 & 1991 & 1980 & 1991 \\
\hline Cotia & 4,71 & 3,50 & 160,62 & 328,68 \\
\hline Embu & 4,61 & 3,86 & 1408,82 & 2291,43 \\
\hline Embu-Guaçu & 4,59 & 3,16 & 123,06 & 209,78 \\
\hline Itapecirica & 4,59 & 3,59 & 184,38 & 283,09 \\
\hline Juquitiba & 4,40 & 2,47 & 22,71 & 36,12 \\
\hline Taboão & 4,51 & 3,82 & 4882,75 & 7994,70 \\
\hline
\end{tabular}

Fonte: Fundação SEADE, 1993.

Todos estes municípios apresentaram grande crescimento urbano na década de 80 (GATTÁS, 1996) (Tabela 5).

Tabela 5 - Distribuição dos municípios do ERSA - 12, segundo taxa de crescimento urbano. Região Sudoeste da

Grande São Paulo - SP, 1980 - 1991.

\begin{tabular}{l|c|c} 
Municipios & $\begin{array}{c}\text { taxa de crescimento } \\
\text { urbano } \\
(\%)\end{array}$ & $\begin{array}{c}\text { taxa anual de } \\
\text { crescimento }\end{array}$ \\
$\begin{array}{l}\text { 1. Taboão da Serra } \\
100\end{array}$ & 4,58 \\
\hline 2. Embu & 100 & 4,52 \\
\hline $\begin{array}{l}\text { 3. Itapecirica da Serra (São } \\
\text { Lourenço) }\end{array}$ & 91,4 & 3,97 \\
\hline $\begin{array}{l}\text { 4. Juquitiba } \\
\text { 5. Embu-Guaçu }\end{array}$ & 68,9 & 4,31 \\
\hline 6. Cotia (Vargem Grande & 94,7 & 4,97 \\
\hline Paulista)
\end{tabular}

Fontes: Fundação SEADE 1993; SUAREZ, 1996. 
Alguns fatores são apontados para o aumento dessa taxa, sendo que apenas uma pequena parte pode ser atribuída ao crescimento vegetativo. Acredita-se que a urbanização desorganizada, resultado da expulsão de populações da área central do município de São Paulo para municípios periféricos seja o fator que melhor explique essa explosão. Esse movimento migratório tem provocado a instalação de favelas e domicílios precários, muitas vezes sem as devidas condições de saneamento (GATTÁS, 1996).

$\mathrm{Na}$ época em que a coleta de dados foi feita a região contava com cinco hospitais, sendo que no Embú e em Taboão da Serra não havia nenhum. Cotia possuía, em 1989, cinco Centros de Saúde da rede estadual para seus 100.000 habitantes, enquanto Taboão da Serra contava com apenas dois para uma cobertura de 160 mil pessoas (Fundação SEADE, 1993).

\section{2 - Fonte dos Dados}

Esse estudo utilizou parte dos dados primários obtidos por entrevistas domiciliares, realizadas através do inquérito populacional "MORBIDADE REFERIDA E UTILIZAÇÃO DE SERVIÇOS DE SAÚDE NO ERSA-12 1989/1990" (CESAR e col., 1996).

Esse banco foi criado a partir de coleta de dados realizada em um período de doze meses, com 9.842 domicílios visitados, e 10.199 entrevistas realizadas, na região sudoeste da Área Metropolitana de São Paulo, que para fins administrativos era denominada de ESCRITÓRIO REGIONAL DE SAÚDE ITAPECERICA DA SERRA (ERSA - 12). 


\section{3 - População de Estudo}

Para efeito desse estudo foram considerados, no banco de dados criado a partir do Inquérito, todos os indivíduos de 20 anos e mais de idade, residentes na área especificada, e que referiram hipertensão arterial (pressão alta). Para isso foi usada a questão 66 ("O sr(a) tem algum desses problemas de saúde" - seguida de lista) e selecionados todos os questionários com resposta positiva para o primeiro item desta questão (pressão alta).

\section{4 - Amostragem}

O processo amostral para o inquérito e criação do banco de dados primário utilizou a técnica de amostragem conhecida como "amostragem de área". Os individuos são selecionados a partir de seus domicilios de residência.

Esse processo apresentou as seguintes fases :

1) seleção de amostra representativa da população residente em cada um dos municípios da região estudada. Cada município foi considerado como um conjunto de setores e sub-setores censitários e foram divididos, segundo a densidade de domicílios, em dois grupos chamados estratos. O estrato I ficou constituído por setores e sub-setores com grande quantidade de domicilios por $\mathrm{Km}^{2}$ e o estrato II pelos setores e sub-setores com baixa concentração de domicilios.

2) após a estratificação foram sorteados 30 setores ou sub-setores em cada municipio, sendo que $70 \%$ estavam no estrato I. Em seguida foi realizada a atualização dos mapas e conferido o número de domicílio de cada um. No estrato I foi realizado uma segunda etapa de sorteio e selecionados 4 quarteirões do total do setor. Em seguida foram selecionados os domicilios dentro desses 
quarteirões. No estrato ll a segunda etapa do sorteio correspondeu à seleção direta dos domicílios. Dessa forma a amostra de domicílios ficou representativa do total de domicilios de cada município da área.

3) foi realizada a definição dos grupos de idade e sexo para estudo, a fim de que ficassem garantidos números suficientes para as análises. Isso foi feito porque alguns grupos populacionais, como os menores de 1 ano e os de idade mais avançada, representam proporção muito pequena da população e são, ao mesmo tempo, aqueles que mais apresentam problemas de saúde e que buscam assistência nos serviços. Para garantir a participação desses grupos foi entrevistado em cada domicílio sorteado número igual de indivíduos de cada domínio. Foi definido como 200 o número de individuos a serem entrevistados em cada domínio. Os domínios considerados foram: menores de 1 anos; 1 a 6 anos; 7 a 19 anos; 20 a 49 anos masculinos; 20 a 49 anos femininos; 50 anos e mais masculinos e 50 anos e mais femininos. Para alcançar uma taxa de cobertura de $80 \%$ e considerando as possibilidades de perdas e recusas, foram sorteados em cada domínio, 250 indivíduos. O tamanho da amostra foi calculado utilizando-se a prevalência correspondente à situação de variabilidade máxima $(0,50)$ e admitindo como aceitável uma precisão onde o erro máximo de amostragem não ultrapassasse $7 \%$, em $95 \%$ das possiveis amostras.

4) outra fase do processo foi a ponderação e ajuste. Em razão da forma de seleção da amostra tornou-se necessário realizar a ponderação dos dados para permitir a análise. Foram consideradas as frações amostrais específicas, na população total de cada município. Foi feito também o ajuste levando-se em conta as informaçōes do Censo do IBGE - 1991. Foi estimada a população total de cada município para $1{ }^{-}$de janeiro de 1990 , a partir da população censitária de 1980 e 1991. Dividiu-se a 
população de cada domínio, estimada para $1^{0}$ de janeiro de 1990 , pelo número de indivíduos, do mesmo domínio, na população amostral, obtendo assim o peso específico para cada domínio. $O$ cálculo foi feito para todos os domínios em cada município, expandindo a população amostral conforme os pesos específicos encontrados.

O desenho da amostra com maiores detalhes já foi objeto de publicações anteriores (CESAR e col., 1996; CESAR e TANAKA, 1996; GATTÁS, 1996).

\section{5 - Coleta de Dados}

O questionário para coleta dos dados para o banco primário foi organizado em 14 blocos (anexo 1) e os temas abordados foram: morbidade referida para os 15 dias anteriores à entrevista; referência de doença crônica ou de deficiência física; teste de CAGE - indicativo de alcoolismo; consumo de medicamentos nos três dias anteriores à entrevista; utilização de serviços de saúde e de seguro-saúde; uso de serviços odontológicos; uso de serviços materno-infantis (pré-natal, parto e puericultura); imunizações; conhecimento sobre saúde - doença e opinião sobre os serviços utilizados; condição sócioeconômica dos indivíduos entrevistados maiores de 14 anos; condição sócio-econômica dos chefes de familia; caracterização da habitação e consumo de bens duráveis.

Neste estudo foi identificado, a partir da questão 66, todos de, no mínimo 20 anos, que assinalaram a presença de pressão alta como morbidade referida. A partir desta identificação foram analisadas as respostas de todas as questões do Bloco 7, que está relacionado com Doenças Crônicas. Desta forma foi possível conhecer a distribuição epidemiológica da hipertensão arterial referida segundo variáveis demográficas e sociais, conhecer a percepção sobre a origem da morbidade 
e o uso dos serviços de saúde e de medicamentos hipotensores, como formas de controle.

\section{6 - Definição das Variáveis}

\subsection{1 - Variáveis Sócio-Demográficas:}

Para o estudo da prevalência da hipertensão arterial referida foram consideradas as variáveis idade, sexo, município de residência, escolaridade e condição de classe social .

A idade foi registrada em anos e o municipio de residência foi considerado segundo a informação do entrevistado.

A escolaridade foi analisada pela freqüência em anos no ensino formal, classificando-se como analfabetos aqueles que não freqüentaram escola e que não sabiam ler; em primeiro grau 10 correspondente à fase chamada de primário; primeiro grau 2, correspondente ao ginásio; segundo grau e superior.

A classe social foi definida, segundo Lenni (1957) citado por LOMBARDI (1988:1) em:

"grandes grupos de homens que se diferenciam entre si pelo lugar que ocupam em um sistema de produção historicamente determinado, pelas relações em que se encontram com respeito aos meios de produção (..), pelo papel que desempenham na organização social do trabalho e, consequentemente, pelo modo e a proporção em que percebem a parte da riqueza social de que dispõem. As classes são grupos humanos, um dos quais pode apropriar-se do trabalho do outro, por ocupar postos diferentes em um regimen determinado de economia social. "

Para análise da condição de classe foi utilizada a operacionalização do conceito de classe social na versão modificada da proposta de Bronfman 
e Tuirán (LOMBARDI e col., 1988), onde considera-se a relação com os meios de produção para a classificação. A distinção entre classes levou em conta a inserção do indivíduo nos processos de produção, circulação e coadjuvantes. Desta forma foram classificados como pertencentes à: burguesia, nova pequena burguesia, pequena burguesia tradicional, proletariado típico, proletariado não típico e subproletariado, sendo que cada classe e frações de classe podem ser assim descritas:

Burguesia: constituída por todos os proprietários dos meios de produção que empregam força de trabalho assalariada, exercendo uma função de exploração do tipo capitalista;

Nova Pequena Burguesia: representada pelos agentes sociais que ocupam postos de mais alto nível técnico e de tomada de decisões, e aqueles que apesar de não ocuparem cargos de direção exercem funções que exigem formação profissional de nivel universitário (diretores de empresas, gerentes, altos oficiais do exército e da polícia, quadros diretivos da burocracia, legisladores, engenheiros, cientistas, professores);

Pequena Burguesia Tradicional: composta por agentes sociais que, sem formação universitária, têm meios de produção próprio e portanto a capacidade de reproduzir-se de maneira independente. (agentes da indústria artesanal, pequenos comerciantes)

Proletariado: inclui os agentes sociais, sem formação de nível superior, que não dispõem dos meios de produção e de trabalho e vendem a sua força de trabalho, ficando sob a relação de exploração não exercendo eles mesmos, nem direta ou indiretamente, a função de exploração. E de acordo como este trabalho é realizado podem ainda ser distinguidos em dois subgrupos:

- Proletariado Típico: trabalhadores que desempenham atividades diretamente vinculadas a produção e transporte de mercadorias (motoristas, pedreiros, operários);

- Proletariado Não Típico: têm relação indireta com a produção (bancários, funcionários públicos)

Subproletariado: inclui os agentes sociais que desempenham uma atividade predominantemente não assalariada, em geral instável, com a qual 
obtém salários e/ou rendimentos inferiores ao custo mínimo da reprodução da força de trabalho. (vendedores ambulantes, serviços domésticos, engraxates).

Nesta classificação os pensionistas, estudantes e donas de casas não são considerados, e deverão surgir no estudo como dados não classificados.

\subsection{2 - Categorização para Estudo da Percepção sobre a Doença:}

Para o estudo da percepção quanto a origem da doença foi usada a questão 69 do questionário ("Por que sr(a) acha que esse problema apareceu ?"). Para isso foram consideradas todas as respostas registradas para proceder a categorização. Como se tratava de uma questão aberta e que possibilitava respostas variadas, foi necessário organizar estas respostas mediante o agrupamento em categorias para fins de análise.

1. Inicialmente foram escolhidos aleatoriamente 300 questionários do total, entre aqueles que referiram pressão alta e tinham idade mínima de 20 anos. Foram listadas as respostas desta questão, exatamente na forma em que estavam registradas, de acordo com o número do questionário no municipio de residência. Na medida em que as respostas começaram a apresentar um padrão de repetição considerou-se ter atingido uma cobertura suficiente para a construção das categorias e foi suspensa a listagem (PATTON, 1980). O número de questionários escolhidos inicialmente para a categorização obedeceu ao critério de repetição.

2. Em seguida, esta listagem foi usada para criar categorias que apresentavam um padrão semelhante. Como por exemplo, respostas em branco, negativas, relacionadas a sintomas, à situação sócio-econômica, etc.

3. As respostas foram classificadas segundo estas categorias e posteriormente os modelos etiológicos, propostos por LAPLANTINE (1991), foram usados para classificação destes grupos.

4. A partir da criação destes grupos observou-se que era possível construir um quadro para que fossem apresentadas as categorias distribuídas 
conforme cada grupo e segundo os modelos em que se enquadravam. Para cada categoria e subgrupo foi dado um código alfanumérico que identificava a resposta. Por exemplo:

EXÓGENO $=(A)$ CAUSAS SÓCIO-ECONÓMICAS $=(A 1)$ condições ambientais /clima/poluição = respostas:

- "foi para o litoral e a pressão aumentou"

- "é o tempo de calor"

- "é o clima daqui..."

ENDÓGENO $=(\mathrm{C})$ CAUSAS PSICOSSOCIAIS $=$ (C5) nervosismo; preocupação $=$ respostas:

- "devido problemas de fundo nervoso"

- "passou muito nervoso com a família"

- "passou muito nervoso e ainda passa"

5. Em seguida, todas as respostas $(n=1681)$, além daquelas usadas inicialmente, foram transcritas em uma listagem em editor de texto, constando identificação do questionário, e a resposta na íntegra, conforme expressado pelo indivíduo.

6. A partir desta listagem completa todas as respostas receberam então um código correspondente a categoria e subgrupo proposto.

7. Depois de codificadas todas as respostas foi criado um novo campo, agregado ao banco de dados primário, para receber o código da categoria, criando-se assim a possibilidade da análise da percepção sobre a origem da hipertensão arterial.

As categorias propostas, com seus subgrupos e códigos dentro de cada modelo, podem ser vistas no Quadro 2: 
Quadro 2

Categorização das respostas quanto à percepção da população sobre a origem da Hipertensão Arterial.

\begin{tabular}{|c|c|c|}
\hline NIVEL 1 & NIVEL 2 & NIVEL 3 \\
\hline MODELOS & CATEGORIAS & RESPOSTAS \\
\hline ETIOLÓGICOS & (CAUSAS) & \\
\hline EXOGENO & $\begin{array}{l}\text { (A) SOCIO- } \\
\text { ECONO̊MICA }\end{array}$ & $\begin{array}{l}\text { (a1) condições ambientais / } \\
\text { clima / poluição } \\
\text { (a2) situação de trabalho } \\
\text { (a3) situação de vida }\end{array}$ \\
\hline EXÓGENO & $\begin{array}{l}\text { (B) SITUAÇŐES } \\
\text { COMPORTAMENTAIS E } \\
\text { DE HÁBITOS DE VIDA }\end{array}$ & $\begin{array}{l}\text { (b1) dietas } \\
\text { (b2) tabagismo } \\
\text { (b3) alcoolismo } \\
\text { (b4) sedentarismo } \\
\text { (b5) medicamentos / } \\
\text { acidentes }\end{array}$ \\
\hline ENDÓGENO & (C) PSICOSSOCIAIS & $\begin{array}{l}\text { (c1) doença na família } \\
\text { (c2) morte na familia } \\
\text { (c3) separação } \\
\text { (c4) relacionamento familiar } \\
\text { (c5) nervosismo; } \\
\text { preocupação }\end{array}$ \\
\hline ENDÓGENO & $\begin{array}{l}\text { (D) NATURAIS I } \\
\text { BIOLÓGICAS }\end{array}$ & $\begin{array}{l}\text { (d1) idade } \\
\text { (d2) hereditariedade } \\
\text { (d3) outras doenças / } \\
\text { sintomas } \\
\text { (d4) gestação } \\
\text { (d5) menopausa }\end{array}$ \\
\hline \multicolumn{3}{|l|}{ (E) OUTROS } \\
\hline \multicolumn{3}{|c|}{ (F) ASSOCIAÇŐES } \\
\hline NÃO RESPONDE & & \\
\hline
\end{tabular}




\subsection{3 - Questōes Usadas para Estudo do Controle da Doença:}

A análise sobre o controle da hipertensão arterial, entre aqueles que referiram a morbidade, foi feita utilizando-se das questões $68,70,71,73,74$, 76 e 77 do questionário. São questões sobre o uso dos serviços de saúde e de medicação especifica:

Questão 68 - Foi algum médico quem disse que o sr. (a) tem essa doença? Esta questão objetivava reconhecer se o entrevistado tinha tomado conhecimento da pressão alta através de diagnóstico médico ou não.

Questão 70 - O sr. Visita o médico ou o serviço de saúde periodicamente por causa deste problema?

A resposta a esta questão identifica os indivíduos que têm como hábito a busca por assistência ao problema específico da hipertensão arterial.

Questão 71 - Por que o sr.(a) não vai periodicamente ?

A justificativa para não buscar assistência para o problema de saúde diagnosticado pode servir para identificar os motivos que provocam a não adesão ao tratamento.

Questão 73 - Alguma vez Ihe foram receitados medicamentos de rotina para este problema?

Neste caso foi investigado junto ao entrevistado se ele tinha recebido receita de profissional médico e definido que medicamento de rotina era aquele que era receitado com uma certa regularidade e com especificidade para determinada doença.

Questão 74 - O sr. (a) tomou algum (s) medicamento (s) regularmente para este problema nos últimos 30 dias ?

Para registrar a resposta a esta questão foram utilizadas as informações referentes à questão 73 .

Questão 76 - Por que o sr. (a) não tomou? 
Neste caso, dependendo do que o entrevistado respondeu pode existir mais de uma resposta.

Questão 77 - Como foi obtido este (s) medicamento?

Esta questão buscava identificar a forma como a medicação hipotensora era obtida pelos indivíduos, isto é, se compravam ou se obtinham no serviço público onde buscavam assistência.

\section{7 - Análise dos Dados}

O banco de dados utilizado, como fonte primária, foi codificado com utilização do pacote estatístico Statistical Package for Social Science (SPSS) no Centro de Computação Eletrônica da USP (CCE).

A análise específica desse trabalho foi feita utilizando-se do mesmo pacote, apresentando o cruzamento entre as variáveis, segundo seus valores absolutos na amostra e os cálculos de proporções e coeficientes na amostra ponderada (SPSS, 1993). Utilizou-se também do software Statistica (STASOFT, 1998) para o processamento dos dados e elaboração de gráficos.

\subsection{1 - Análise da Prevalência da Hipertensão Arterial Referida}

Neste estudo utilizou-se banco de dados, como fonte secundária para análises de distribuições e proporções e cálculo da prevalência da hipertensão arterial segundo as variáveis especificadas.

A análise da distribuição etária das populações dos municípios da região mostrou que há diferenças importantes que os caracterizam. Diante disso optou-se por trabalhar o coeficiente de prevalência da hipertensão arterial padronizado por idade, a fim de possibilitar a comparação das variáveis (LAURENTTI e col., 1985). 
A primeira parte deste estudo apresenta a descrição do perfil epidemiológico da hipertensão arterial referida, utilizando-se o resultado do cálculo do coeficiente de prevalência e segundo as variáveis sexo, idade, município de residência, escolaridade e condição de classe social. Estas informações permitem conhecer como a morbidade está presente na região e sua importância como agravo coletivo.

A prevalência da hipertensão foi calculada considerando no numerador 0 total de hipertensos nos diferentes grupos etários, diferentes municipios e niveis de escolaridade e no denominador o total da população no mesmo grupo. Desta forma procurou-se verificar se a prevalência apresentava uma distribuição uniforme nas diversas categorias de cada variável de interesse. Os coeficientes de prevalência foram padronizados segundo a idade, e analisados de acordo com a distribuição.

Para o cálculo destes coeficientes foram utilizados os dados da amostra ponderada de forma que fosse mantida a referência populacional deste indicador. Os dados são apresentados em sua freqüência absoluta e os coeficientes sobre a amostra ponderada. Foram calculados os intervalos de confiança da distribuição da prevalência da Hipertensão Arterial referida para comparação. Outros testes estatísticos não foram realizados em razão do uso da amostra expandida.

\subsection{2 - Análise do Modelo Etiológico da Hipertensão Arterial}

Nesta parte o foco do trabalho passou a ser somente o grupo formado pelos hipertensos. Foi feita a análise da percepção que esta população traz sobre a origem da doença. Para isto foi utilizada parte da idéia do que seria o Modelo Explanatório. Como se trata de um banco de dados construido à priori e que continha uma única questão de acesso à explanação individual sobre a doença, decidiu-se por usar este dado, pois a riqueza das demais informações poderiam sobrepor a limitação do questionário aplicado. Foi analisada na amostra esta percepção e como isto se dá segundo as variáveis do estudo. 
A questão 69 foi categorizada e foram usadas as categorias para a classificação segundo os modelos etiológicos endógeno e exógeno no primeiro nível. As respostas têm características hierárquicas, e neste nível apresentar-se-ão sempre binárias. Neste nivel os dados assim classificados, foram analisados segundo sua distribuição na população de hipertensos e as associações com as variáveis do estudo (Qui-quadrado - com correção de Yates).

No segundo nivel das categorias (causas) e o terceiro nível (respostas) foi realizada análise estatística descritiva a partir das tabelas e gráficos. Optou-se por não realizar testes neste nível pois há um número muito grande de caselas vazias, o que poderia prejudicar a validade dos resultados.

3.7.3 - Análise sobre o uso dos serviços de saúde e uso de medicamentos como formas de controle sobre a hipertensão arterial

A terceira parte apresenta uma análise da forma como a população faz o controle sobre a doença.

Esta forma de controle foi considerada de acordo com a rotina de busca por assistência e o uso de medicamento específico. Estas categorias foram descritas segundo as variáveis do estudo.

Ainda neste nivel foram realizados testes Qui-quadrado de independência para verificar se existia relação entre as variáveis do controle e as variáveis independentes (sexo, idade etc) As justificativas das respostas (segundo e/ou terceiro nivel das variáveis) foram objeto de análise descritiva com relação às variáveis independentes.

Com estas três partes da análise pretendeu-se traçar o perfil dos hipertensos de acordo com sua distribuição epidemiológica, sua percepção da doença e a forma como fazem o controle sobre a morbidade. Foram análises realizadas separadamente.

A última parte do estudo apresenta a análise conjunta desses perfis. 


\subsection{4 - Regressão Logística Múltipla}

Para verificar o efeito conjunto das variáveis do estudo e das formas de percepção sobre as formas de controle apresentadas utilizou-se a análise de regressão logística múltipla.

Os modelos construídos procuraram descrever o efeito conjunto das variáveis independentes (sexo, idade, condição de classe social, escolaridade e modo de percepção) sobre as variáveis dependentes (uso dos serviços de saúde e uso de medicação). Foram incluidas somente as variáveis independentes que apresentaram alguma importância na determinação das variáveis respostas e estudado o poder real de cada uma. Para a análise multivariada foram utilizadas somente as variáveis que mostraram significância $(p<0,05)$ na descrição dos dados (modelos de percepção, sexo, faixa etária, escolaridade, condição de classe social).

Os modelos foram construidos separadamente para análise sobre o uso dos serviços de saúde e o uso de medicamentos pelos indivíduos hipertensos. Cada modelo apresentou a relação das variáveis com os modos de percepção e o controle sobre a morbidade (PREGIBON 1981; HANLEY 1983).

Os modelos construidos refletem a probabilidade do indivíduos hipertenso utilizar os serviços de saúde ou fazer uso de medicamento hipotensor, quando são ajustadas as outras características. Uma razão de chances maior do que um significa que a presença da característica é risco para a variável dependente (BERQUO e col., 1981). 


\section{RESULTADOS}

\section{1 - Descrição da Amostra}

Os procedimentos utilizados para a seleção da amostra (descritos nos Métodos) exigem o ajuste dos dados antes que se proceda a análise. A amostra ponderada representa no seu conjunto, a população do estudo.

A amostra total obtida foi de 10.199 indivíduos entrevistados, 6355 $(54,0 \%)$ tinham idade igual ou superior a 20 anos, sendo $3043(49,4 \%)$ do sexo masculino e $3312(50,6 \%)$ do sexo feminino. A média da idade foi de 37,41 anos (mínimo de 20 e máximo de 98 anos; desvio padrão $=13,48$ ). Foram descartados 3844 observações provenientes de indivíduos com idade inferior a 20 anos (Tabela 6).

Tabela 6 - Distribuição da população ( $\geq 20$ anos) segundo sexo.

Região Sudoeste da Grande São Paulo, 1989 -1990.

\begin{tabular}{l|c|c|c|c|c|c|c|c}
\hline & \multicolumn{4}{c}{ Amostra } & \multicolumn{1}{c}{ Amostra Expandida } \\
sexo & $n^{\circ}$ & $\%$ & média & $\mathrm{dp}$ & $\mathrm{n}^{\circ}$ & $\%$ & Média & $\mathrm{dp}$ \\
\hline Masculino & 3043 & 47,9 & 46,3 & 16,3 & 147406 & 49,4 & 37,4 & 13,3 \\
\hline Feminino & 3312 & 52,1 & 45,5 & 16,6 & 150978 & 50,6 & 37,4 & 13,6 \\
\hline Total & $\mathbf{6 3 5 5}$ & $\mathbf{1 0 0 . 0}$ & $\mathbf{4 5 , 9}$ & $\mathbf{1 6 , 5}$ & $\mathbf{2 9 8 3 8 4}$ & $\mathbf{1 0 0 , 0}$ & $\mathbf{3 7 , 4}$ & $\mathbf{1 3 , 5}$ \\
\hline
\end{tabular}

Na população total de entrevistados ( $n=10199)$, o número de pessoas que referiram ter pressão alta foi de $1708(16,7 \%)$ sendo que, destes, 27 tinham idade inferior a 20 anos $(0,8 \%$ de prevalência nessa faixa etária).

Entre os indivíduos de idade mínima de 20 anos, 1681 (26,4\%) referiram ter hipertensão arterial. Este grupo de hipertensos era composto por $678(40,3 \%)$ homens e $1003(59,7 \%)$ mulheres. A maioria desses indivíduos tinha idade mínima de 50 anos. As idades média, mediana e o desvio padrão foram respectivamente iguais a 55,6anos, 56 anos e 12,7 anos no sexo masculino e 55,2 anos, 56 anos e 13,9 anos para as mulheres (Tabela 7). 
Tabela 7 - Distribuição da população hipertensa ( $\geq 20$ anos), segundo sexo e respectivas idades médias e desvio padrão. Regiăo Sudoeste da Grande São Paulo, 1989-1990.

\begin{tabular}{l|c|c|c|c|c|c|c|c}
\hline & $n^{\circ}$ & $\%$ & $\begin{array}{c}\text { Média } \\
\text { Idade } \\
\text { Sexo anos) }\end{array}$ & $\begin{array}{c}\text { Desvio } \\
\text { Padräo } \\
\text { (em anos) }\end{array}$ & $n^{\circ}$ & $\%$ & $\begin{array}{c}\text { Média } \\
\text { Idade } \\
\text { (em anos) }\end{array}$ & $\begin{array}{c}\text { Desvio } \\
\text { Padrão } \\
\text { (em anos) }\end{array}$ \\
\hline Masculino & 678 & 40,3 & 55,6 & 12,7 & 21918 & 40,8 & 47,3 & 13,5 \\
\hline Feminino & 1003 & 59,7 & 55,2 & 13,9 & 31797 & 59,2 & 46,7 & 15,0 \\
\hline TOTAL & 1681 & 100,0 & 55,4 & 13,5 & 53715 & 100,0 & 47,0 & 14,4 \\
\hline
\end{tabular}

Com relação à escolaridade, a maioria dos indivíduos hipertensos tinha a primeira fase do primeiro grau $(58,8 \%)$ ou eram analfabetos $(16,5 \%)$. E aqueles com menor escolaridade eram os que pertenciam às faixas etárias mais velhas.

A maior parte dos individuos estava na situaçăo de classe do Proletariado Não Típico $(34,5 \%)$ e $703(41,8 \%)$ indivíduos não foram classificados em nenhuma condiçăo, pois eram estudantes ou donas de casa. A operacionalizaçăo do conceito de classe proposto exclui das condiçōes de classe todos os que não estăo inseridos no sistema de produção. Neste estudo os estudantes e donas de casa, foram mantidos para análise, considerados năo classificados, por terem representado uma grande proporção na amostra.

\section{2 - A Prevalência da Hipertensăo Arterial Referida}

Dentre as doenças crônicas referidas no inquérito, a pressão alta foi a segunda mais citada $(8,8 \%)$, perdendo somente para doença dos nervos $(9,3 \%)$ (CESAR, 1992).

Do total de 1681 hipertensos com idade minima de 20 anos, a grande maioria $(93,4 \%)$ informou ter tido diagnóstico médico. 
4.2.1 - A Prevalência da Hipertensăo Arterial e suas Associaçб̋es com as Variáveis

O município que apresentou a maior prevalência foi Embú com 20,9\%. E as menores prevalências foram encontradas em Itapecirica da Serra $(15,8 \%)$ e Cotia (16,2\%). Nos demais municipios os coeficientes encontrados apresentam-se semelhantes (Tabelas 8 e 9). Estes coeficientes de prevalência foram padronizados segundo sexo e idade, portanto a distribuição apresentada é independente da composição etária das populações.

Tabela 8 - Distribuiçăo dos coeficientes de prevalência da hipertensăo arterial referida segundo o municipio de residência. Região Sudoeste da Grande São Paulo, 1989-1990.

\begin{tabular}{l|c|c|c|c|c} 
Municípios & $(1)$ & $(2)$ & $(3)$ & $(4)$ & $(5)$ \\
Taboåo da Serra & 220 & 778 & 15372 & 84542 & 18,5 \\
\hline Embu & 364 & 1089 & 15057 & 76780 & 20,9 \\
\hline Itapecerica da Serra & 241 & 1054 & 7223 & 46381 & 15,8 \\
\hline Embu-Guaçu & 310 & 1135 & 3500 & 18105 & 18,4 \\
\hline Juquitiba & 257 & 1190 & 1972 & 9957 & 17,9 \\
\hline Cotia & 289 & 1109 & 10574 & 62540 & 16,2 \\
\hline Total & 1681 & 6355 & 53698 & 298305 & 18,0 \\
\hline
\end{tabular}

(1) número absoluto de hipertensos na amostra não ponderada

(2) populaçăo total na amostra não ponderada

(3) número de hipertensos na amostra ponderada

(4) populaçăo total na amostra ponderada

(5) prevalência (\%) na amostra ponderada padronizada por idade 
Tabela 9 - Intervalos com 95\% de Confiança dos coeficientes de prevalência

(\%) da hipertensão arterial referida ( $\geq 20$ anos) segundo o município de residência. Região Sudoeste da Grande São Paulo, 1989-1990.

\begin{tabular}{|c|c|c|c|}
\hline \multirow{3}{*}{ Municipios } & \multirow{3}{*}{$\begin{array}{c}\text { Prevalência } \\
\%\end{array}$} & \multicolumn{2}{|c|}{ Intervalo de confiança } \\
\hline & & Limite inferior & Limite superior \\
\hline & & $\%$ & $\%$ \\
\hline Taboão da Serra & 18,5 & 17,9 & 19,1 \\
\hline Embu & 20,9 & 20,3 & 21,5 \\
\hline Itapecerica da Serra & 15,8 & 15,0 & 16,6 \\
\hline Embu-Guaçu & 18,4 & 17,1 & 19,7 \\
\hline Juquitiba & 17,9 & 16,2 & 19,6 \\
\hline Cotia & 16,2 & 15,5 & 16,9 \\
\hline Total & 18,0 & 17,7 & 18,3 \\
\hline
\end{tabular}

A hipertensão segundo o sexo apresentou maior prevalência entre as mulheres $(20,8 \%)$ do que entre os homens $(15,1 \%)$.

A prevalência da hipertensão arterial apresentou um crescimento diretamente proporcional com a idade, alcançando o maior índice na faixa de 60 a 69 anos (50,2\%). A partir dos 50 anos a porcentagem de hipertensos na população total sempre esteve acima de $30 \%$ (Tabela 10). 
Tabela 10 - Distribuição do número de casos e coeficientes de prevalência de hipertensão arterial referida na população segundo faixa etária. Região Sudoeste da Grande São Paulo - SP, 1989 - 1990.

\begin{tabular}{l|c|c}
\hline \multicolumn{1}{|c}{ Faixa etária } & $\begin{array}{c}\text { Frequência } \\
(1)\end{array}$ & $\begin{array}{c}\text { Prevalência (\%) } \\
\text { 20|-- } 29\end{array}$ \\
\hline $30 \mid--39$ & 152 & 6,8 \\
\hline $40 \mid--49$ & 204 & 13,1 \\
\hline $50 \mid--59$ & 564 & 23,5 \\
\hline $60 \mid--69$ & 452 & 36,6 \\
\hline $70+$ & 223 & 50,2 \\
\hline Total & 1681 & 44,1 \\
\hline
\end{tabular}

(1) número absoluto na amostra não ponderada

(2) coeficiente de prevalência na amostra ponderada

A prevalência da hipertensão arterial sofre influências do nível de escolaridade (Figura 3). A prevalência padronizada foi maior nas faixas com menos anos de estudo formal. Entre os analfabetos foi de $19,8 \%$ e entre aqueles com curso primário (I grau 1) foi de 19,7\%, padronizados segundo faixa etária. Conforme aumenta o nível de escolaridade a prevalência diminui.

\section{Figura 3}

Coeficiente de prevalência (\%) da hipertensão arterial referida segundo nivel de escolaridade. Região Sudoeste da Grande São Paulo -

$$
\text { SP, } 1989-90 \text {. }
$$

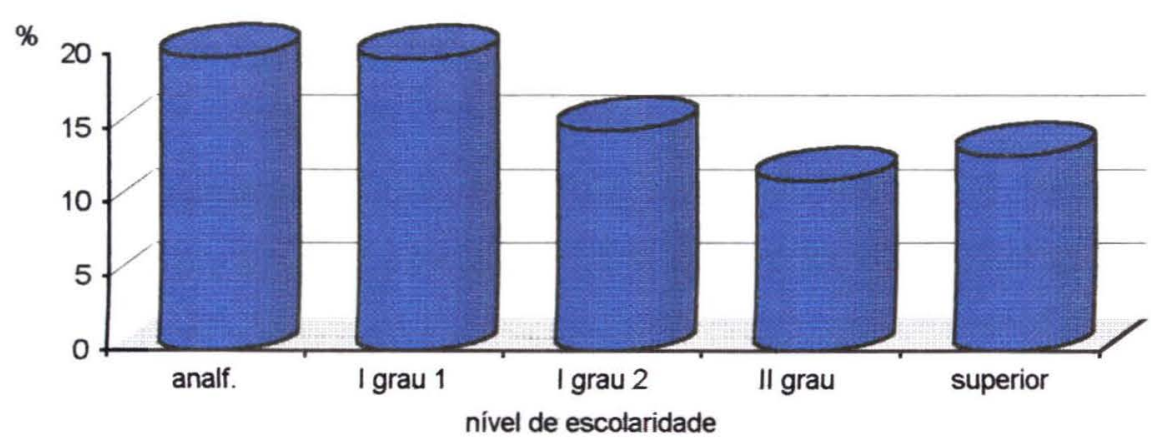


Em relação à condição de classe as maiores prevalências foram encontradas entre a burguesia $(20,1 \%)$ e o proletariado típico $(19,3 \%)$. Os grupos diferem pouco com relação a prevalência da hipertensão referida $e$ condição de classe (Tabela 11).

Tabela 11 - Número e coeficiente de prevalência (\%) de Hipertensão Arterial na população segundo condição de classe. Região Sudoeste da

Grande São Paulo - SP, 1989 - 1990.

\begin{tabular}{|c|c|c|}
\hline \multirow[t]{3}{*}{ Condição de classe } & \multicolumn{2}{|c|}{ Total } \\
\hline & (1) & (2) \\
\hline & & $\%$ \\
\hline Subproletariado & 196 & 17,9 \\
\hline Proletariado Típico & 262 & 19,3 \\
\hline Proletariado Não Típico & 334 & 18,4 \\
\hline Nova Pequena Burguesia & 30 & 13,6 \\
\hline Pequena Burguesia Tradicional & 151 & 14,3 \\
\hline Burguesia & 5 & 20,1 \\
\hline Não classificados & 703 & - \\
\hline Total & 1681 & 18,0 \\
\hline
\end{tabular}

(1)Números absolutos de hipertensos na amostra não ponderada

(2) Coeficiente de prevalência (\%) na amostra ponderada e padronizada segundo faixa etária

A maior prevalência da hipertensão arterial referida foi encontrada no município de Embú (20,9\%).

Observou-se, através dos coeficientes padronizados, prevalências mais altas entre os indivíduos com menor nível de escolaridade e mais velhos.

A distribuição segundo a condição de classe social apresentou uma taxa de $20,1 \%$ para a Burguesia e $13,6 \%$ para a Nova Pequena Burguesia. A operacionalização do conceito de condição de classe utilizado não atendeu a necessidade da análise de distribuição dos dados. 


\section{3 - Os Modelos Etiológicos e suas Associações com as Variáveis}

Conforme já descrito, foi utilizada uma questão aberta ("Porque o sr.(a) acha que tem essa doença ?") na tentativa de apreender qual a percepção que os individuos hipertensos apresentavam sobre a origem da enfermidade. As respostas foram categorizadas conforme já explicado no capítulo de Material e Métodos e a análise foi realizada através da classificação das respostas segundo as categorias propostas e as variáveis do banco de dados.

Assim, no primeiro nivel analisou-se os modelos etiológicos, no segundo nivel as causas identificadas e no terceiro as respostas que compunham os grupos de causas (categorias). Os testes estatísticos somente foram aplicados até o nivel (2) das categorias. As respostas (nivel 3) são analisadas qualitativamente.

A partir da distribuição das categorias foram identificados os modelos etiológicos endógeno e exógeno (Tabela 12 e 13). Foi possível classificar 981 respostas dos indivíduos hipertensos segundo os modelos. A diferença de 700 , em relação ao total da amostra $(n=1681)$, foi atribuida a falta de respostas possíveis de serem classificadas (brancos, negativos, associações e outros). 
Tabela 12 - Número e porcentagem de hipertensos referidos segundo as categorias de percepção sobre a origem da Hipertensão Arterial. Região Sudoeste da Grande São Paulo, 1989 - 1990.

\begin{tabular}{c|l|c|c} 
Código & Categorias & \multicolumn{3}{c}{ Total } \\
\multicolumn{2}{|l}{ Condições ambientais e causas sócio-econômicas } & 107 & 5,4 \\
\hline A & Hábitos de vida e comportamentos & 128 & 8,0 \\
\hline B & Causas internas psicossociais & 326 & 19,6 \\
\hline D & Causas internas biológicas, naturais & 420 & 25,8 \\
\hline E & Outros & 88 & 5,0 \\
\hline F & Associações & 103 & 6,5 \\
\hline NS & não respondeu & 509 & 29,7 \\
\hline total & & 1681 & 100,0 \\
\hline
\end{tabular}

(1) Números absolutos na amostra não ponderada

(2) Percentuais na amostra ponderada

Tabela 13 - Número e porcentagem de hipertensos referidos segundo os modelos etiológicos. Região Sudoeste da Grande São Paulo, 1989 - 1990.

\begin{tabular}{c|l|c|c}
\multicolumn{1}{c}{ Modelos } & \multicolumn{1}{c}{ Categorias } & \multicolumn{2}{c}{ Total } \\
\multirow{2}{*}{ EXÓGENO } & Condições ambientais/causas sócio-econômicas & \multirow{2}{*}{235} & \multirow{2}{*}{24,0} \\
\cline { 2 - 3 } & Hábitos de vida e comportamentos & & \\
\hline \multirow{2}{*}{ ENDÓGENO } & Causas internas psicossociais & \multirow{2}{*}{746} & 76,0 \\
\cline { 2 - 3 } & Causas internas biológicas, naturais & 981 & 100,0 \\
\hline total & &
\end{tabular}

Desta forma a distribuição apresenta-se conforme a figura 4. 
Figura 4

Distribuição da porcentagem de hipertensos referidos segundo os modelos etiológicos relacionados à hipertensão arterial. Região Sudoeste da Grande São Paulo - SP, 1989 - 90.

$$
(n=981)
$$

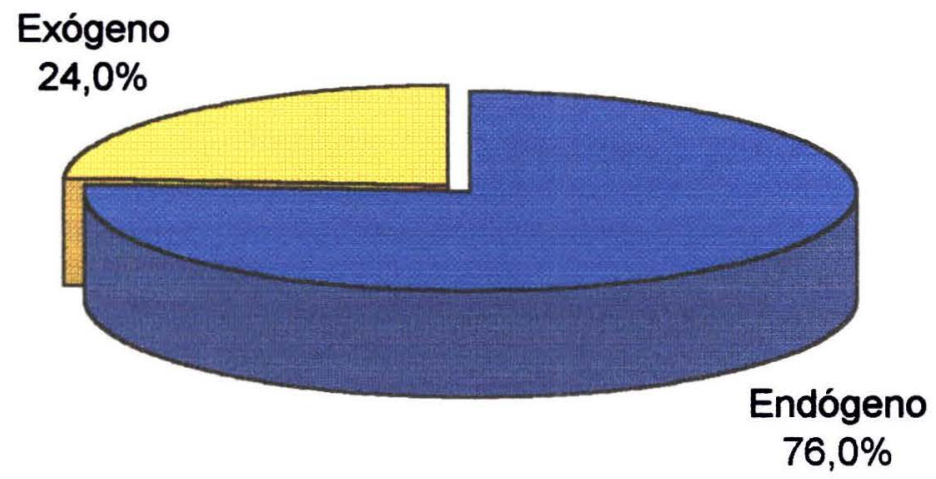


A análise da percepção sobre a origem da doença, segundo o modelo etiológico identificado, mostrou que não há diferenças estatisticamente significante associada ao município de residência do indivíduo (Figura 5) (Qui-quadrado $=4,72356 ; p=0,45054$ ).

Figura 5

Distribuição do número de hipertensos referidos segundo os municípios de residência e os modelos etiológicos sobre hipertensão arterial. Região Sudoeste da Grande São Paulo - SP , 1989 - 90.

$$
(n=981)
$$

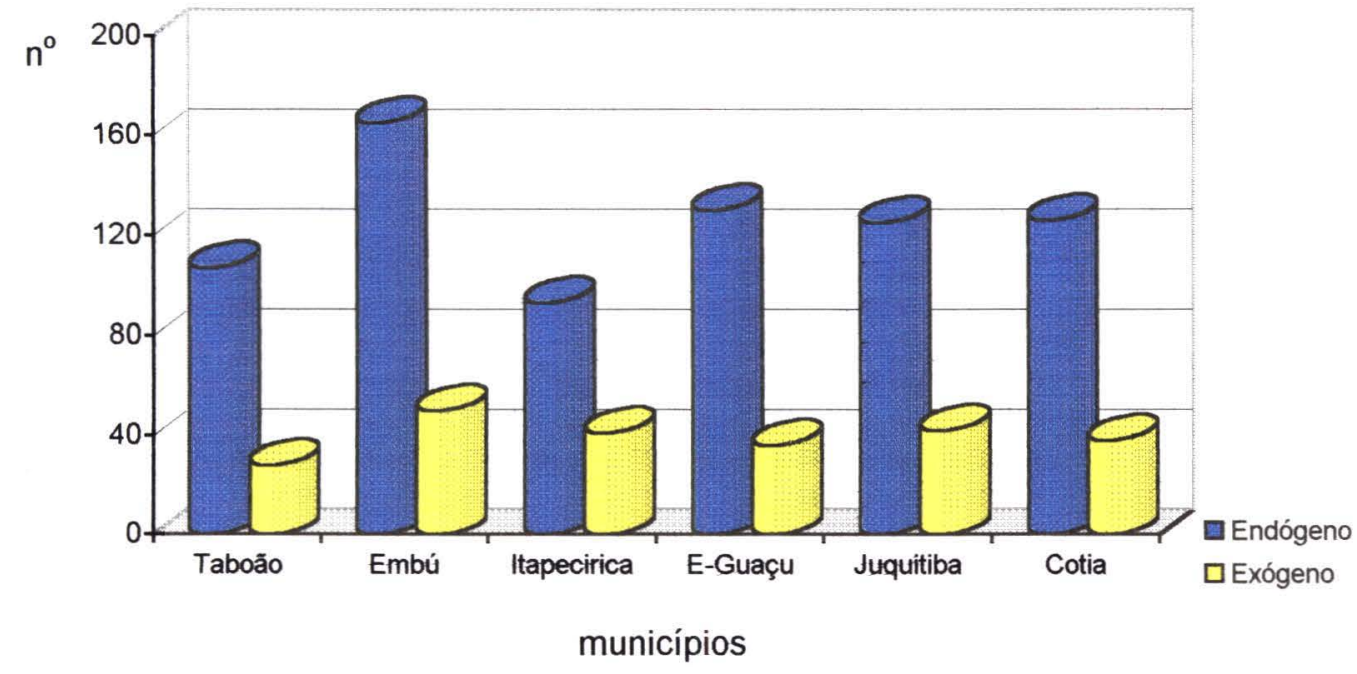


Com relação ao sexo, houve associação estatisticamente significante. Homens e mulheres percebem de modo diferente a origem da doença. As mulheres tendem a citar menos causas exógenas que os homens (Figura 6) (Qui-quadrado $=87,65585 ; \mathrm{p}<0,00001$ ).

\section{Figura 6}

Distribuição do número de hipertensos referidos segundo sexo e os modelos etiológicos sobre a hipertensão arterial. Região Sudoeste da Grande São Paulo - SP , 1989 - 90.

$$
(n=981)
$$

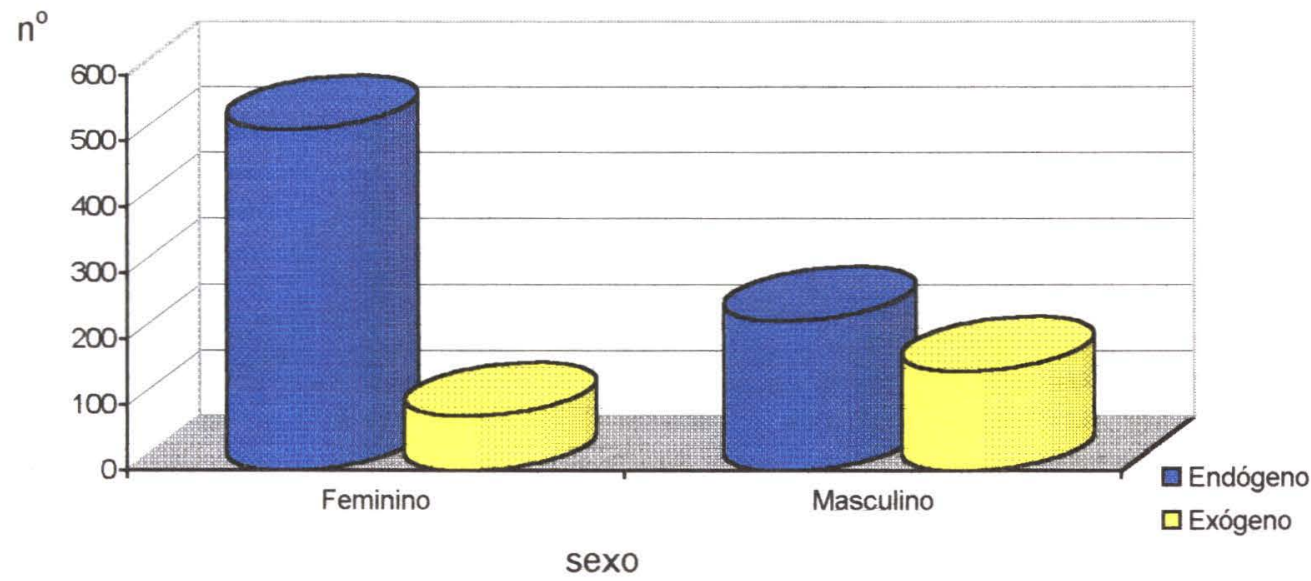


A idade não esteve associada estatisticamente com a percepção sobre a origem da doença (Figura 7) (Qui-quadrado $=2,92500 ; p=0,71155$ ).

Figura 7

Distribuição do número de hipertensos referidos segundo a idade e os modelos etiológicos sobre a hipertensão arterial. Região Sudoeste da Grande São Paulo - SP , 1989 - 90.

$$
(n=981)
$$

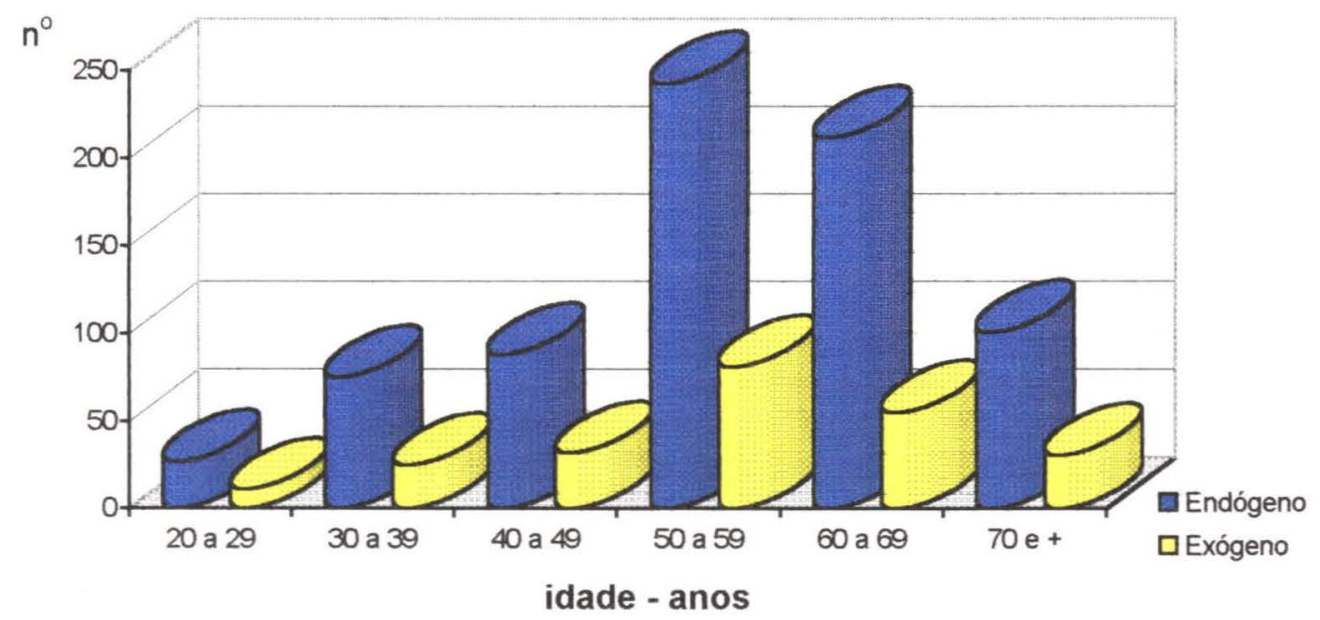


O nível de escolaridade não mostrou associação com os modelos etiológicos de percepção (Qui-quadrado $=4,30434 ; p=0,50648$ ) (Figura 8) .

Figura 8

Distribuição do número de hipertenso referidos segundo nível de escolaridade e os modelos etiológicos sobre a hipertensão arterial. Região Sudoeste da Grande São Paulo - SP , 1989 - 90.

$(n=981)$

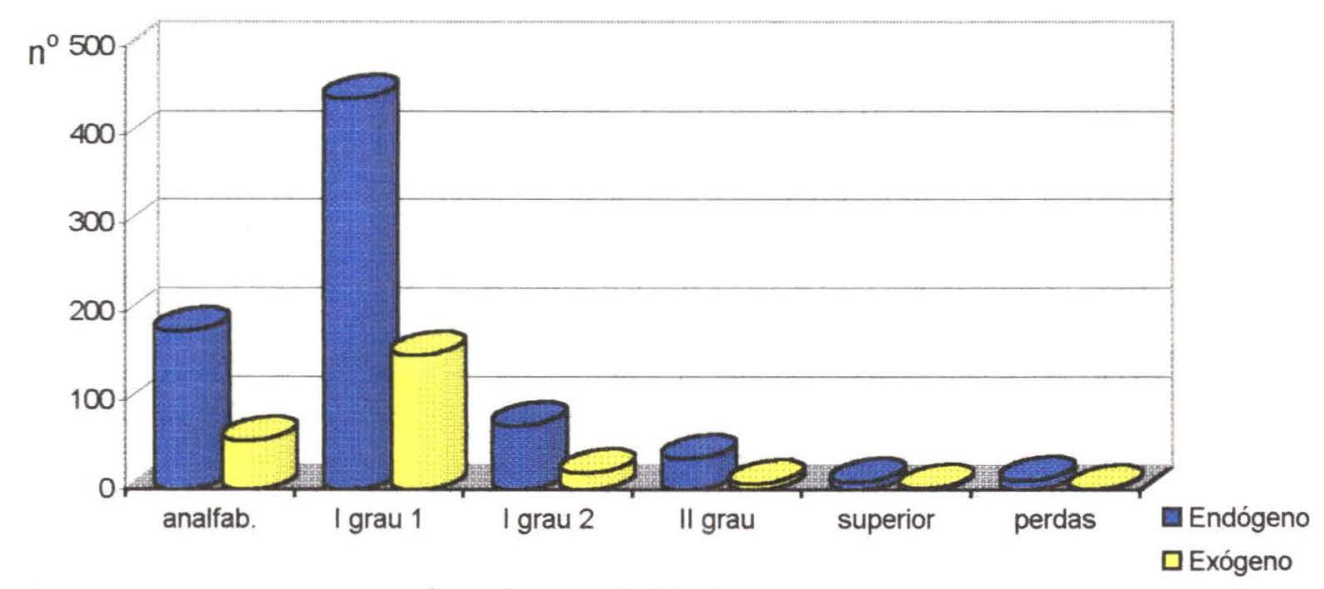

nível de escolaridade 
A condição de classe estava associada com a percepção. Assim, as categorias como proletariado típico e não típico tiveram comportamento semelhante, com respostas voltadas para o modelo endógeno. (Quiquadrado = 78,29969; $p<0,00001)$ (Figura 9)

Figura 9

Distribuição do número de hipertensos referidos segundo a condição de classe e os modelos etiológicos sobre a hipertensão arterial. Região Sudoeste da Grande São Paulo - SP, 1989 - 90.

$(n=981)$

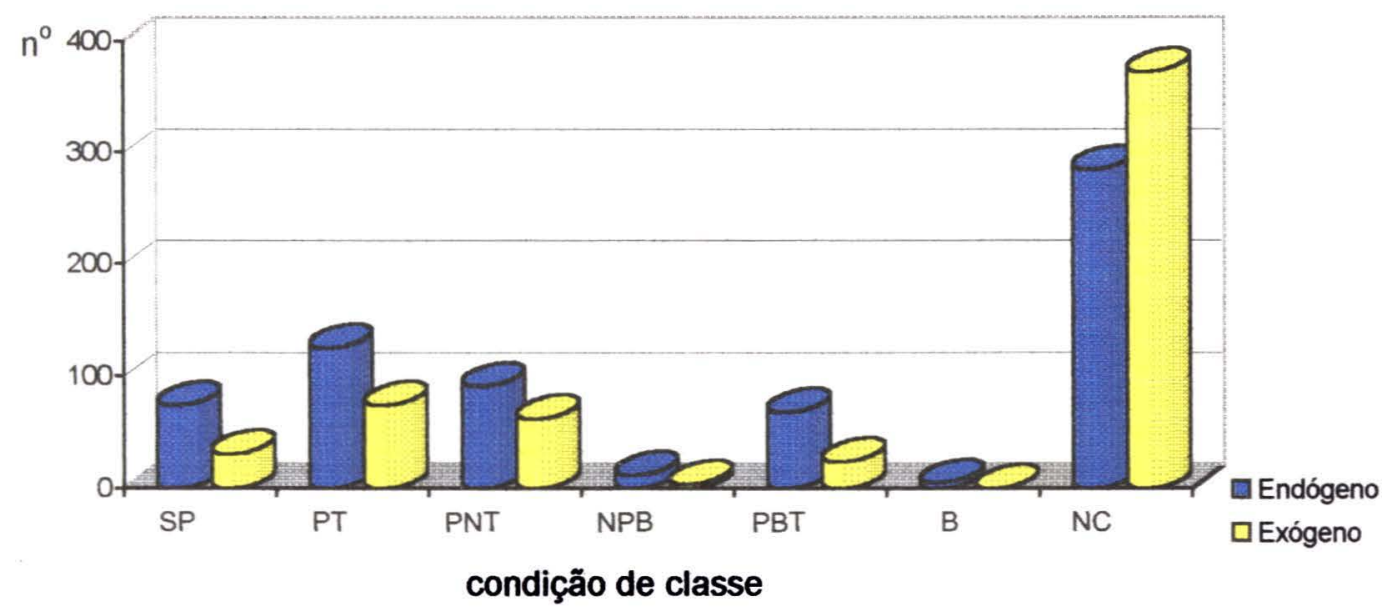

Legenda:

$\mathrm{SP}=$ Subproletariado

PT $=$ Proletariado Típico

PNT = Proletariado Não Típico

NPB $=$ Nova Pequena Burguesia

PBT = Pequena Burguesia Tradicional

$B=$ Burguesia

$N C=$ não classificados

As variáveis que contribuíram para diferenciar o modelo de percepção foram o sexo e a condição de classe. As mulheres percebem a origem da doença a partir de um modelo etiológico endógeno. A associação com as condições de classe mostraram o Proletariado (motoristas, pedreiros, bancários, funcionários públicos), voltados para este modelo. 


\subsection{1 - As Categorias e Respostas da Percepção e suas} Associações com o sexo e idade

Ao serem consideradas as categorias (segundo nível) de cada modelo etiológico pode-se observar que a distribuição entre os sexos apresenta diferenças importantes, principalmente no que se refere ao modelo exógeno - condições ambientais, causas sócio-econômicas e hábitos de vida e comportamentos (A e B) (Qui-quadrado = 98,37902; $p<0,00001$ ) (Figura 10).

Figura 10

Distribuição do número de hipertensos referidos segundo as categorias dos modelos etiológicos e o sexo. Região Sudoeste da Grande São Paulo - SP, 1989 -90.

$$
(n=1681)
$$

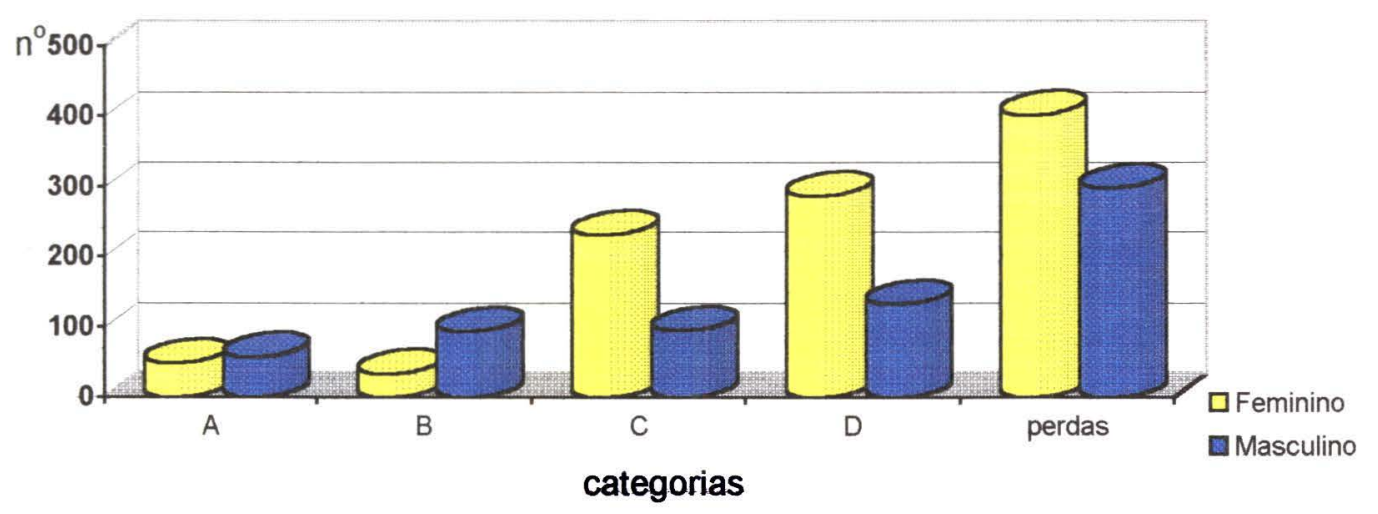

Legenda

$A=$ condições ambientais e causas sócio-econômicas

$B=$ Hábitos de vida e comportamentos

$\mathrm{C}=$ causas internas psicossociais

$\mathrm{D}=$ causas internas biológicas, naturais

Perdas = outros, respostas em branco, negativas, associações 
As causas externas - condições ambientais e causas sócioeconômicas (A) são utilizadas como justificativas por $54,2 \%$ dos homens e $45,8 \%$ das mulheres, e as causas relacionadas a situações comportamentais e de hábitos de vida (B) são citadas por $73,4 \%$ dos homens.

Ressalta-se que a análise do terceiro nível (respostas) é qualitativa e os dados apresentados têm função descritiva.

As respostas dos homens estiveram relacionadas à situações de trabalho e hábitos de vida (Figura 11) como:

"eu trabalho durante a noite e quase não durmo direito"

\section{Figura 11}

Distribuição do número de hipertensos referidos segundo as respostas da categoria $\mathrm{A}$ - condições ambientais e causas sócio-econômicas e o sexo. Região Sudoeste da Grande São Paulo - SP, 1989 - 90.

$$
(n=107)
$$

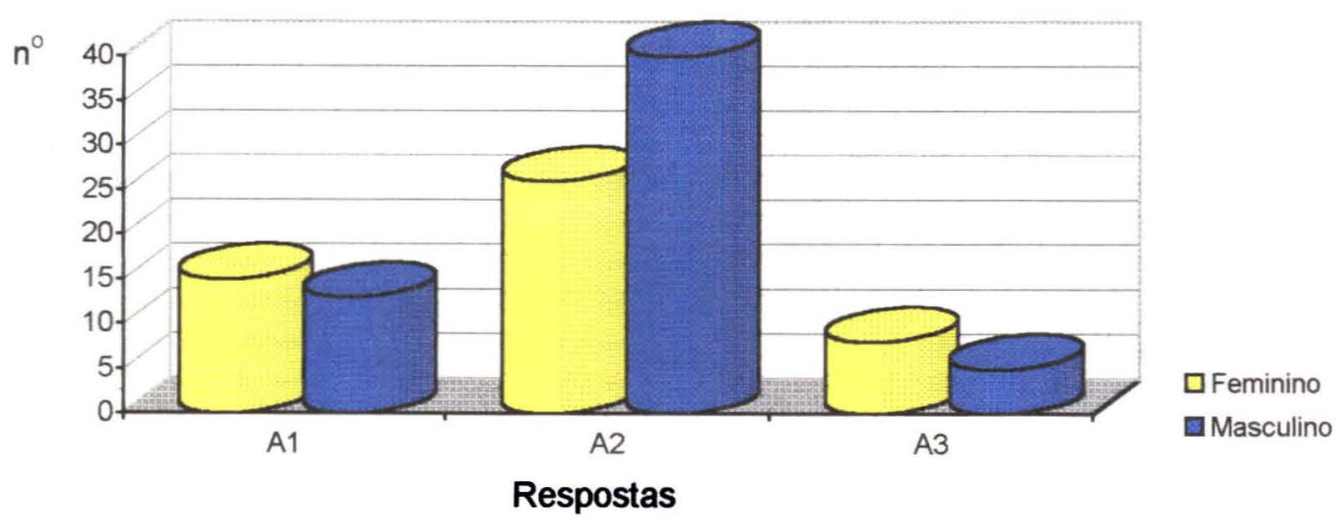

Legenda:

A1 = condições ambientais / clima / poluição

A2 = situação de trabalho

$A 3$ = situação de vida 
A análise das respostas na categoria (B) - Situações comportamentais e de hábitos de vida, mostrou que os homens tendem a relacionar mais a causa da hipertensão com o alcoolismo, sedentarismo e tabagismo (Figura 12).:

"quando bebe bebida alcoólica"

"excesso de café e cigarro"

Enquanto as mulheres associaram mais as respostas ao uso de outros medicamentos e ocorrência de acidentes (Figura 12):

"depois que foi operada"

"por causa do remédio para úlcera"

Figura 12

Distribuição do número de hipertensos referidos segundo as respostas da categoria $\mathrm{B}$ - situações comportamentais e de hábitos de vida e o sexo. Região Sudoeste da Grande São Paulo - SP, 1989 - 90.

$$
(n=128)
$$

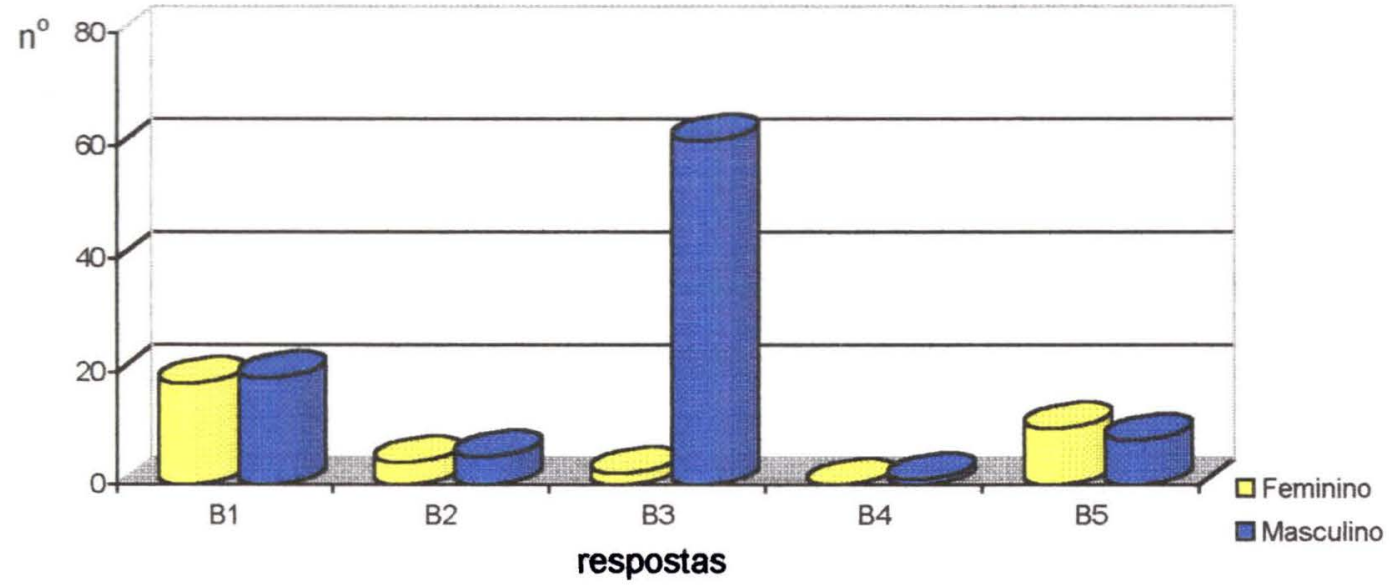

Legenda:

B1 = dietas

$\mathrm{B} 2$ = tabagismo

B3 = alcoolismo

B4 = sedentarismo

B5 = medicamentos $/$ acidentes 
A análise da respostas na categoria (C) - causas psicossociais segundo o sexo, mostrou que as mulheres predominaram em todas as respostas desta categoria. As causas endógenas - causas internas psicossociais (C), foram citadas por $70,9 \%$ das mulheres. (Figura 13):

"nervoso com a familia"

"por causa de motivos emocionais"

"num ano só perdi minha mãe e meu marido"

\section{Figura 13}

Distribuição do número de hipertensos referidos segundo as respostas da categoria C - causas psicossociais e o sexo. Região Sudoeste da Grande São Paulo - SP, 1989 - 90.

$$
(n=326)
$$

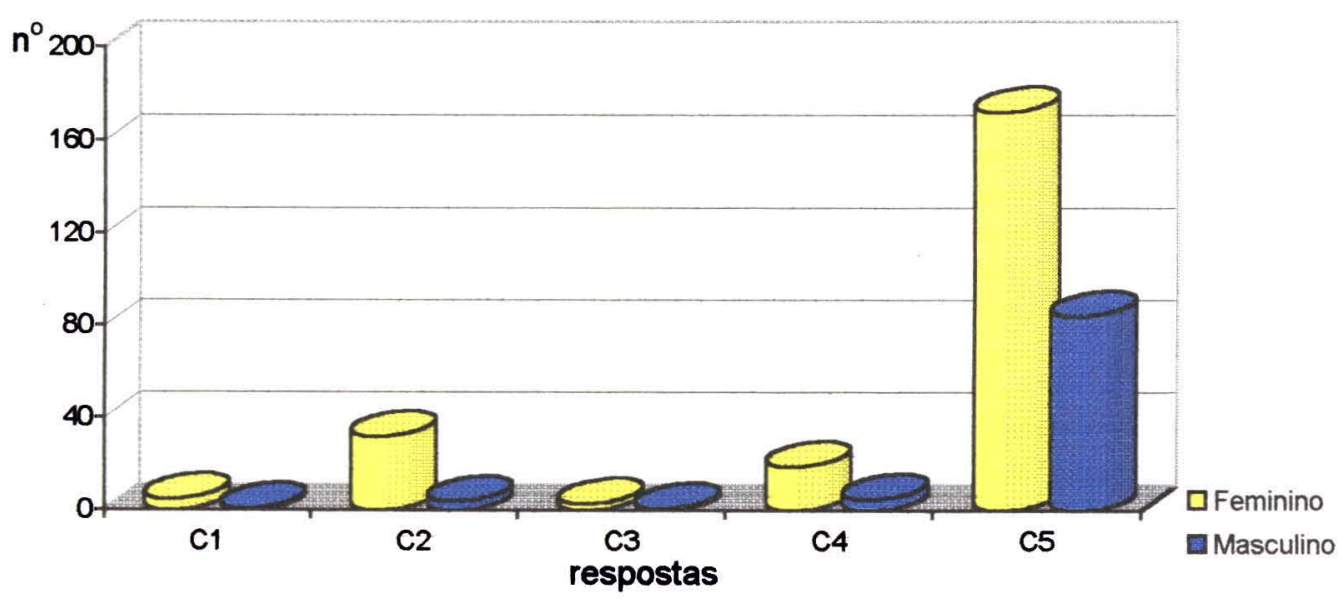

Legenda:

C1 = doenças na família

C2 = morte na família

C3 = separação (divórcio)

C4 = relacionamento familiar

C5 - nervosismo / preocupação 
A análise das subcategorias da percepção (D) - Causas Naturais, mostrou que as mulheres predominaram $(68,3 \%)$ em todas as respostas (Figura 14):

- "acredito que foi por causa do emocional, com a separação do marido"

- "é por causa da menopausa"

- "após a gravidez de meu filho"

\section{Figura 14}

Distribuição do número de hipertensos referidos segundo as respostas da categoria D - causas naturais e o sexo. Região Sudoeste da Grande São Paulo - SP, 1989 - 90.

$$
(n=420)
$$

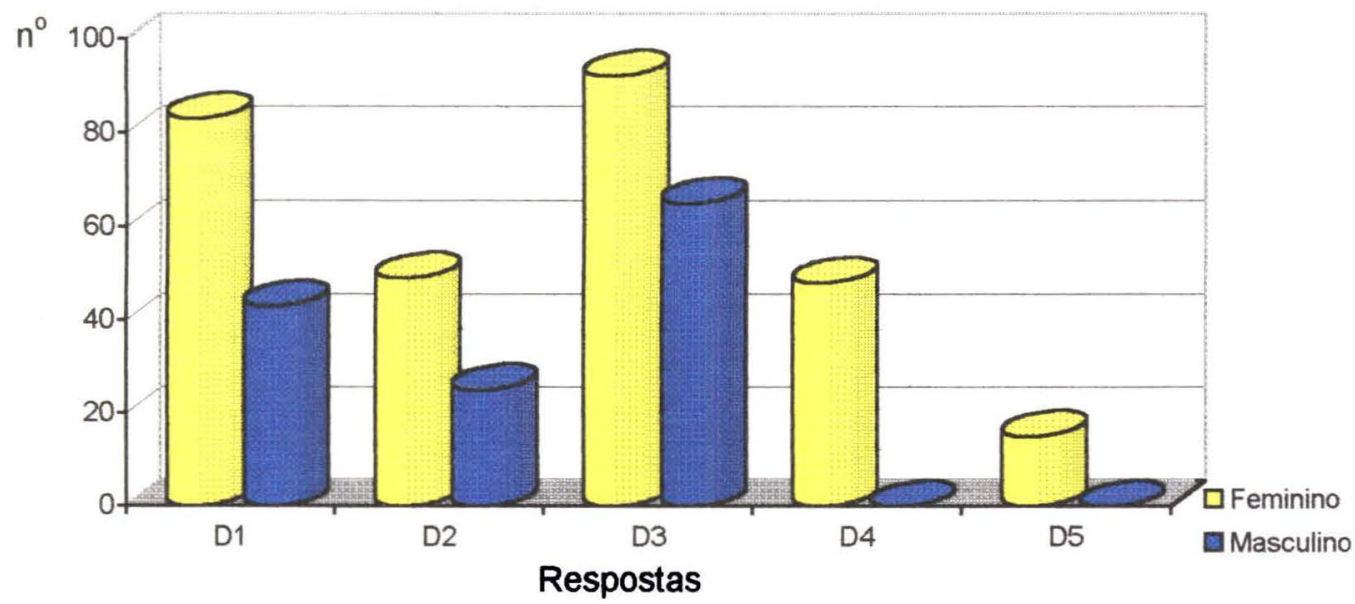

Legenda:

D1 = idade

D2 = hereditariedade

D3 = outras doenças/ sintomas

D4 = Gestação

D5 = Menopausa 
Houve associação entre as faixas etárias e as categorias (Quiquadrado $=35,33832 ; p=0,01837$ ).

As perdas (respostas em branco, negativas, associaçōes) apresentaram as maiores proposições em todas as faixas etárias, sendo maior entre aqueles da faixa de 50 a 59 anos. E na categoria $\mathrm{A}$ - causas externas - sócio-econômicas, a faixa etária mais presente foi de 60 a 69 anos (Figura 15).

Figura 15

Distribuição do número de hipertensos referidos segundo as categorias e faixas etárias. Região Sudoeste da

Grande São Paulo - SP, 1989 - 90.

$$
(n=1681)
$$

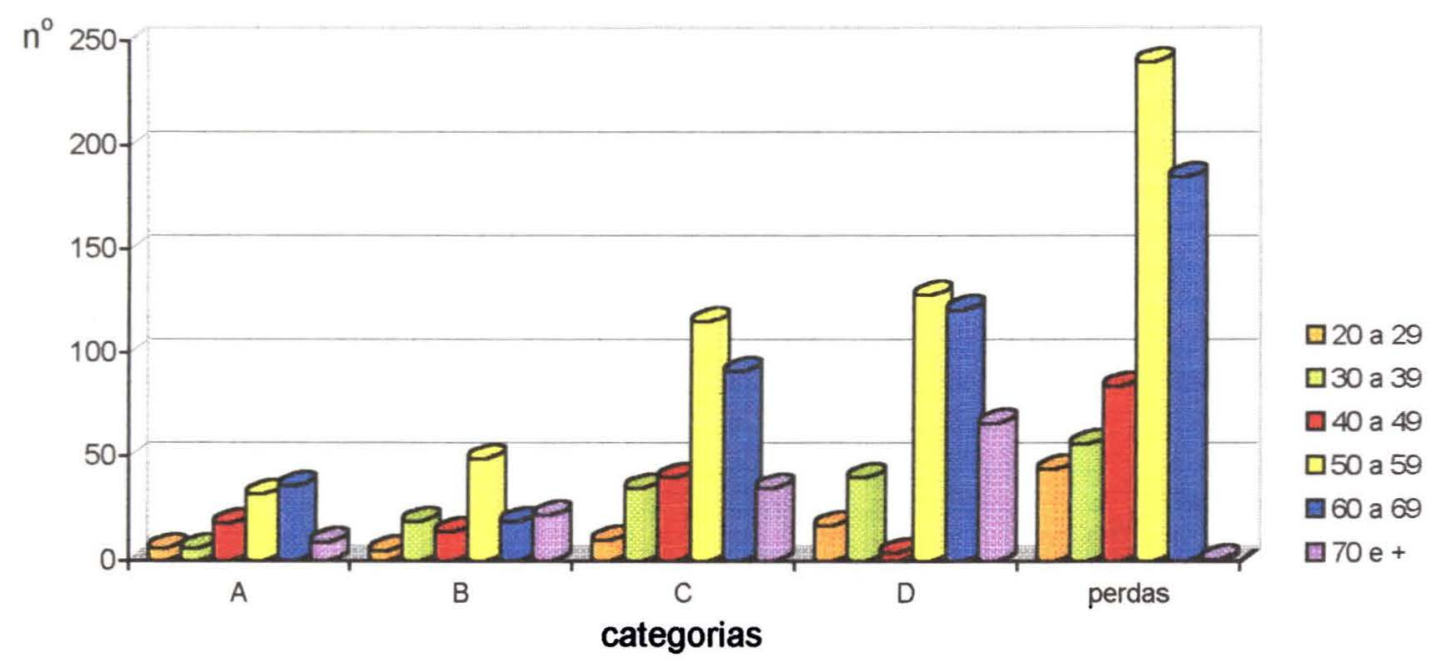

Legenda

$A=$ condições ambientais e causas sócio-econômicas

$B=$ Hábitos de vida e comportamentos

$\mathrm{C}=$ causas internas psicossociais

$\mathrm{D}=$ causas internas biológicas, naturais

Perdas $=$ outros, respostas em branco, negativas, associações 
A análise descritiva da figura 16 mostra que os mais jovens tendem a citar condições ambientais como causa da hipertensão. Já as pessoas mais velhas (acima de 50 anos) citaram mais situações de trabalho:

"acho que é o clima daqui; morava em São Paulo e não tinha problema"

"desde quando trabalhava; acho que era o serviço"

Figura 16

Distribuição do número de hipertensos referidos segundo as respostas da categoria $\mathrm{A}$ - condições ambientais e causas sócio-econômicas e faixa etária. Região Sudoeste da Grande São Paulo - SP, 1989 - 90.

$$
(n=107)
$$

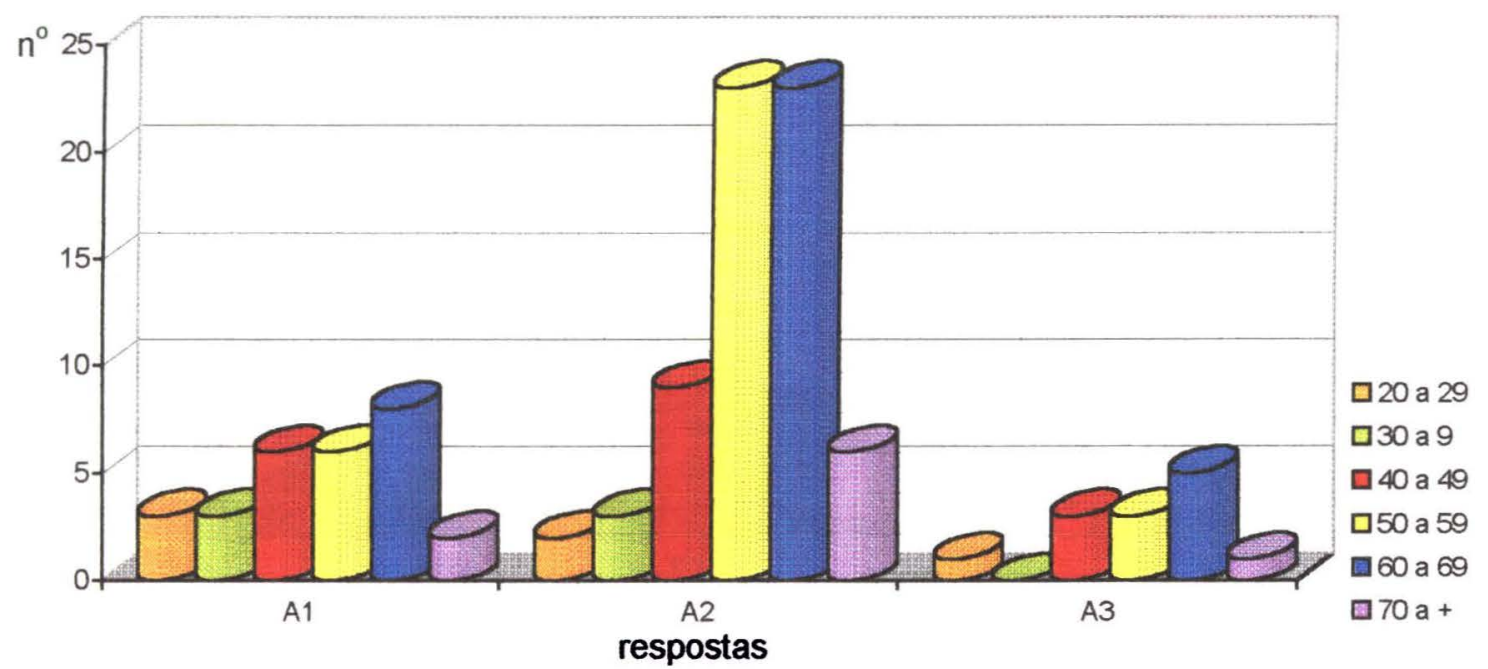

Legenda $=$

A1 = condições ambientais / clima / poluição

$A 2$ = situação de trabalho

A3 = situação de vida econômica 
As respostas que relacionaram a origem da doença com dietas foram, em sua maioria de indivíduos a partir de 50 anos. $E$ as respostas relacionadas ao alcoolismo foram mais presentes entre indivíduos nas faixas de 50 a 59 e 30 a 39 anos. (Figura 17):

"pelo sal, comia muito puxado no sal"

"problema de cerveja, bebia muito"

Figura 17

Distribuição do número de hipertensos referidos segundo as respostas da categoria $\mathrm{B}$ - situações comportamentais e de hábitos de vida e faixa etária. Região Sudoeste da Grande São Paulo - SP, 1989 - 90.

$$
(n=128)
$$

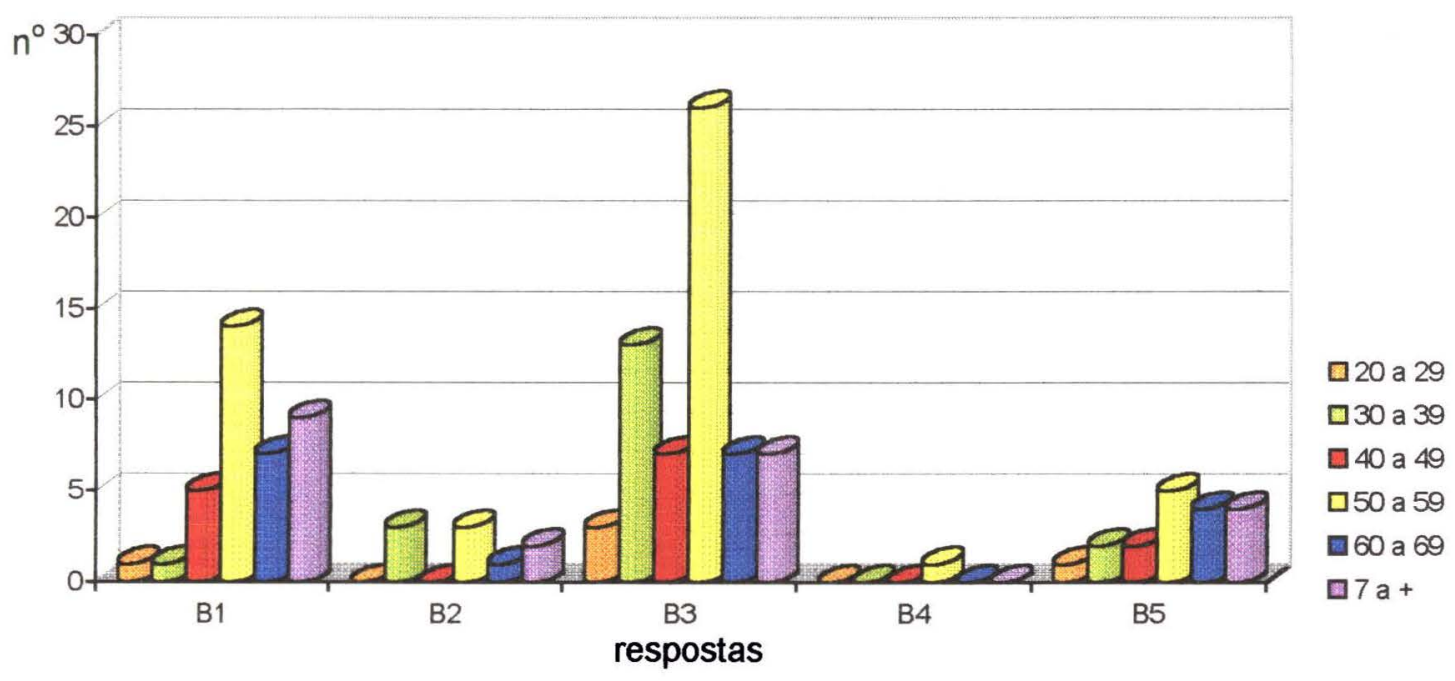

Legenda:

$\mathrm{B1}=$ dietas

B2 = Tabagismo

B3 = Alcoolismo

B4 $=$ Sedentarismo

B5 = outros medicamentos $/$ acidentes/ tratamentos 
$\mathrm{Na}$ categoria $\mathrm{C}$ - causas psicossociais, predominaram repostas que relacionavam a origem da doença com preocupação e nervosismo (C5), em todas as faixas etárias. $E$ aqueles que lembraram de mortes na família como causa para doença pertenciam a faixas etárias acima de 50 anos (Figura 18):

"por causa do falecimento de minha mãe há 9 anos"

"muito nervoso que a gente passa"

Figura 18

Distribuição do número de hipertensos referidos segundo as respostas da categoria $\mathrm{C}$ - causas psicossociais e faixa etária. Região Sudoeste da Grande São Paulo - SP, 1989 - 90.

$$
(n=326)
$$

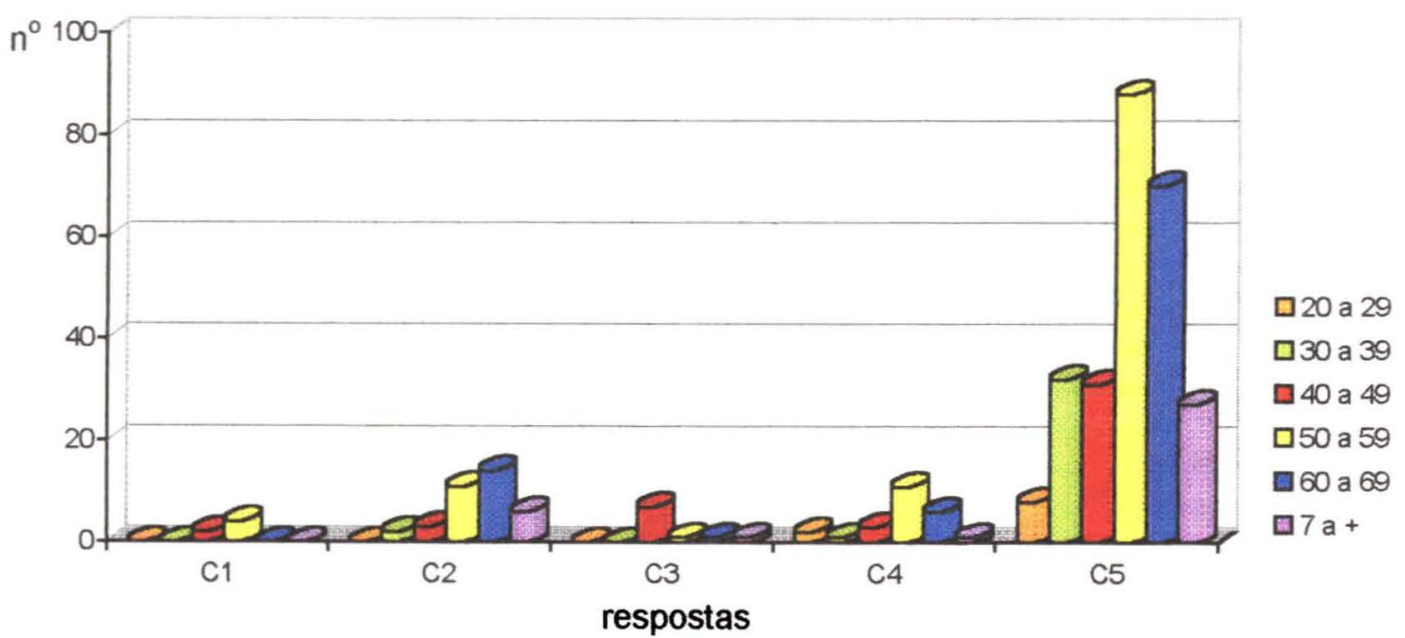

Legenda:

C1 = doença na família

$\mathrm{C} 2$ = morte na família

C3 $=$ Separação

C4 = Relacionamento familiar problemático

C5 $=$ Nervosismo, preocupação 
As respostas que associaram a origem da Hipertensão Arterial com a idade foram mais presentes em indivíduos nas faixas etárias mais velhas ((60 a 69 anos). E também são eles que mais associaram com outras doenças e sintomas. A hereditariedade foi mais lembrada por indivíduos na faixa de 50 a 59 anos. A gestação foi apresentada como resposta por indivíduos na faixa de 30 a 40 anos. (Figura 19):

"é coisa de velho"

"na gravidez do primeiro filho"

"é problema de família"

Figura 19

Distribuição do número de hipertensos referidos segundo as respostas da categoria D - causas naturais e faixa etária. Região Sudoeste da Grande São Paulo - SP, 1989 - 90.

$$
(n=420)
$$

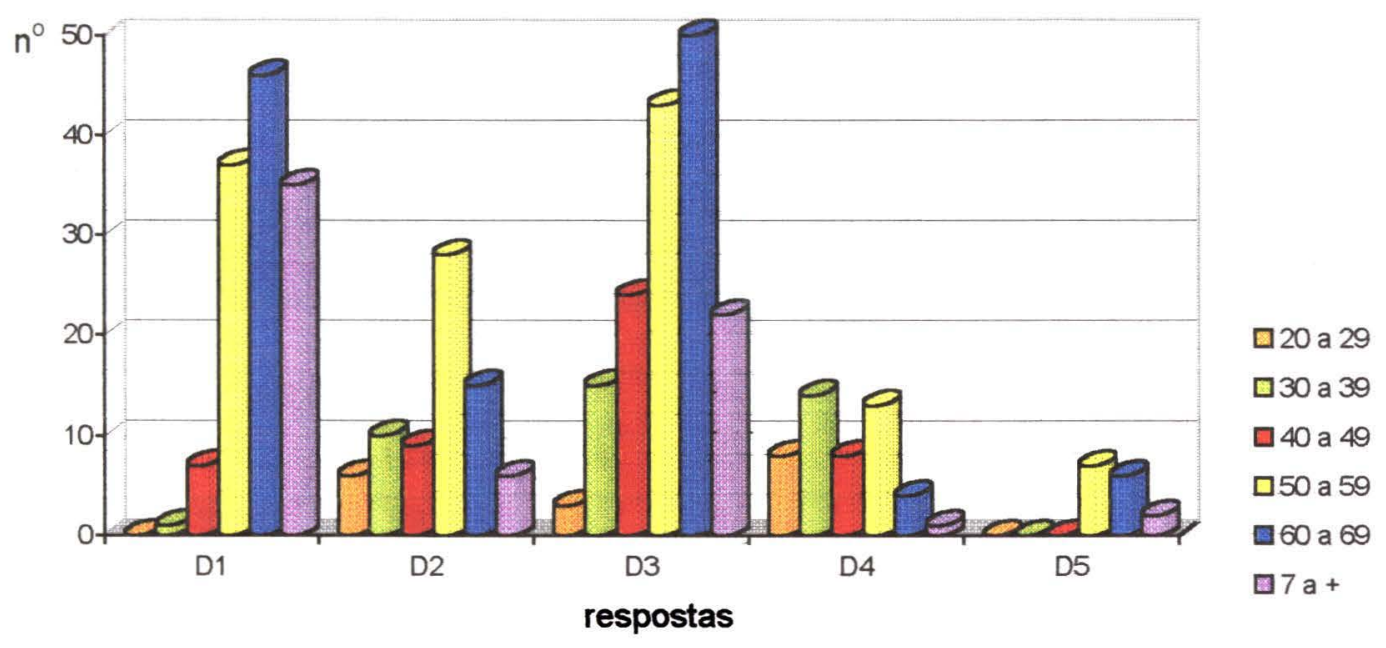

Legenda:

D1 = idade

D2 $=$ hereditariedade

D3 = outras doenças/ sintomas

D4 = Gestação

D5 = Menopausa 


\section{4 - As Formas de Controle da Hipertensão Arterial}

As formas de controle sobre a doença foram analisadas segundo o uso dos serviços e uso de medicação específica. Estas questões foram analisadas segundo suas distribuições em cada variável do estudo.

\subsection{1 - O Uso dos Serviços de Saúde}

A maioria dos indivíduos hipertensos relataram não visitar o médico rotineiramente $(63,8 \%)$.

Os indivíduos residentes em Embu foram aqueles que buscam menos assistência para o problema da hipertensão arterial (Tabela 14). Não houve associação significativa entre município de residência e o uso dos serviços (Qui-quadrado $=7,3755 ; p=0,19418$ ).

Tabela 14- Distribuição do número e porcentagens dos hipertensos referidos que usam os serviços de saúde. Região Sudoeste da Grande São Paulo - SP, 1989 - 90.

\begin{tabular}{|c|c|c|c|c|c|c|}
\hline & & dos $\mathrm{s}$ & cos de & & & \\
\hline MUNICIPIO & & & & & & \\
\hline & (1) & (2) & (1) & (2) & (1) & (2) \\
\hline Itapecirica da Serra & 82 & 3,75 & 160 & 9,76 & 242 & 13,51 \\
\hline Embú & 144 & 10,68 & 219 & 17,37 & 363 & 28,05 \\
\hline Taboão da Serra & 99 & 12,33 & 118 & 16,37 & 217 & 28,70 \\
\hline Juquitiba & 102 & 1,38 & 155 & 2,31 & 257 & 3,69 \\
\hline Embu-Guaçu & 125 & 2,27 & 184 & 4,24 & 309 & 6,51 \\
\hline Cotia & 107 & 5,81 & 181 & 13,73 & 288 & 19,55 \\
\hline Perdas & 5 & - & - & - & 5 & - \\
\hline Total & 664 & 100,0 & 1017 & 100,0 & 1681 & 100,0 \\
\hline
\end{tabular}

(1) Números absolutos na amostra

(2) Porcentagem na amostra ponderada 
Com relação ao sexo e o uso dos serviços foi identificado que as mulheres procuram mais assistência para o problema da hipertensão arterial do que os homens (Qui-quadrado $=18,36260 ; p=0,00002$ ) (Figura 20).

\section{Figura 20}

Distribuição dos número de hipertensos referidos segundo o uso dos serviços de saúde e sexo. Região Sudoeste da

Grande São Paulo - SP, 1989 - 90.

$$
(n=1681)
$$

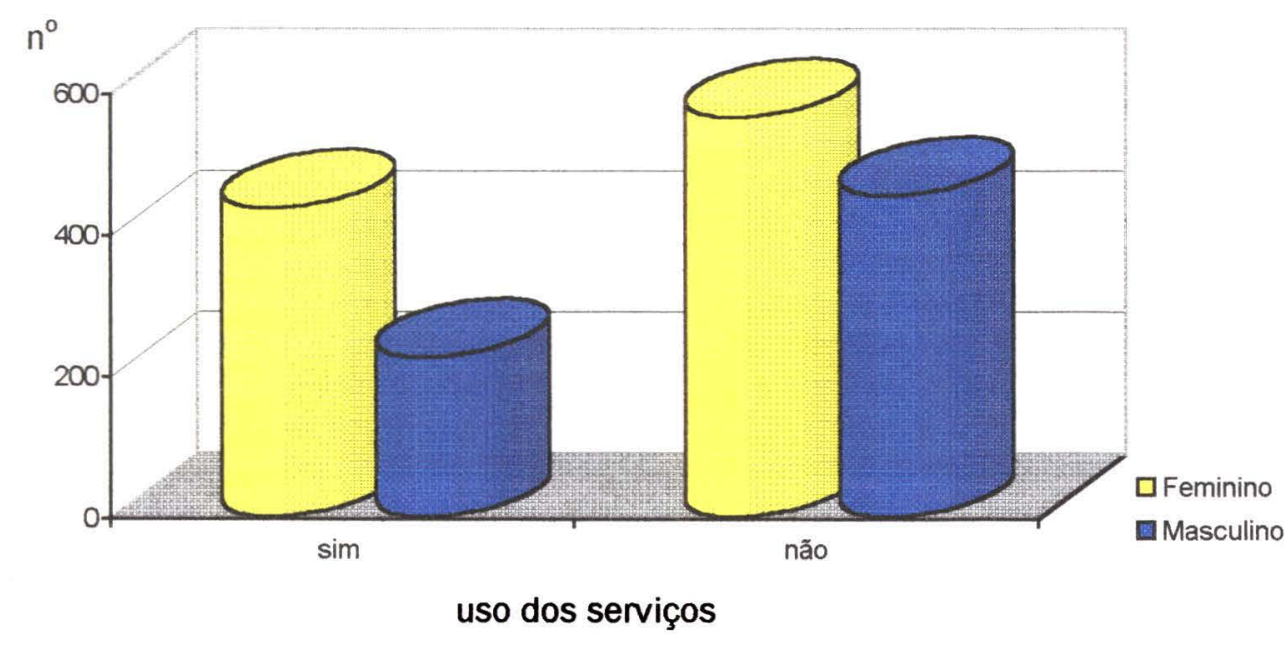


Com relação a idade, são os mais novos os que menos procuram assistência de rotina. Os mais velhos (acima de 50 anos) procuram mais pela assistência (Qui-quadrado $=54,96627 ; p<0,00001$ ) (Figura 21).

Figura 21

Distribuição do número de hipertensos referidos segundo o uso dos serviços e faixa etária. Região Sudoeste da

Grande São Paulo - SP, 1989 - 90.

$$
(n=1681)
$$

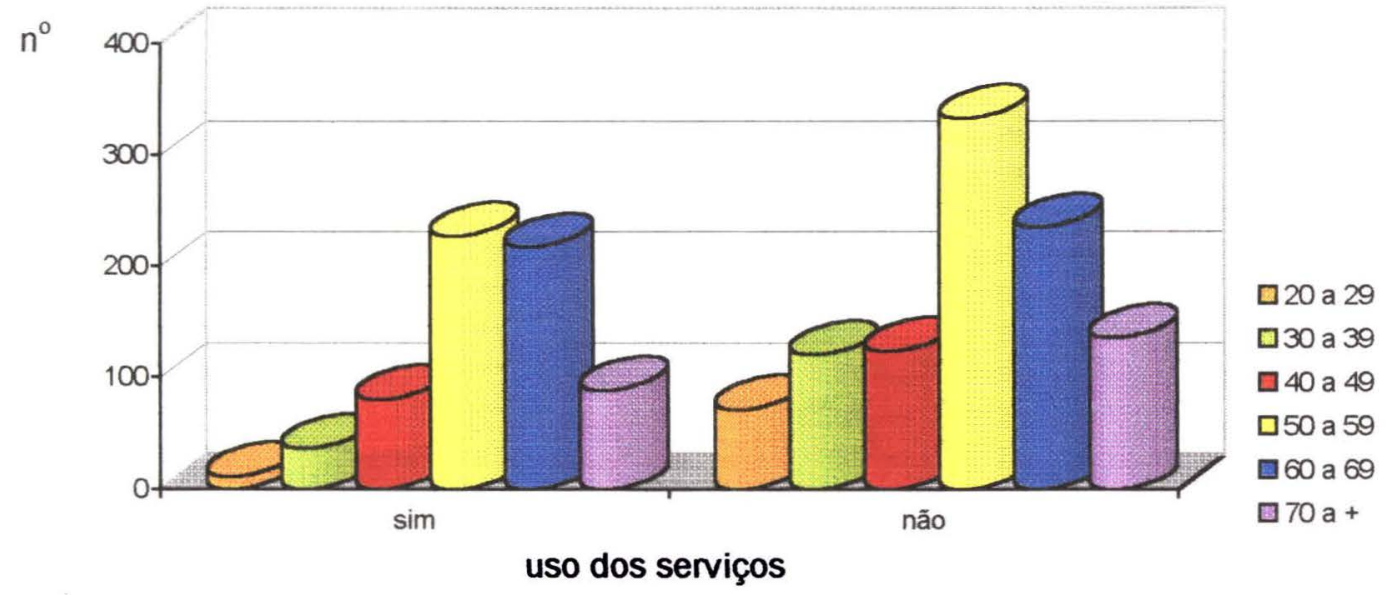

Não houve associação entre o uso dos serviços de saúde e o nível de escolaridade (Qui-quadrado $=9,86962 ; p=0,07901$ ). 
Segundo a condição de classe, o grupo que menos procura assistência pertence ao proletariado não típico. A condição de classe apresentou associação significativa com o uso dos serviços (Qui-quadrado = 20,00792; $p=0,00276$ ) (Figura 22).

Figura 22

Distribuição do número de hipertensos referidos segundo o uso dos serviços e a condição de classe. Região Sudoeste da

Grande São Paulo - SP, 1989 - 90.

$$
(n=1681)
$$

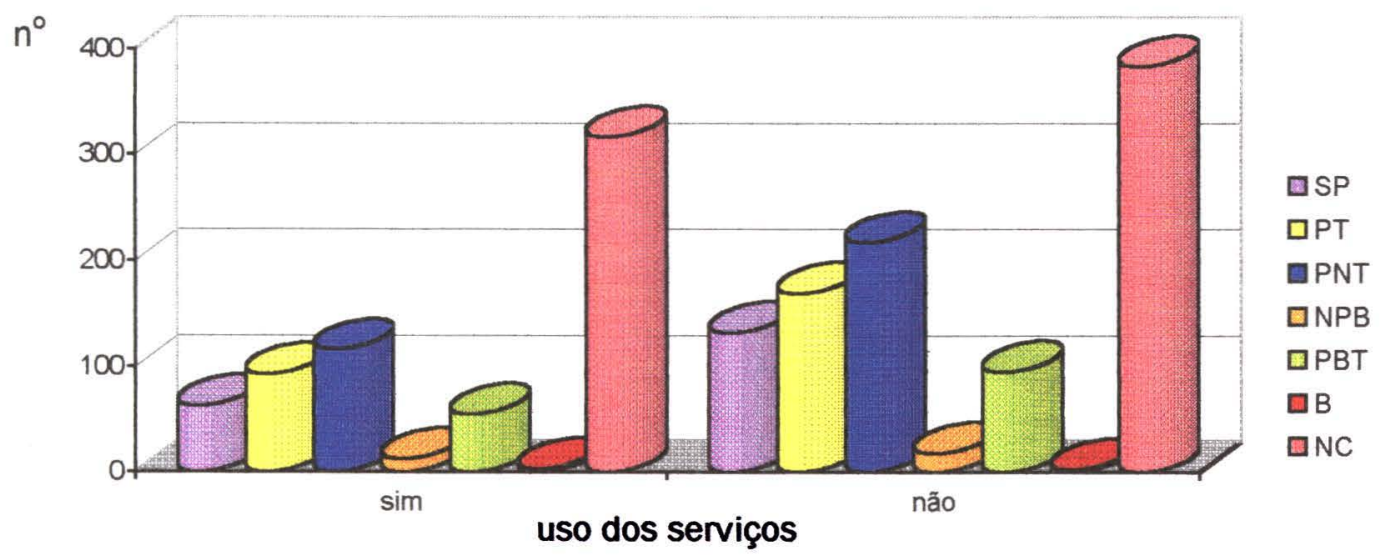

Legenda:

SP $=$ Subproletariado

$\mathrm{PT}=$ Proletariado Típico

PNT = Proletariado Não Típico

NPB = Nova Pequena Burguesia

PBT = Pequena Burguesia Tradicional

$B=$ Burguesia

$N C=$ não classificados 
Dentre as justificativas para não procurar assistência a maioria respondeu que não julgava necessário ("não acha preciso" $=45,2 \%$ ) (Tabela 15).

Tabela 15 - Distribuição da freqüência e porcentagem dos hipertensos referidos segundo as respostas justificando a falta da procura por assistência. Região Sudoeste da Grande São Paulo - SP, 1989 - 90.

\begin{tabular}{l|c|c|c}
\hline Respostas & \multicolumn{1}{c}{$\mathrm{n}^{\circ}$} & $\%$ & $\%$ \\
\hline NS-NR & $(1)$ & $(2)$ & $(3)$ \\
\hline É caro & 28 & 2,7 & 3,4 \\
\hline É muito longe & 29 & 2,8 & 3,0 \\
\hline Acha que não resolve & 38 & 3,7 & 2,9 \\
\hline Não tem tempo & 57 & 5,6 & 5,4 \\
\hline Outros & 121 & 11,8 & 14,1 \\
\hline Não gosta de ir ao médico & 137 & 13,4 & 13,4 \\
\hline Não acha preciso & 144 & 14,1 & 12,5 \\
\hline Total & 468 & 45,8 & 45,2 \\
\hline
\end{tabular}

(1) freqüência na amostra absoluta

(2) porcentagem na amostra absoluta

(3) porcentagem na amostra ponderada 
O fato de "não achar preciso" buscar assistência foi significativamente mais presente entre as mulheres (Qui-quadrado=14,84462; $p=0,03804$ ) (Tabela 16) .

Tabela 16 - Distribuição da freqüência e porcentagem de hipertensos referidos segundo as justificativas da falta de procura por assistência e o sexo. Região Sudoeste da Grande São Paulo - SP, 1989 - 90.

\begin{tabular}{|c|c|c|c|c|c|c|}
\hline \multirow[t]{2}{*}{ Respostas } & \multicolumn{2}{|c|}{ Masculino } & \multicolumn{2}{|c|}{ Feminino } & \multicolumn{2}{|c|}{ Total } \\
\hline & $n^{0}$ & $\%$ & $n^{\circ}$ & $\%$ & $n^{\circ}$ & $\%$ \\
\hline NS-NR & 16 & 3,5 & 12 & 2,1 & 28 & 2,7 \\
\hline É caro & 19 & 4,2 & 10 & 1,8 & 29 & 2,8 \\
\hline$\hat{E}$ muito longe & 10 & 2,2 & 28 & 4,9 & 38 & 3,7 \\
\hline Acha que não resolve & 21 & 4,6 & 36 & 6,3 & 57 & 5,6 \\
\hline Não tem tempo & 55 & 12,1 & 66 & 11,6 & 121 & 11,8 \\
\hline Outros & 55 & 12,1 & 82 & 14,5 & 137 & 13,4 \\
\hline Não gosta de ir & 62 & 13,6 & 82 & 14,5 & 144 & 14,1 \\
\hline Não acha preciso & 217 & 47,7 & 251 & 44,3 & 468 & 45,8 \\
\hline Total & 455 & 100,0 & 567 & 100,0 & 1022 & 100,0 \\
\hline
\end{tabular}

\subsection{2 - O Uso de Medicamentos Especificos}

Outra questão usada para análise do controle que é exercido sobre a morbidade foi sobre o uso de medicação específica. Do total de indivíduos hipertensos $44,0 \%$ não faziam uso da medicação rotineiramente (ter feito uso nos últimos 30 dias).

O município onde menos se usava medicamentos hipotensores foi Taboão da Serra (14,6\%), onde praticamente metade da população de hipertensos não estava tomando medicamentos. Os hipertensos do município de Juquitiba tomam medicamento em percentual superior aos hipertensos dos demais municípios. (Qui-quadrado $=23,75476 ; p=$ 0,00024). 
As mulheres $(70,0 \%)$ apresentaram mais o hábito do uso de medicamento do que os homens (Qui-quadrado $=16,22521 ; p=0,00006$ ) (Figura 23).

Figura 23

Distribuição do número de hipertensos referidos segundo o uso de medicamentos específicos e sexo. Região Sudoeste da

Grande São Paulo - SP, 1989 - 90.

$$
(n=1269)
$$

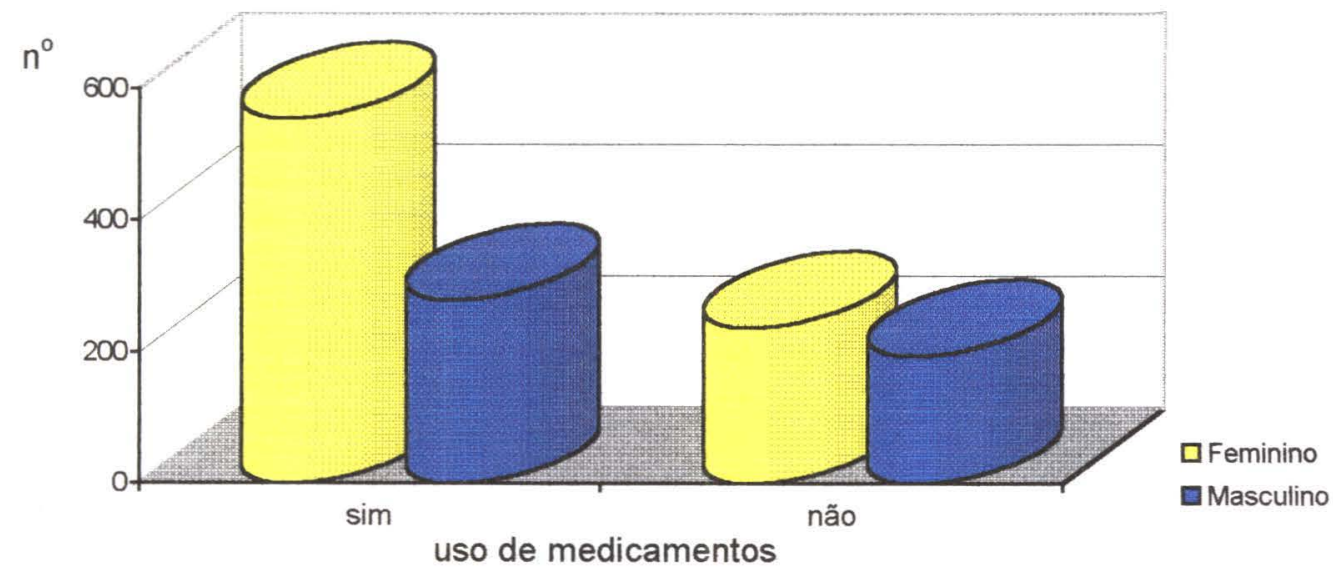


A faixa etária identificada que menos faz uso do medicamento está entre 30 e 50 anos (23,0\%). São os mais jovens os que menos usam medicamento e quanto mais velho mais presente o hábito do uso dos medicamentos (Qui-quadrado =62,52342; $p=0,0001$ ) (Figura 24).

\section{Figura 24}

Distribuição do número de hipertensos referidos segundo o uso de medicamentos específicos e faixa etária. Região Sudoeste da Grande São

$$
\begin{gathered}
\text { Paulo - SP, } 1989-90 \\
(n=1269)
\end{gathered}
$$

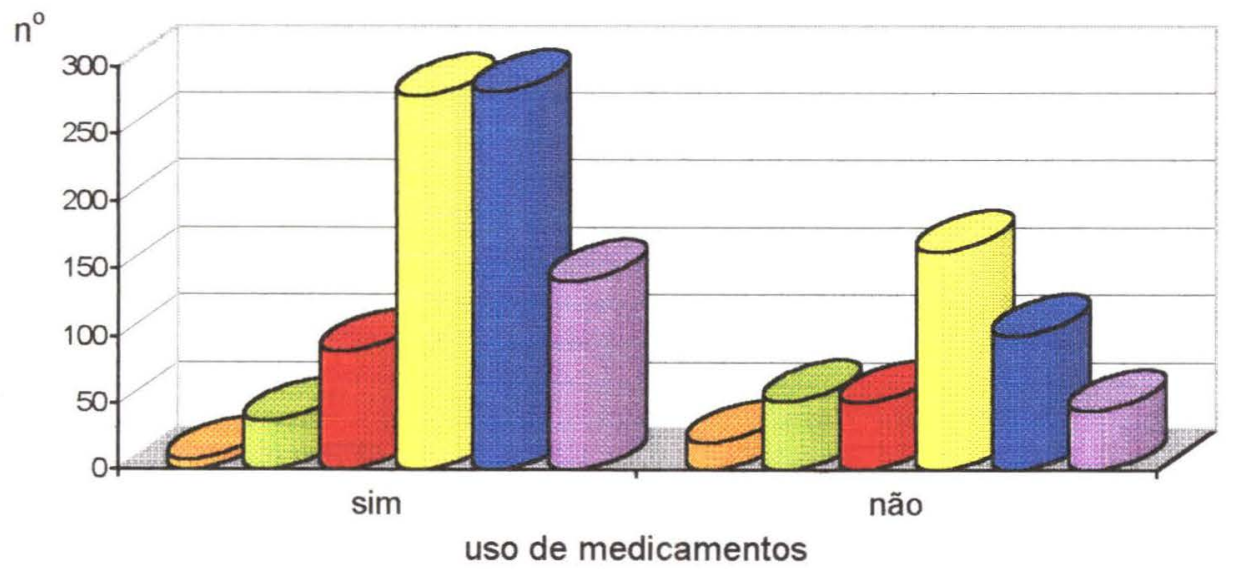


Os que mais usavam medicamentos tinham o nivel de escolaridade de primeiro grau 1. No entanto não é significativa a associação entre escolaridade e uso de hipotensores (Qui-quadrado $=3,31704 ; p=0,65123$ ).

A condição de classe que menos toma medicamentos pertence ao Proletariado Não Típico, Subproletariado e proletariado típico (Qui-quadrado $=21,16798 ; p=0,00171$ ) (Figuras 25).

Figura 25

Distribuição do número de hipertensos referidos segundo o uso de medicamentos específicos e a condição de classe. Região Sudoeste da Grande São Paulo - SP, 1989 - 90.

$$
(n=1269)
$$

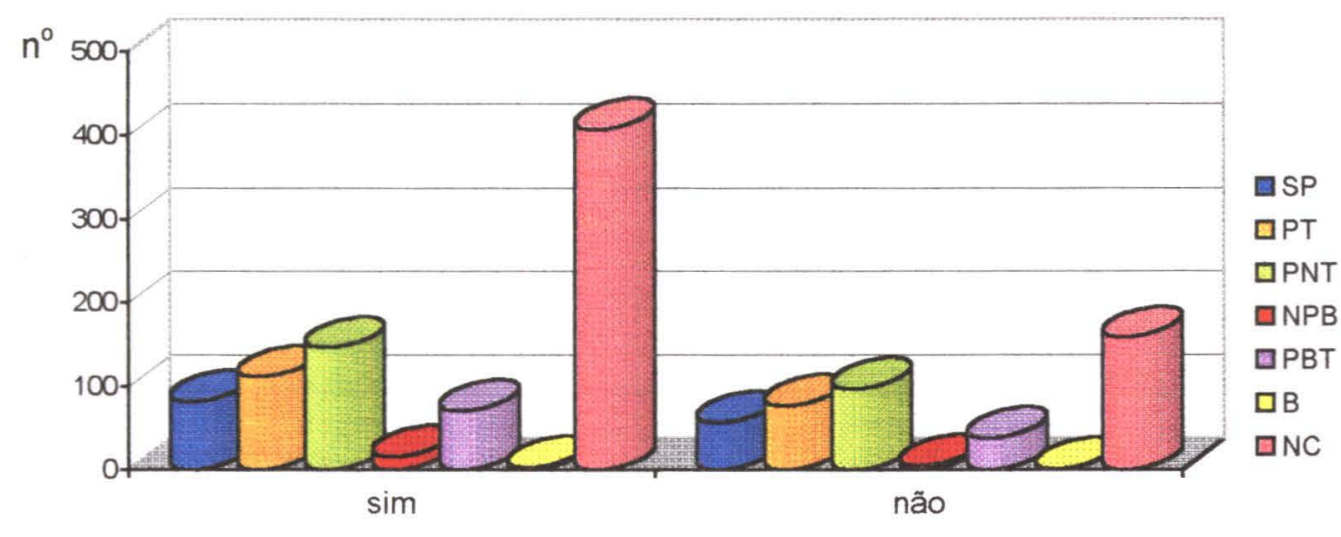
uso de medicamentos

Legenda:

$\mathrm{SP}=$ Subproletariado

PT = Proletariado Típico

PNT = Proletariado Não Típico

NPB = Nova Pequena Burguesia

PBT = Pequena Burguesia Tradicional

$B=$ Burguesia

$N C=$ não classificados 
O não uso de medicamentos para o controle da hipertensão foi justificado pela maioria $(57,2 \%)$ pela ausência de sintomas da doença (Tabela 17).

Tabela 17 - Distribuição dos indivíduos hipertensos que não fazem uso de medicamento segundo a justificativa. Região Sudoeste da Grande São Paulo - SP, $1989-90$

\begin{tabular}{l|c|c|c} 
Respostas & \multicolumn{1}{c}{$n^{\circ}$} & $\%$ & $\%$ \\
\hline NSNR & $(1)$ & $(2)$ & $(3)$ \\
\hline Teve complicações & 7 & 1,6 & 1,2 \\
\hline O remédio não estava fazendo efeito & 11 & 2,5 & 4,1 \\
\hline O médico suspendeu & 14 & 3,2 & 3,0 \\
\hline Os remédios era caros & 17 & 3,9 & 2,8 \\
\hline Resolveu não tomar & 36 & 8,2 & 6,3 \\
\hline Outros & 48 & 10,9 & 12,7 \\
\hline Não teve sintomas & 55 & 12,5 & 11,7 \\
\hline Total & 251 & 57,2 & 58,0 \\
\hline
\end{tabular}

(1) freqüência na amostra absoluta

(2) porcentagem na amostra absoluta

(3) porcentagem na amostra ponderada 
Os homens usaram mais a justificativa da falta de sintomas para não tomar a medicação $(63,6 \%)$ (Qui-quadrado $=15,50467 ; p=0,03005)$ (Tabela 18).

Tabela 18 - Distribuição das justificativas do não uso de medicação específica segundo o sexo. Região Sudoeste da Grande São Paulo - SP, 1989 - 90.

\begin{tabular}{|c|c|c|c|c|c|c|}
\hline \multirow[t]{2}{*}{ Respostas } & \multicolumn{2}{|c|}{ Masculino } & \multicolumn{2}{|c|}{ Feminino } & \multicolumn{2}{|c|}{ Total } \\
\hline & $n^{0}$ & $\%$ & $n^{\circ}$ & $\%$ & $\mathrm{n}^{\circ}$ & $\%$ \\
\hline NS/NR & 5 & 2,1 & 2 & 0,8 & 7 & 1,6 \\
\hline Teve complicações & 0 & 0 & 11 & 4,6 & 11 & 2,5 \\
\hline Não estava fazendo efeito & 5 & 2,5 & 9 & 3,8 & 14 & 3,2 \\
\hline O médico suspendeu & 8 & 4,0 & 9 & 3,8 & 17 & 3,9 \\
\hline Os remédios eram caros & 16 & 8,1 & 20 & 8,3 & 36 & 8,2 \\
\hline Resolveu não tomar & 18 & 9,1 & 20 & 12,5 & 48 & 10,9 \\
\hline Outros & 21 & 10,6 & 34 & 14,2 & 55 & 12,5 \\
\hline Não teve sintomas & 126 & 63,6 & 125 & 52,1 & 251 & 57,2 \\
\hline Total & 199 & 100,0 & 230 & 100,1 & 439 & 100,0 \\
\hline
\end{tabular}




\subsection{3 - O Uso dos Serviços de Saúde Associado ao Uso de Medicamentos Específicos}

Quando foram observadas as respostas relativas a procura por assistência e o uso de medicamentos pode-se identificar que há a dependência entre a visita ao serviço de saúde e o uso de hipotensores. Os indivíduos que visitam o médico usam medicamentos com mais freqüência (Qui-quadrado $=163,21046 ; p<0,00001$ ) (Figura 26).

\section{Figura 26}

Distribuição do número de hipertensos referidos segundo o uso dos serviços de saúde e uso de medicamentos específicos. Região Sudoeste da Grande São Paulo - SP, 1989 - 90.

$$
(n=1269)
$$

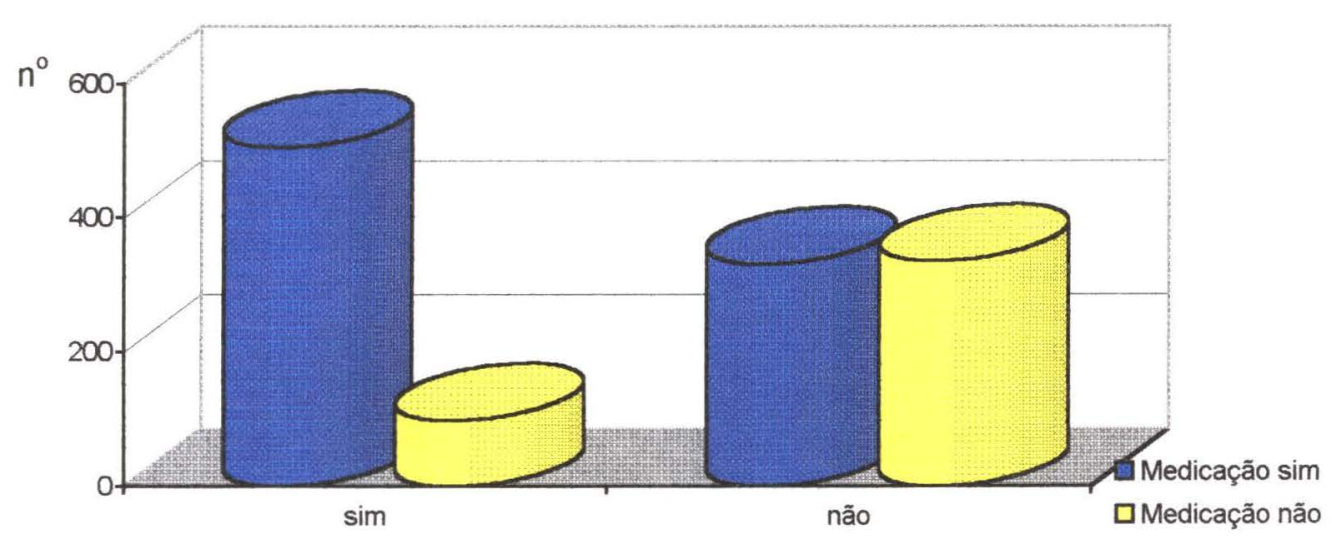

uso dos serviços de saúde 


\section{5 - A Influência do Modelo Etiológico nas Formas de Controle sobre a} Morbidade.

\subsection{1 - O Modelo Etiológico e o Uso dos Serviços de Saúde:}

A análise dos modelos etiológicos construídos a partir da percepção individual dos hipertensos sobre a origem da doença, mostrou que há evidências de que esta percepção possa influenciar a procura ou não por assistência. Pode-se dizer que aqueles que apresentaram a percepção dentro de um modelo endógeno são os que mais procuram por assistência médica (Qui-quadrado $=15,58465 ; p=0,00041$ ) (Figura 27).

\section{Figura 27}

Distribuição do número de hipertensos referidos segundo os modelos etiológicos e a procura por assistência. Região Sudoeste da Grande São

$$
\text { Paulo - SP, } 1989-90 .
$$

$$
(n=981)
$$

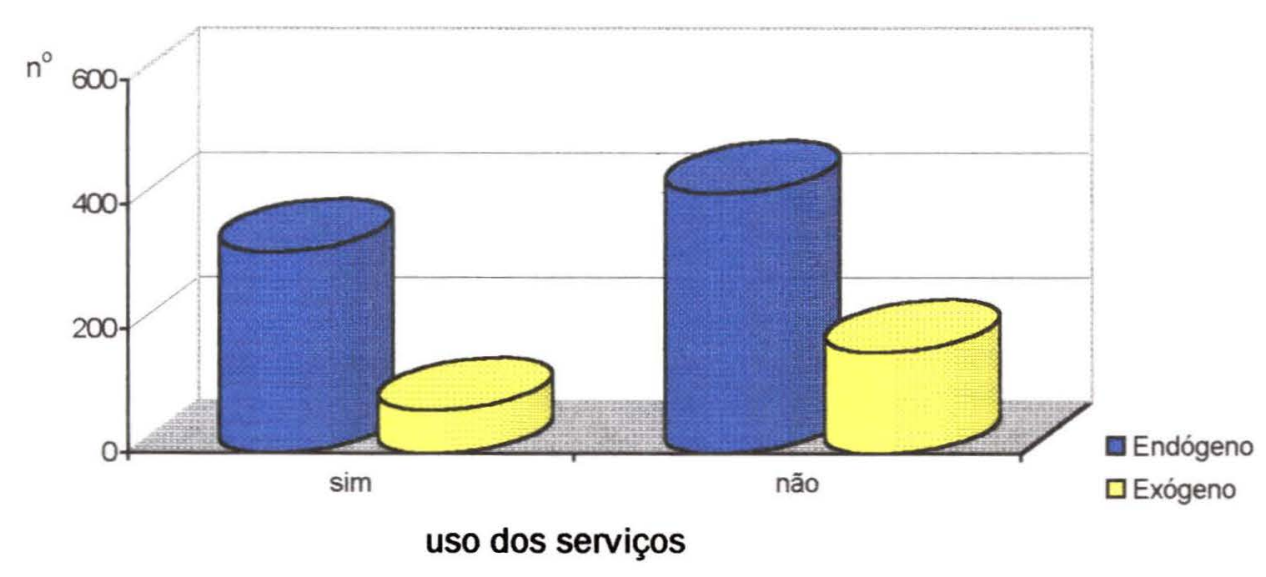

O modelo de percepção exógeno apresenta indivíduos que procuram menos os serviços de saúde. E a justificativa mais presente entre eles é por achar que esta assistência não é necessária.

A tabela 19 apresenta a distribuição das variáveis e suas associações com o uso dos serviços. 
Com relação ao uso dos serviços de saúde pode-se observar que, com exceção do nivel de escolaridade, as demais variáveis mostraram associação com o uso de medicamentos específicos (Tabela 19).

Tabela 19 - Distribuição das variáveis segundo o uso dos serviços de saúde em hipertensos ( $\geq 20$ anos). Região sudoeste da

Grande São Paulo - SP, 1989 - 1990.

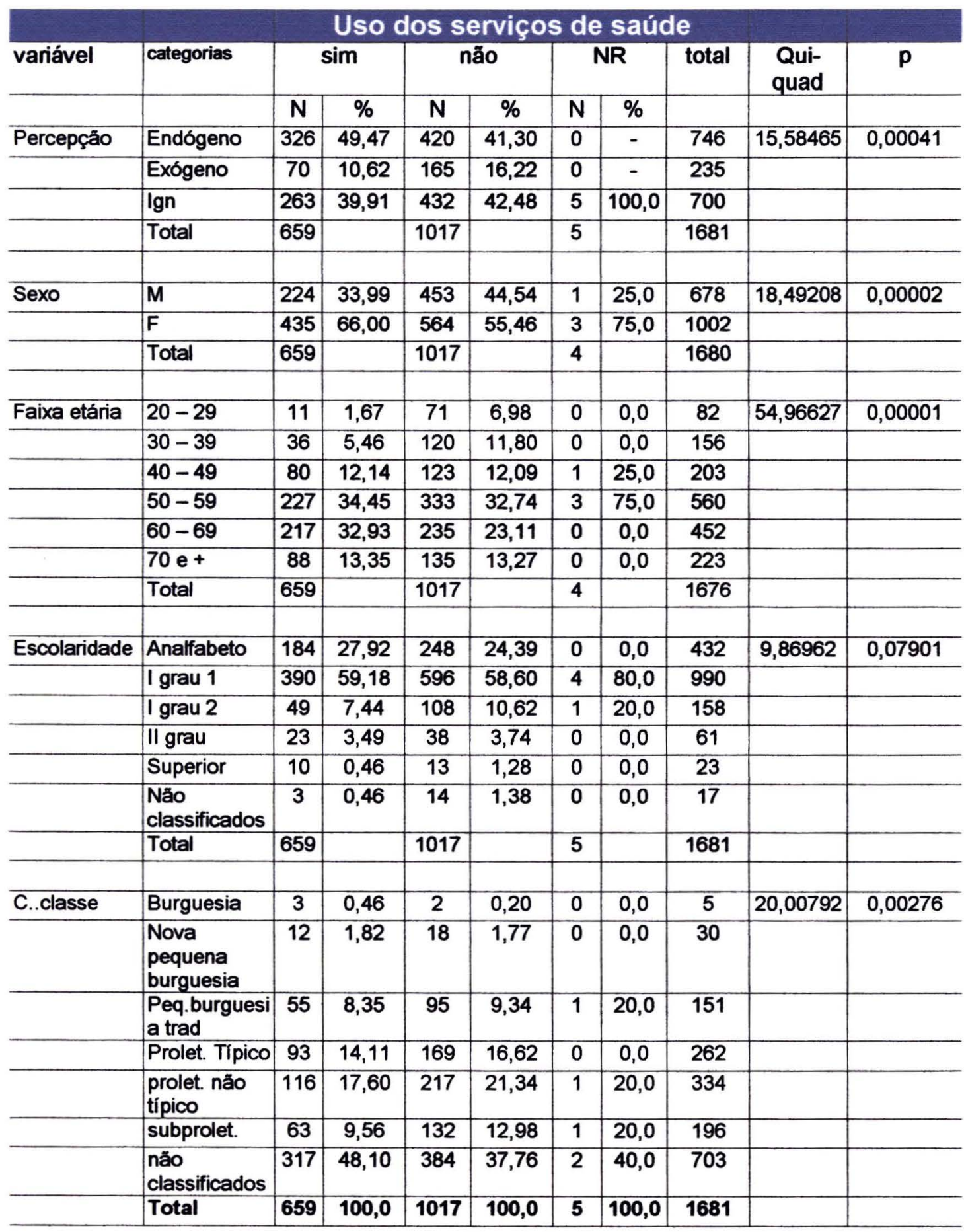




\subsection{2 - O Modelo Etiológico e o Uso de Medicamentos Específicos}

O modelo etiológico não apresentou associação significativa com a ingestão de medicamento (Qui-quadrado $=2,21204 ; p=0,33087$ ) (Figura 28)

Figura 28

Distribuição do número de hipertensos referidos segundo os modelos etiológicos e o uso de medicamentos específicos. Região Sudoeste da Grande São Paulo - SP, 1989 - 90.

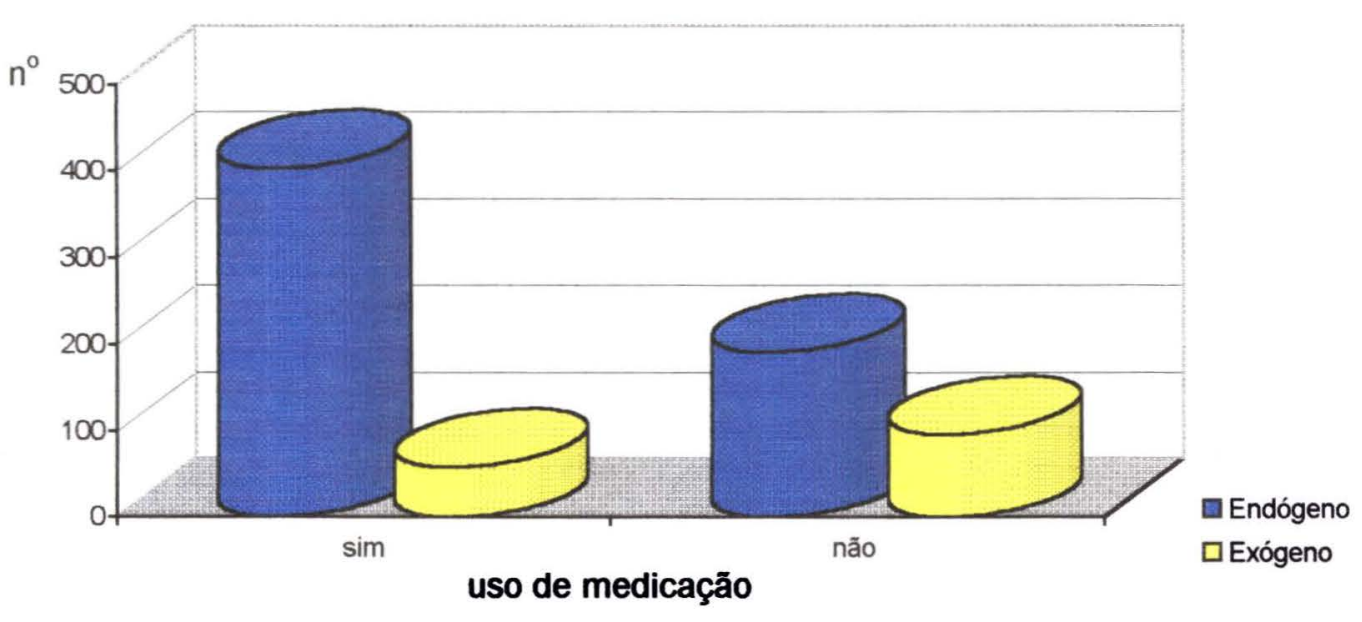

$$
(n=748)
$$

A tabela 20 apresenta a distribuição das variáveis e suas associações com o uso de medicamentos específicos.

Com relação ao uso de medicação hipotensora pode-se observar que, com exceção do nível de escolaridade e os modelos etiológicos, as demais variáveis mostraram associação (Tabela 20). 
Tabela 20 - Distribuição das variáveis segundo o uso de medicação por hipertensos ( $\geq 20$ anos). Região sudoeste da

Grande São Paulo - SP, 1989 - 1990.

\begin{tabular}{|c|c|c|c|c|c|c|c|c|c|c|}
\hline & \multicolumn{9}{|c|}{ Uso de medicação } & \multirow[b]{3}{*}{ p } \\
\hline & & \multicolumn{2}{|c|}{ Sim } & \multicolumn{2}{|c|}{ Não } & \multicolumn{2}{|c|}{ NR } & \multirow{2}{*}{\begin{tabular}{c|} 
Total \\
$\mathbf{N}$
\end{tabular}} & \multirow[b]{2}{*}{ Qui-quad } & \\
\hline & & $\mathbf{N}$ & $\%$ & $\mathbf{N}$ & $\%$ & $\mathbf{N}$ & $\%$ & & & \\
\hline \multirow[t]{4}{*}{ Percepção } & Endógeno & 403 & 48,21 & 191 & 44,11 & 152 & 36,90 & 746 & 2,21204 & 0,33087 \\
\hline & Exógeno & 96 & 11,48 & 58 & 13,40 & 81 & 19,66 & 235 & & \\
\hline & ign & 337 & 40,31 & 184 & 42,50 & 179 & 43,45 & 700 & & \\
\hline & Total & 836 & & 433 & & 412 & & 1681 & & \\
\hline \multirow[t]{3}{*}{ Sexo } & $M$ & 280 & 33,49 & 195 & 45,04 & 203 & 49,3 & 678 & 16,22521 & 0,00006 \\
\hline & $F$ & 556 & 66,51 & 238 & 54,97 & 209 & 50,7 & 1003 & & \\
\hline & Total & 836 & & 433 & & 412 & & 1681 & & \\
\hline \multirow[t]{7}{*}{ Faixa etária } & $20-29$ & 8 & 0,96 & 21 & 4,85 & 53 & 12,9 & 82 & 62,52342 & 0,00001 \\
\hline & $30-39$ & 37 & 4,43 & 52 & 12,01 & 67 & 16,3 & 156 & & \\
\hline & $40-49$ & 89 & 10,65 & 51 & 11,78 & 64 & 15,5 & 204 & & \\
\hline & $50-59$ & 279 & 33,37 & 163 & 37,64 & 122 & 29,6 & 564 & & \\
\hline & $60-69$ & 282 & 33,73 & 101 & 23,33 & 69 & 16,7 & 452 & & \\
\hline & $70 e^{+}$ & 141 & 16,87 & 45 & 10,39 & 37 & 9,0 & 223 & & \\
\hline & Total & 836 & & 433 & & 412 & & 1681 & & \\
\hline \multirow[t]{7}{*}{ Escolaridade } & Analfabeto & 233 & 27,87 & 117 & 27,02 & 82 & 19,90 & 432 & 3,31704 & 0,65123 \\
\hline & I grau 1 & 497 & 59,45 & 252 & 58,20 & 241 & 58,50 & 990 & & \\
\hline & 1 grau 2 & 60 & 7,18 & 43 & 9,93 & 55 & 13,35 & 158 & & \\
\hline & II grau & 28 & 3,35 & 13 & 3,00 & 20 & 4,85 & 61 & & \\
\hline & Superior & 11 & 1,32 & 4 & 0,92 & 8 & 1,94 & 23 & & \\
\hline & $\begin{array}{l}\text { Não } \\
\text { classificados }\end{array}$ & 7 & 0,84 & 4 & 0,92 & 6 & 1,46 & 17 & & \\
\hline & Total & 836 & & 433 & & 412 & & 1681 & & \\
\hline \multirow[t]{8}{*}{ C. classe } & Burguesia & 3 & 0,36 & 1 & 0,23 & 1 & 0,24 & 5 & 21,16798 & 0,00171 \\
\hline & $\begin{array}{l}\text { Nova peq. } \\
\text { Burguesia }\end{array}$ & 16 & 1,91 & 5 & 1,15 & 9 & 2,18 & 30 & & \\
\hline & $\begin{array}{l}\text { Peq.burg. } \\
\text { trad }\end{array}$ & 71 & 8,49 & 38 & 8,78 & 42 & 10,19 & 151 & & \\
\hline & Prolet. típico & 111 & 13,28 & 77 & 17,78 & 74 & 17,96 & 262 & & \\
\hline & $\begin{array}{l}\text { Prolet. não } \\
\text { tipico }\end{array}$ & 146 & 17,46 & 97 & 22,40 & 91 & 22,09 & 334 & & \\
\hline & $\begin{array}{l}\text { Subproletaria } \\
\text { do }\end{array}$ & 82 & 9,81 & 57 & 13,16 & 57 & 13,83 & 196 & & \\
\hline & $\begin{array}{l}\text { Não } \\
\text { classificados }\end{array}$ & 407 & 48,68 & 158 & 36,49 & 138 & 33,5 & 703 & & \\
\hline & Total & 836 & 100,0 & 433 & 100,0 & 412 & 100,0 & 1681 & & \\
\hline
\end{tabular}


Para verificar o efeito conjunto das variáveis do estudo e das formas de percepção construíram-se dois modelos de regressão logística. No primeiro Tabela 21) a variável dependente foi o uso ou não dos serviços de saúde e no segundo (Tabela 22) foi utilizado o uso ou não de medicamentos especificos como variável dependente.

Tabela 21 - Análise multivariada do uso dos serviços de saúde segundo as variáveis do estudo. Região sudoeste da Grande

São Paulo - SP, 1989 - 1990.

\begin{tabular}{|c|c|c|c|}
\hline VARIÁVEL & CATEGORIA & $\begin{array}{c}\text { OR } \\
\text { ajustada }\end{array}$ & $\mathbf{P}$ \\
\hline \multirow{2}{*}{ Modelos de percepcão } & Endógeno & 1,5429 & 0,0102 \\
\hline & Exógeno (1) & 1,0 & \\
\hline \multirow{2}{*}{ Sexo } & Feminino & 1,5453 & 0,0028 \\
\hline & Masculino (1) & 1,0 & \\
\hline \multirow{6}{*}{ Faixa Etária } & 20 a 29 & 1,0 & \\
\hline & 30 a 39 & 2,0505 & 0,0605 \\
\hline & 40 a 49 & 4,4822 & 0,0000 \\
\hline & 50 a 59 & 4,9475 & 0,0000 \\
\hline & 60 a 69 & 6,5628 & 0,0000 \\
\hline & 70 e mais & 4,6324 & 0,0000 \\
\hline \multirow[t]{6}{*}{ Escolaridade } & Analfabeto & 4,0920 & 0,0305 \\
\hline & 1 grau 1 & 4,3792 & 0,0227 \\
\hline & 1 grau 2 & 4,4551 & 0,0262 \\
\hline & II grau & 5,1144 & 0,0215 \\
\hline & Superior & 8,5754 & 0,0391 \\
\hline & Não Classificados (1) & 1,0 & \\
\hline \multirow[t]{7}{*}{ Condicão de classe } & Proletariado Típico & 1,4344 & 0,0956 \\
\hline & Proletariado Não Típico & 1,2264 & 0,3147 \\
\hline & $\begin{array}{l}\text { Nova Pequena } \\
\text { Burguesia }\end{array}$ & 1,0047 & 0,9950 \\
\hline & $\begin{array}{l}\text { Pequena Burguesia } \\
\text { Tradicional }\end{array}$ & 1,1529 & 0,5499 \\
\hline & Burguesia & 2,7462 & 0,2833 \\
\hline & Não classificados & 1,3798 & 0,0779 \\
\hline & Subproletariado (1) & 1,0 & \\
\hline
\end{tabular}

A análise dos fatores independentes, associados à busca de assistência mostrou que os modelos de percepção influenciam no uso de 
serviços, sendo que entre aqueles com a percepção sobre a origem da doença dentro de um modelo endógeno, há 1,5 vezes mais chances de busca por assistência quando comparado com o modelo exógeno.

O gênero também mostrou forte influencia na busca por assistência médica. As mulheres têm 1,5 vezes mais chance de uso dos serviços quando comparadas com os homens.

A variável idade também influencia na busca por serviço. Entre os mais jovens a busca por esta assistência é menor. Enquanto entre os indivíduos de 60 a 69 anos a chance de uso do serviço é de 6,5 vezes em relação aos menores de 30 anos; entre os indivíduos de 30 a 39 anos esta chance é de 2 vezes

A escolaridade mostrou forte influencia sobre o uso dos serviços. Entre indivíduos com menor nível de escolaridade a busca por assistência é menor. Indivíduos com nível superior têm a chance de 8,6 vezes maior de usar os serviços de saúde quando comparados com os não classificados.

Não foi evidenciada influência da condição de classe social sobre o uso dos serviços. 
Tabela 22 - Análise multivariada do uso de medicamentos segundo as variáveis do estudo. Região sudoeste da Grande

São Paulo - SP, 1989 - 1990.

\begin{tabular}{|c|c|c|c|}
\hline VARIÁVEL & CATEGORIA & OR & $\mathbf{P}$ \\
\hline \multirow[t]{2}{*}{ Modelos de percepcão } & Endógeno & 1,0551 & 0,7916 \\
\hline & Exógeno (1) & 1,0 & \\
\hline \multirow[t]{2}{*}{ Sexo } & Feminino & 1,6786 & 0,0030 \\
\hline & Masculino (1) & 1,0 & \\
\hline \multirow{6}{*}{ Faixa Etária } & 20 a 29 & 1.0 & \\
\hline & 30 a 39 & 2,0833 & 0,1248 \\
\hline & 40 a 49 & 5,4751 & 0,0003 \\
\hline & 59 a 59 & 5,7485 & 0,0001 \\
\hline & 60 a 69 & 9,6850 & 0,0000 \\
\hline & 70 e mais & 10,8335 & 0,0000 \\
\hline \multirow{6}{*}{ Escolaridade } & Analfabeto & 1,2428 & 0,7408 \\
\hline & Primeiro Grau I & 1,6795 & 0,4278 \\
\hline & Primeiro Grau II & 1,7261 & 0,4261 \\
\hline & Segundo Grau & 2,4699 & 0,2341 \\
\hline & Superior & 1,7262 & 0,6466 \\
\hline & Não classificado (1) & 1,0 & \\
\hline \multirow[t]{7}{*}{ Condição de classe } & Proletariado Típico & 1,4077 & 0,1709 \\
\hline & Proletariado Nã̃o Típico & 1,2404 & 0,3514 \\
\hline & Nova Pequena Burguesia & 2,7036 & 0,2663 \\
\hline & Pequena Burguesia Tradicional & 1,2574 & 0,4108 \\
\hline & Burguesia & 2,3768 & 0,4716 \\
\hline & Não classificados & 1,5337 & 0,0423 \\
\hline & Subproletariado (1) & 1,0 & \\
\hline
\end{tabular}

O controle sobre a morbidade feito através do uso de medicamentos mostrou sofrer influências do gênero e faixa etária. O modelo de percepção, - nivel de escolaridade e a condição de classe não mostraram influência significativa. 0 modelo de percepção não foi fator de risco significativo (Tabela 22).

Em relação ao gênero, as mulheres apresentaram 1,7 vezes mais chances do uso da medicação específica quando comparadas com os homens.

Observou-se que quanto mais velho o individuo hipertenso maior a sua chance de estar usando medicaçăo, sendo que entre aqueles com mais de 70 anos esta chance é de 10,8 vezes maior em relação aos indivíduos de 20 a 29 anos. 
Quadro 3 - Resumo dos resultados encontrados. Região Sudoeste da Grande São Paulo - SP, 1989 - 90.

\section{I - A prevalência da Hipertensão Arterial referida}

As maiores prevalência foram encontradas:

- Município de Embú $=20,9 \%$

- Mulheres $=20,8 \%$

- Faixa etária 60 a 69 anos $=50,2 \%$

- Analfabetos $=19,8 \%$

- Burguesia $=20,1 \%$

\section{II - A percepção da origem da morbidade - MODELOS}

Prevaleceu o modelo endógeno $=76,0 \%$

O modelo endógeno é mais citado pelas mulheres

\section{III - A percepção da origem da morbidade - CATEGORIAS}

Os homens citam mais:

- causas sócio-econômicas $=$ situações de trabalho

- hábitos e comportamentos = alcoolismo; sedentarismo; tabagismo

As mulheres citam mais:

- condições ambientais / situações de vida

- causas psicossociais $=$ nervosismo $/$ preocupações

- causas naturais = hereditariedade; outras doenças

\section{IV - O uso dos serviços de saúde}

A maioria dos hipertensos não usam o serviços de saúde $(63,8 \%)$

A principal justificativa foi : "não acham preciso" $(45,8 \%)$ e foi dada pelas mulheres As mulheres procuram mais os serviços de saúde

\section{V - O uso de medicamentos especificos}

Dos hipertensos diagnosticados e, com medicação prescrita, 44,0\% referiram o uso As mulheres usam mais medicamentos especificos

A falta de sintomas $(57,2 \%)$ foi a principal justificativa para não usar a medicação e foi dada pelos homens

VI - A percepção e as formas de controle

Quem procura pela assistência usa mais medicação

O modelo de percepção sobre a origem da morbidade esteve associado com o uso dos serviços de saúde, mas não mostrou associação com o uso dos medicamentos específicos. 


\section{DISCUSSÃO}

\section{1 - A Prevalência da Hipertensão Arterial Referida}

Dentre as doenças crônicas referidas no inquérito, a pressão alta foi a segunda maior proporção $(8,8 \%)$ sendo que a grande maioria destes indivíduos $(93,4 \%)$ informava ter diagnóstico médico (CESAR, 1992).

O número de hipertensos com informação de diagnóstico médico indica que o dado referido pode ser um indicador do uso dos serviços de saúde da região. Por se tratar de doença pobre em sintomatologia e lenta em seu curso natural o seu diagnóstico na maioria das vezes é feito ao acaso. Geralmente as pessoas não procuram o serviço de saúde diretamente para este diagnóstico. Esta não é uma morbidade que pudesse ser referida pela população baseada unicamente em seu conhecimento popular. Como acontece, por exemplo, com as chamadas "doenças dos nervos", quando muitas pessoas fazem referência a sofrer de um mal que elas pensam existir, mas que não tiveram qualquer avaliação profissional para seu diagnóstico. As associações feitas pelo leigo, entre sintomas e a presença de pressão alta, surgem mais como expressão de "estados emocionais" e não propriamente à morbidade hipertensão arterial. Pode-se sustentar com tais números que a prevalência calculada para a região com dados referidos é reflete a cobertura dos serviços de saúde para esta morbidade.

A prevalência da hipertensão referida, para os maiores de 20 anos, calculada a partir da amostra expandida foi de 18,0\%. É conveniente ressaltar que se trata de um estudo que considerou a presença de morbidade referida pela população e que, ao se analisar a presença da hipertensão arterial, não pode ser deixado de lado características próprias da doença. O seu diagnóstico é pouco procurado pela população. Sabe-se que dentre as pessoas hipertensas, de um terço a 50,0\% desconhece sua condição. Deve-se sublinhar que uma prevalência referida de 18,0\% está 
subestimando a taxa real, que poderia ser muito maior caso fossem utilizados dados de medida da pressão arterial (HYPERTENSION DETECTION AND FOLLOW-UP PROGRAM COOPERATIVE GROUP, 1977; WHELTON, 1994; KANNEL, 1996; INTERAMERICAN ASSOCIATION SOCIATY OF HYPERTENSION, 1996).

Em estudo semelhante, utilizando-se de informações sobre morbidade referida, realizado no municipio de Botucatu $-\mathrm{SP}$, a hipertensão arterial apresentou um coeficiente de $4,9 \%$. Nessa mesma população foi realizado estudo posterior, com medidas da pressão arterial e o coeficiente de prevalência foi de $12,3 \%$ na faixa etária acima de 16 anos. Portanto, na mesma população, quando os dados referidos foram avaliados pela medida da pressão arterial, a prevalência foi mais do que o dobro. Isto confirma a preposição de que os dados referidos subestimam os valores reais da prevalência (LEBRÃO 1991; HABERMAN 199?).

Em outro estudo realizado em New York, onde foram feitas entrevistas por telefone com 911 indivíduos, com idade entre 20 e 69 anos, com posterior consulta médica, foi encontrado que a prevalência da hipertensão arterial, calculada a partir do dado referido, era de 21,0 e $22,0 \%$ para homens e mulheres e a prevalência real era de 37,0 e 36,0\% respectivamente, evidenciando uma baixa sensibilidade e que quase a metade dos indivíduos hipertensos desconheciam sua condição. Estes dados mostram, mais uma vez, que a prevalência referida é inferior à prevalência real (medida da pressão arterial) e que esta diferença retrata a dificuldade do diagnóstico da doença e a baixa cobertura dos serviços de saúde para as doenças crônicas, mesmo em países desenvolvidos (BOWLIN e col., 1993).

Desta forma, a prevalência estimada com o uso de dados referidos tem uma representatividade inferior ao dado real, e deve ser vista com cuidado, pois identifica somente aqueles que já alcançaram o diagnóstico. Assim este coeficiente estaria representando uma taxa de conhecimento (taxa de detecção de casos) sobre a morbidade e não a prevalência 
calculada a partir de medidas indiretas da pressão arterial em momentos pontuais.

Estudos epidemiológicos realizados no Brasil mostraram prevalências variadas segundo a metodologia e grupos analisados (Quadro 5). No Rio Grande do Sul, em uma população maior de 18 anos, e com obtenção dos dados no domicílio com questionários e aferição da pressão arterial, a prevalência encontrada foi de $12,68 \%$, segundo o critério da Organização Mundial da Saúde (OMS $160 \times 95 \mathrm{mmHg}$ ) e subindo para $29,8 \%$ quando se considerava o critério e $140 \times 90 \mathrm{mmHg}$ (FUCHS e col., 1994). Já no municipio de Volta Redonda - RJ, onde foram analisados 650 pessoas com idade entre 20 e 74 anos, usando questionários e a aferição da pressão arterial, a prevalência foi de 10,1\%, segundo o critério da OMS (KLEIN e col., 1985). Em Araraquara - SP (1987), a prevalência, entre 1.199 indivíduos de 15 a 74 anos, foi de $28,3 \%$ segundo os critérios da OMS e representou a maior taxa entre os estudos nacionais (LÓLIO, 1990a). Em trabalho realizado no interior do Brasil, Firminópolis - GO, incluindo no cálculo do coeficiente os casos que estavam com valores pressóricos sob controle, foi encontrada prevalência de $24,1 \%$ na população maior de 18 anos, segundo os critérios de $140 \times 90 \mathrm{mmHg}$ (MOURA e col., 1995).

Um sumário de alguns estudos realizados no Brasil, com diferentes metodologias e variadas prevalências pode ser visto na tabela 23. 
Tabela 23 - Prevalências (\%) da hipertensão em alguns estudos.

Brasil - 1999.

\begin{tabular}{|c|c|c|c|}
\hline Referência & Local & $\begin{array}{c}\text { Prevalência }{ }^{(1)} \\
\%\end{array}$ & $\begin{array}{l}\text { Idade } \\
\text { anos }\end{array}$ \\
\hline AYRES, 1991. & Piracicaba - SP & 32,7 & $>=15$ \\
\hline BASTOS e col., 1993. & Botucatú - SP & 7,05 & 4 a 14 \\
\hline BLOCH e col., 1994. & Ilha do Governador - RJ & 24,9 & $>=20$ \\
\hline CARNEIRO e JARDIM ,1993. & Tribo Xavante - MT & 0,0 & $>=18$ \\
\hline CARVALHO e col., 1983. & Rio de Janeiro - RJ & 16,1 & 20 a 70 \\
\hline COSTA e col., 1984 & Uberlândia - MG & 13,2 & 18 a 80 \\
\hline DUNCAN e col., 1993. & Porto Alegre - RS & 15,0 & 15 a 64 \\
\hline FUCHS e col., 1994. & Porto Alegre - RS & 29,8 & $>=18$ \\
\hline HABERMANN, 199?. * & Botucatu - SP & 12,3 & $>=16$ \\
\hline JARDIM e col., 1992. & Kalunga - GO & 6,3 & 16 a 101 \\
\hline KLEIN, 1985. & Volta Redonda - RJ & 20,2 & 20 a 74 \\
\hline KLEIN e col., 1995. & Ilha do Governador - RJ & 24,9 & $?$ \\
\hline LEBRÅO e col., 1991. * & Botucatú - SP & 5,3 & $>=16$ \\
\hline LESSA, 1987. & Salvador - BA ${ }^{* 1}$ & 17,0 & 35 a 66 \\
\hline LOLIO, 1990a. & Araraquara - SP & 28,3 & 15 a 74 \\
\hline MOURA e col., 1995. & Firminópolis - GO & 24,1 & $>=20$ \\
\hline PICCINI e VICTORA, 1994. & Pelotas - RS & $\begin{array}{l}18,3-H \\
21,2-M\end{array}$ & 20 a 69 \\
\hline RACHID e col., 1996. & Rio de Janeiro - RJ & 12,5 & 3 a 14 \\
\hline REGO e col., 1990. & São Paulo - SP & 22,3 & $?$ \\
\hline RIBEIRO e col., 1981. & São Paulo - SP & $\begin{array}{c}18,1-H \\
6,6-M\end{array}$ & 15 a 65 \\
\hline SIMONATTO e col., 1991. & São Paulo - SP & 6,9 & 6 a 18 \\
\hline SIQUEIRA-BATISTA e col.,1994. & Bangu - RJ & 25,2 & $?$ \\
\hline SOUZA e col. 1988. & Rio de Janeiro - RJ & 24,6 & $?$ \\
\hline
\end{tabular}

* Morbidade Referida

Chamada (1): Os valores de corte da pressão arterial diastólica para diagnóstico, variaram entre 90 e $95 \mathrm{mmHg}$ nestes estudos.

Fonte: referências em ordem alfabética.

\footnotetext{
${ }^{1}$ Comunicação pessoal feita a autora do trabalho com permissão para publicação.
} 
Nos Estados Unidos da América do Norte, durante a década de 70 a prevalência da hipertensão arterial (> $160 \times 95 \mathrm{mmHg}$ ) permaneceu estável próxima dos valores de 18,0\%. Entre 1976 e 1991 houve uma redução substancial. Dois terços da população hipertensa encontrada durante o NHANES III (1988 - 1991) era conhecedora de seu diagnóstico. Na Europa, Ásia e América a prevalência oscila: Grécia, 12,0\%; Países Baixos, 33,0\%; América do Norte, 20,0\%; Norte do Japão, 39,0\%; Colômbia, 9,2\%. Na Índia as taxas de prevalência tem variado de $11,0 \%$ a $14,1 \%$, sendo que 0 problema é maior na zona urbana (SUAREZ, 1985; BURT e col., 1995; GUPTA e col.,1996).

Existem comunidades tribais, como nas Ilhas FIJI, San Blas, Ilhas Cook, índios lanomamis, índios Cunas (Colômbia) e outras, onde a prevalência da hipertensão é muito baixa ou mesmo inexistente. Entre índios da tribo Xavante do Estado do Mato Grosso e população Yanomami do norte do Brasil não foi encontrado nenhum indivíduo hipertenso (MADDOCKS, 1961; PAGE, 1976; SUAREZ, 1985; BLOCH e col., 1993; CARNEIRO e JARDIM, 1993).

Esta prevalência entre os povos é determinada por diversos fatores, tais como nivel sócio econômico, escolaridade, idade e proporções entre os sexos. A presença de uma morbidade deve ser considerada tanto no grupo populacional, com suas características sociais e demográficas, quanto nos espaços por eles ocupados (JUNQUEIRA, 1998). A área estudada apresentou diferenças nesta distribuição. Itapecirica da Serra e Cotia foram os municipios que apresentaram as menores prevalências. $E$ o maior coeficiente de prevalência foi encontrado no municipio de Embú. Algumas caracteristicas destes municípios podem justificar parte da distribuição destes coeficientes. Por exemplo, Cotia é um município considerado mais desenvolvido, onde foi encontrada maior proporção de indivíduos com nivel de escolaridade superior e também onde mais se identificou a condição de classe social associada com a Burguesia, menor razão de dependência e melhores condições de moradia. A idéia de que as doenças cardiovasculares estejam mais presentes entre as classes mais 
desenvolvidas socialmente não pode ser sustentada com os dados encontrados.

A distribuição das doenças tem sido a expressão da realidade determinada socialmente. Para JUNQUEIRA (1998:15) "é o espaço geográfico onde se dão as relações, mas que também é construido socialmente." A alta prevalência da hipertensão arterial nestas populações só confirma esta assertiva (CARVALHO e col., 1983; POSSAS, 1989; REGO e col., 1990; BORREL, 1997; MACKENBACH e col., 1997).

A prevalência distribuída segundo o sexo e faixa etária dos indivíduos também mostrou diferenças. A construção das taxas com os dados de morbidade referida é influenciada pela própria estrutura etária da população e pelas proporçōes entre os sexos. No caso de doenças crônicas, como a hipertensão arterial, se as populações são mais velhas vão apresentar taxas de morbidade mais elevadas. O mesmo pode acontecer se são usados dados de populações com baixa razão de masculinidade, uma vez que entre as mulheres as taxas de morbidade referida apresentam-se mais elevadas, talvez pelo uso dos serviços de saúde reprodutiva, ou até mesmo pela capacidade de percepção delas sobre as morbidades (CARVALHO e col., 1988; MEDICI, 1990; LEBRÃO, 1991).

A prevalência da hipertensão arterial apresentou um crescimento diretamente proporcional com a idade. Os dados encontrados referentes a hipertensão segundo faixa etária são consistentes com a literatura.

A correlação entre idade e pressão arterial já tem sido consistentemente documentada em estudos realizados em diferentes países, com culturas diversas e diferentes estágios de desenvolvimento econômico. Estudos transversais realizados na Itália (1976), no Japão (1980), Austrália (1980) e nos USA (1976 - 1980) comprovam a elevação da pressão arterial, na medida em que são acrescidos anos de vida na população. Dentre os fatores que influenciam a pressão arterial a idade parece ser o que produz maior impacto. De acordo com os critérios do $\mathrm{V}$ Relatório do JOINT a prevalência na população geral varia de 4,0\% naqueles com idade de 18 a 30 anos para $65,0 \%$ naqueles com idade maior 
ou igual a 80 anos (PAGE, 1976; DRIZD e col., 1986; V JNC, 1993; WHELTON, 1994; HOFFMEISTER e col., 1994).

Contrastando com isso, em populações isoladas há pouca evidência da mudança da pressão arterial com alterações na idade. O que vem indicar que mudanças relacionadas com a idade não são imposições fisiológicas. Tem sido observado que quando uma sociedade passa por processos de aculturação surge uma predisposição em aumentar a pressão arterial com a idade, principalmente quando são adotados estilo de vida ocidental. Quando são comparadas populações com pressão arterial baixa e de origem semelhante, que têm assimilado a cultura ocidental, a pressão arterial mostra elevação com a idade entre os grupos aculturados. E juntamente com as alterações na pressão, surgem também mudanças biológicas como alterações nos lipídios séricos. Isso parece encaminhar para uma resposta relativa ao meio ambiente e não especificamente a influências genéticas (LOWENSTEIN, 1961;PAGE, 1976; JARDIM e col., 1992; WHELTON, 1994).

Com relação às diferenças na distribuição desta morbidade segundo o gênero, alguns estudos tem evidenciado que em faixas etárias mais jovens há pouca diferença, mas já na adolescência os homens tendem a apresentar niveis médios mais elevados.

Neste estudo as mulheres apresentaram maior prevalência da hipertensão arterial em todas as faixas etárias. Sabe-se que entre o sexo feminino a prevalência tende a crescer após os 50 anos ou após a fase da menopausa. Até a entrada no climatério as mulheres apresentam menor prevalência devido à proteção hormonal, devendo ultrapassar o sexo masculino a partir dos 50 - 60 anos. Em faixas etárias mais jovens era esperado que a prevalência fosse maior entre os homens. $O$ fato da prevalência entre as mulheres ter se apresentado sempre superior a masculina, em praticamente todas as faixas etárias deste estudo, sugere que pode ser devido o uso dos dados referidos, pois sabe-se que na população feminina há uma percepção maior sobre morbidade e também sobre usos de serviços de saúde. Além disso deve-se considerar que habitualmente as mulheres apresentam mais queixas do que os homens e 
tendem a se preocupar mais em cumprir com o tratamento (COSTA, 1983; MEDICI, 1990; LÓLIO, 1990b; MOURA e col., 1995; GINTER,1995).

Considera-se também que, entre os homens, é menor o contato com os serviços de saúde, principalmente no setor público. Este setor atende mais a demanda da população idosa, mulheres e crianças, e fica para os convênios - empresa o atendimento da população economicamente ativa. $E$, geralmente o horário de atendimento dos serviços de saúde privilegiam o sexo feminino e aqueles sem vínculo formal no mercado de trabalho. Convém lembrar, também, que os serviços médicos de empresa nem sempre podem diagnosticar livremente os casos de hipertensão arterial, até mesmo a pedido dos próprios usuários que temem por sua situação de trabalho. Isto poderia justificar a baixa detecção de casos de hipertensão arterial entre os homens (HYPERTENSION DETECTION AND FOLLOW-UP PROGRAM COOPERATIVE GROUP, 1977; LEBRÃO, 1991; HANSSON e ZANCHETTI ,1995; CESAR e TANAKA, 1996).

Com relação à escolaridade a prevalência foi maior nas faixas com menos anos de estudo formal. Alguns estudos têm comprovado uma relação inversa da prevalência da hipertensão arterial com a escolaridade formal, com menores cifras tensionais nos maiores níveis de instrução. Essa variável não deve ser analisada desconsiderando a idade, situação de classe social, situação de moradia e estresse psicossocial (COSTA, 1983; ROBERTS e ROWLANDR, 1981; DRIZD e col., 1986; LÓLIO, 1990a).

Em estudo apresentado por LÓLIO e col. (1993), em Araraquara - SP, a prevalência ajustada $(29,8 \%)$ foi maior no grupo dos analfabetos ou com menos de 4 anos completos de escolaridade. E no Rio Grande do Sul, em 1978 a prevalência bruta entre os analfabetos também foi maior, com taxa igual a 22,4\% entre a população de 20 a 74 anos (COSTA 1983, Lólio, 1990b).

Com relação a condição de classe deve-se considerar que 0 envolvimento da situação de trabalho e a etiologia da hipertensão arterial ainda é muito discutido e não elucidado. Os fatores ambientais tem sido investigados na gênese desta doença e a ocupação representa um desses. 
Foram encontradas maiores prevalências entre trabalhadores não especializados e com menores salários (RIBEIRO, 1983; CARVALHO e col., 1983; KLEIN e col., 1986; CORDEIRO, 1993).

COSTA (1983) utilizando classificação do setor de atividade econômica do indivíduo encontrou prevalência de 2 a 3 vezes maior nos trabalhadores dos setores econômicos terciário e secundário do que entre os proprietários. Outros estudos apresentaram resultados semelhantes (GEIGER e SCOTCH, 1963; ANTONOVSCKY, 1968; RIBEIRO e col., 1981; CARVALHO e col., 1983; LÓlIO e col., 1993).

A condição de classe social isoladamente não se apresenta como um bom indicador para análise da distribuição da hipertensão arterial. Neste estudo a operacionalização utilizada não foi suficientemente adequada para possibilitar a análise da influência da condição de classe sobre esta morbidade. Deve-se ressaltar que se trata de uma variável de difícil construção e que está associada a outros fatores de mensuração complexa, como nivel de estresse, condições de vida e ambiente de trabalho. A hipertensão arterial apresenta-se como uma morbidade associada com todos estes fatores com diferentes pesos e importâncias.

$\mathrm{Na}$ população deste estudo, o coeficiente de prevalência da hipertensão arterial referida esteve dentro dos limites esperados de uma prevalência real e representou a detecção de casos pelos serviços de saúde. Foi maior entre as mulheres, em idades mais avançadas e com baixos niveis de escolaridade.

\section{2 - Os Modelos Etiológicos}

Dentro dos modelos etiológicos já apresentados no início deste trabalho, observou-se que os indivíduos hipertensos na área estudada apresentaram uma nítida tendência para o modelo etiológico endógeno.

Esta forma de perceber a origem da doença coloca o problema no interior do individuo e assim passa a ser uma propriedade e alguma coisa 
que não é mais desconhecida. $O$ indivíduo não é apenas o participante de sua doença, mas cria ele próprio a gênese de sua morbidade e é pois, o responsável por seu próprio estado. Esta "representação do movimento causal da doença como centrifugo e não mais centripeto" assume formas diversas (LAPLANTINE, 1991).

No modelo endógeno ressurge o pensamento hipocrático de que a doença é resultado de um desequilibrio interno ou ainda, na interpretação de Aristóteles, que considera a patologia surgindo da própria natureza (physis) do indivíduo que a produz. Distúrbios funcionais como a diabetes, hipertensão arterial, bronquite asmática etc., parecem impor como evidência esta etiologia endógena (NGOKWEY, 1988; LAPLANTINE, 1991).

Estudo realizado por BRIGAGÃO (1994) sobre artrite reumatóide, mostrou não haver diferença significativa na explanação dos indivíduos entre as teorias endógenas e exógenas de causação daquela doença. Já no estudo de HERZLICH (1968) e HERZLICH e col., (1988) as explicações exógenas, chamadas de modo de vida, foram mais importantes na determinação das doenças. A gênese, tanto da saúde quanto da doença, está associada ao modo de vida e, portanto, às noções de indivíduo e sociedade. Deve ser ressaltado que as formas de abordagem nestes estudos não são semelhantes e suas comparações devem ser feitas com cuidado.

Logo, no caso específico da hipertensão arterial, o modelo surge de forma singular, com predomínio da relação com o modelo etiológico endógeno. Embora a cultura ocidental tenha uma opção pela exterioridade das causas e as condições sociais não devam ser esquecidas, a pressão alta apresentou-se como resultado de conflitos internos na visão popular.

A distribuição dos modelos segundo o gênero mostrou diferenças importantes na forma como a doença é percebida em sua origem. O modelo endógeno foi predominante entre os indivíduos do sexo feminino.

Homens e mulheres conceitualizam e expressam seus problemas de formas diferentes como produto da variabilidade social em que vivem. As maiores diferenças encontradas entre os sexos em alguns inquéritos estão 
na área de expressão de "subjective distress" e reações psicológicas. Assim como comportamentos de agressividade, violência, tabagismo, alcoolismo e abuso de drogas são mais comuns entre os homens e menos medidos. Isto parece sugerir que os homens são mais inibidos para relatar certos tipos de coisas que envolvam sentimentos (a razão de estar nervoso, ou culpar o nervosismo por alguma coisa) É interessante analisar tais diferenças pois podem ser guias na análise do uso de serviços e mesmo no planejamento de suas atividades. Em geral a procura pelos serviços de saúde é maior entre as mulheres (MECHANIC, 1976; MEDICI, 1990).

É largamente reconhecido que a definição de doença é arbitrária e baseada numa construção social e cultural. As mulheres parecem perceber mais os sintomas do que os homens porque elas tem mais interesse na saúde e mais conhecimento sobre o tema; ou, mesmo que elas não percebam mais sintomas do que os homens, elas sempre estão mais dispostas a relatar o que sentem. Isto é consistente com os padrões de socialização, os quais permitem as mulheres reclamarem mais e parecerem menos estóicas do que os homens (MECHANIC, 1976; HUNT,1989).

Outra teoria para explicar esta diferença é o argumento de que a percepção depende em parte do que a pessoa faz. Circunstâncias externas e comportamentos ajudam as pessoas a interpretarem seus sentimentos internos. As mulheres, por exemplo, por causa de seus papel social, podem ser capazes de aceitarem a doença e acomodarem-se a ela com menos custo social que o homem. Assim, as mulheres estão mais prontas a responderem sobre as doenças identificando origens endógenas, que podem ser reconhecidas em seu universo e que não necessariamente esteja associada com limitações de atividades (MECHANIC, 1976).

"Outra interpretação da diferença que ocorre entre homens e mulheres inclui a variedade de exposição aos fatores de risco e estresse social associado com o papel do homem e da mulher na sociedade moderna "(MECHANIC, 1976:210). 
Mesmo que seja dificil sustentar o argumento que as mulheres sejam mais doentes do que os homens, ou tenham mais hipertensão do que eles; o estudo da percepção sobre a origem desta doença mostra que, entre as mulheres, há mais facilidade, em expressar causas mais subjetivas e que expressem sentimentos e que, por isso, para elas a origem do mal está no seu próprio interior .

A variável sexo foi a que mais participou na diferenciação da distribuição dos modelos etiológicos. $E$ estas diferenças foram identificadas em todos os níveis da categorização.

A categoria (A) causas externas (sócio-econômicas) apresentou diferença na distribuição entre os sexos. Os homens, em faixas etárias entre 50 a 69 anos, associaram mais as respostas sobre a origem da hipertensão com as (A2) situações de trabalho:

"devido a trabalhar demais, era motorista de ônibus"

"trabalhou muito em fábrica de carvão e era muito abafado e mexeu com a pressão"

"não sei, acho que foi depois que eu comecei a trabalhar"

"a gente que é pedreiro trabalha muito e carrega peso"

"trabalhei muito em lavoura, tomava orvalho, chuva..."

"porque trabalhava na roça, tomava água fria com o corpo quente"

"devido ao serviço. Acho que o pó do metal (sou polidor) me prejudicou"

O trabalho, como determinante de produção de bens materiais, ao mesmo tempo que representa o instrumento para a sobrevivência e para a conquista de melhores condições de vida, é também o responsável pela produção da doença.

A explanação popular sobre a causa das doenças, associando-as às condições de vida e trabalho, apresenta o biológico subordinado ao sócioeconômico. A hipertensão arterial tem sido estudada em suas correlações com as atividades econômicas e de condições de vida e existe, no senso comum, o conhecimento que o status social e a organização da sociedade 
tem conexões com a doença. "Há muita doença porque há muita pobreza" (RIBEIRO e col., 1981; EQUIPE DA DIOCESE DE GOIÁS, 1984; NGOKWEY,1988; POSSAS, 1989; CORDEIRO, 1993).

O predomínio de respostas masculinas associadas às causas sócioeconômicas, principalmente às situações de trabalho, em uma amostra que apresentou maior prevalência da hipertensão arterial entre as mulheres, pode estar refletindo a organização social da região. Onde as relações de produção e a responsabilidade pela sobrevivência recaem sobre o homem e este tem sua vida centrada em atividades fora do núcleo familiar.

BRIGAGÃO (1994) encontrou resultados semelhantes ao estudar as representações sociais sobre a origem da artrite reumatóide. $E$ também foram semelhantes os resultados da pesquisa no Vale do São Patrício - GO (1984), onde a falta de condições de trabalho foi identificada como causa da maioria das doenças.

Para MONEGO (1995) as mulheres mostram um raciocinio que estabelece ligação entre a saúde, bem estar e trabalho, sendo que este último é entendido como a forma de produção típica de cada integrante do grupo familiar - brincar, estudar, trabalhar. E será de acordo como o uso funcional do corpo que as doenças serão percebidas e classificadas diferentemente entre homens e mulheres, pois é o corpo que remete à atividades próprias das funções biológicas e sociais dos sexos (BOLTANSKI, 1989).

Já os individuos do sexo feminino e em faixas etárias mais jovens mostraram tendência a argumentar, neste nível, que a causa da hipertensão seria associada às (A1) condições ambientais:

"acho que é o clima daqui"

"porque no calor o sangue se agita; então é o clima daqui"

"muita friagem"

"por causa do clima de São Paulo"

Há uma relação do meio ambiente, dos fenômenos da natureza com a explicação para a origem da hipertensão arterial. Como se a doença 
estivesse associada ao ciclo da vida e por isso, pudesse ser considerada como algo normal ou esperado.

As causas relacionadas com situações comportamentais e de hábitos de vida (B) tiveram predominância do sexo masculino.

Nas respostas que relacionaram situações de comportamentos $e$ hábitos de vida, é importante que se ressalte que os "excessos" é que são vistos como possíveis causas para doenças:

"acho que é por causa do abuso da alimentação"

"comia muito e fora de hora e tomava cervejinha e comia muito" "usava muito sal na comida"

É interessante observar que o alcoolismo foi mais lembrado pelos homens na faixa de 30 a 40 anos como possível causa de morbidade. Sugere que culturalmente o hábito da ingesta alcoólica ainda é mais aceito entre o sexo masculino, daí sua facilidade em citá-lo como possível causa da doença. A forma como era manifestado no discurso reflete a idéia de masculinidade:

"porque eu bebo"

"por causa da bebida mesmo"

"uma vez bebi meio litro de uísque e a pressão subiu"

Já as mulheres, neste nivel das respostas, associaram ao uso de (B5) outros medicamentos, ocorrência de acidentes e outros tratamentos:

"porque eu tomava anticoncepcional"

"acha que após a operação do útero há 15 anos"

"porque eu cai da bicicleta"

"toma muito remédio: doril, melhoral..."

"foi devido ao atropelamento que sofreu há 5 anos"

"depois que eu fiz laqueadura"

Existe no conhecimento popular a percepção que uma intervenção que pode ser terapêutica para determinada doença pode também ser a 
causa de outros males. $\ddot{E}$ o caso específico do uso dos anticoncepcionais que é visto como um fator de desordem no organismo.

Nas categorias (C) Causas Psicossociais e (D) Causas Naturais, que compõem o modelo etiológico endógeno, houve um predomínio do sexo feminino em ambas as categorias.

A associação do (C5) nervosismo com a origem da hipertensão foi mais comum entre mulheres na faixa etária de 50 a 69 anos:

"devido problemas de fundo nervoso"

"passou muito nervoso com a familia"

"por causa do sistema nervoso"

"passou muito nervoso com problemas na infância"

"ficou muito nervosa depois que perdeu o marido"

É curiosa a importância atribuida ao fator emocional. Deve-se ressaltar que os "sentimentos" associados como causa da hipertensão arterial, na verdade estão representando as interações sociais dos indivíduos. São vários os sentimentos expressos como causadores das mais diversas doenças. NGOKWEY (1988) detectou em estudo realizado na Bahia que, a raiva e sentimentos de hostilidade, ansiedade e preocupação são possiveis causas das mais variadas doenças, alcançando desde doença popular caracterizada por "nervoso", como doenças do coração e derrames (acidente vascular cerebral).

As mulheres relatam muito mais sintomas subjetivos que os homens, particularmente aqueles sintomas que podem ser indicativo tanto de doença física ou angústia psicológica (MECHANIC, 1978; NGOKWEY, 1988).

Entre as mulheres a preocupação e o estar nervosa, na maioria das vezes, surgiu seguido de alguma razão identificável dentro do núcleo familiar: morte em familia e dificuldades no relacionamento familiar. Enquanto na fala dos homens a palavra nervosismo aparecia agrupando a razão de todos os problemas, sem a tentativa de relacionar às outras causas.

O polo masculino da identificação do nervosismo surgiu no discurso ao falar sobre as dificuldades no trabalho. Existe uma via de perturbação masculina que é pública e externa e que se articula sobre o plano do trabalho. Enquanto a 
via feminina é particular e interna e se articula no ambiente doméstico. O público e o particular são as vias de perturbação para cada um e daí as formas de expressão encontradas na percepção da origem da hipertensão arterial. (DUARTE, 1986)

"O espaço onde se dão os mais fortes embates emocionais é o das interrelações familiares, de vizinhança e às vezes do ambiente de trabalho" (MINAYO, 1988:371).

Segundo FERREIRA (1991) este aspecto articula-se com a hipótese da existência de mecanismos inadequados para reprimir tendências agressivas e expressar emoções. Desta forma, esta ansiedade, agressividade e hostilidade estariam criando um núcleo de tensão responsável pelo desencadeamento e manutenção dos níveis elevados da pressão arterial.

BLUMHAGEN (1980) ao estudar a forma com a hipertensão é percebida segundo o conhecimento popular encontrou duas causas principais: as psicossociais e as físicas- hereditárias. As causas psicossociais estariam provocando uma doença chamada de "Hyper-Tension" e as físicas seriam responsáveis pela elevação da pressão arterial. Dentre as primeiras causas o nervosismo aparece na forma de estresse externo crônico ou estresse agudo, mas de qualquer modo sendo o responsável pela doença. Este autor também identificou os problemas familiares e tensões no trabalho como causadores da hipertensão.

As respostas obtidas nesta categoria conduzem para a idéia da criação do núcleo de tensão, pois poderiam justificar o seu agrupamento em "nervosismo/ preocupação". Ao analisar as expressões pode-se inferir que "morte na familia, relações familiares difíceis, separação e doença na família", foram expressões usadas para apresentar o "nervosismo" criado por tais situações e que assim seria a causa da pressão alta. O "nervosismo" é apresentado como a causa instrumental.

"O nervoso da vida" surge como uma doença em si mesma e geradora de outros males. Segundo MINAYO (1988) este discurso revela um 
sentimento de opressão e de dificuldade de viver, e que muitas vezes se apresenta em forma de apatia.

"As doenças não são explicadas, elas se mostram: são um desequilíbrio global que as pessoas no conseguem ou não sentem necessidade de verbalizar"(MINAYO, 1988:368).

$\mathrm{Na}$ categoria (D) Causas Naturais, a associação da origem da hipertensão com (D3) outras doenças e/ ou sintomas foi mais presente entre mulheres de 50 a 69 anos:

"é por causa da coluna"

"por causa de uma veia entupida do coração, foi o médico que falou"

"devido a insuficiência da válvula mitral"

"por ter tontura e diagnóstico de hemorróidas"

"por causa da febre reumática que ela teve e deu esse problema"

"sentia tonturas"

"dores de cabeça e tonturas"

"por causa que tem problemas nos rins"

"me dá muita canseira e fadiga"

O conhecimento leigo relaciona os fatores psicossociais e físicos, tanto como causas como resultados. Desta forma cria-se uma relação da hipertensão arterial com sintomas, embora não haja confirmação disso nas pesquisas clínicas que se utilizam das medidas da pressão arterial para comparar valores pressóricos com a presença de um quadro sintomatológico. Os sintomas devem ser considerados na forma que o leigo percebe a doença e não desvalorizados por não encontrarem respaldo no conhecimento da fisiopatoplogia da doença. No conhecimento popular existe uma associação de sintomas como dores de cabeça e tontura à presença da pressão alta e nesta forma de percepção as causas e resultados se misturam porque o conhecimento científico não é fator limitante na construção deste conhecimento. A percepção da doença tem uma 
construção que é produto das relações sociais, culturais e da própria historicidade que cada morbidade carrega.

Ao considerar a resposta dada imputando às outras doenças já presentes, a responsabilidade pela hipertensão arterial, o indivíduo mantém a relação de interioridade com o agravo, mas não se acha diretamente implicado em sua doença.

Talvez, diante da possibilidade de conseguir ampliar a construção da explanação desses individuos sobre a origem de sua pressão alta, e fosse analisada a percepção sobre a origem destas "outras doenças" apresentadas como causas, fosse assim identificada uma relação endógena para estas doenças citadas. Ao imputar a causa da doença atual a outra pré - existente, o indivíduo está vendo o último agravo (a doença atual) como resultado de algo que ele já possuia, ou seja ele vê uma causa endógena para o mal presente, e ao mesmo tempo mantém a exterioridade (é outra doença) afastando as implicações pessoais.

As condições de classe também mostraram associação com a forma de perceber a doença. Entre aqueles pertencentes à condição de classe do proletariado o modelo endógeno prevaleceu. $E$ entre àqueles não inseridos no processo de produção (não classificados) predominou o modelo exógeno. Isso pode ser um reflexo do acesso as informações que tais individuos têm, e também em razão da forma de sua inserção ou não no processo de produção.

Ressalta-se que a construção de concepções sobre saúde e doença é social e histórica e não deve ser olhada isolada deste seu contexto. Ela possui a marca da história e da condição da classe dos que a produzem. Segundo MINAYO (1988) tais concepções se constróem em referência ao "lugar e à posição de classe e no conjunto das experiências dadas por um modo de vida particular". A forma como os individuos hipertensos apresentam suas percepções sobre a origem da hipertensão arterial evidencia que estão repletos de uma cultura de classe, apoiada sobre suas próprias condições materiais de existência. 
A concepção etiológica das doenças a partir da visão popular, nos grupos urbanos, sofre as influências dos conceitos médicos. No caso especifico da hipertensão arterial, por se tratar de doença essencialmente com diagnóstico médico, a percepção popular sobre sua origem não deixa evidente que as influências profissionais modifiquem ou interfiram na concepção do modelo etiológico. Há uma resistência na apresentação deste sistema etiológico. E longe de ser uma imitação do discurso médico, a percepção popular é uma adaptação das alternativas que o indivíduo teve acesso. A fonte do conhecimento popular parte do senso comum, das práticas e crenças religiosas que se reorganiza no contato com a medicina oficial

"as idéias sobre saúde-doença fazem parte de esquemas de pensamento socialmente mais abrangentes sobre a dor, o sofrimento, a vida, a morte, o destino do ser humano, as relações dos homens entre si e com a natureza "(MINAYO, 1988:376).

\section{3 - As Formas de Controle sobre a Hipertensão Arterial}

As questões usadas para analisar como estava sendo feito o controle sobre a doença pelos indivíduos hipertensos, procuraram identificar o uso dos serviços de saúde e o uso da medicação específica.

Mais da metade dos indivíduos hipertensos informaram não procurar os serviços de saúde como rotina para a assistência ao problema da pressão alta. E a metade afirmou não fazer uso da medicação hipotensora prescrita.

Estes dados, assim como os dados de prevalência, servem para confirmar uma situação já descrita. Identifica-se aqui novamente a regra do "The rule of halves", ou seja, somente a metade dos individuos hipertensos de uma comunidade são diagnosticados e, destes, só a metade está sob tratamento (MARQUES-VIDAL e TUOMILETHO, 1997). Possivelmente se fosse aplicada a medida da pressão arterial nesta mesma população de 
estudo, seria encontrado sob controle pressórico, somente a metade entre aqueles que fazem tratamento.

Maior do que o problema de se conseguir o diagnóstico dos hipertensos em uma comunidade é o problema de se obter o acesso ao controle sobre esta morbidade. A falta de adesão ao tratamento tem sido objeto de estudo por vários autores que buscam identificar as razões individuais para o não comprometimento com o tratamento de doença tão séria e incapacitante. Os sistemas de crenças têm sido estudados, modelos comportamentais, técnicas de educação em saúde que auxiliem na melhoria do conhecimento sobre a doença (BRAITHWAITE e MORTON, 1981; LANDER e col., 1993; SANSON-FISCHER e CLOVER, 1995; LESSA e FONSECA, 1997; JARDIM, 1998).

Dependendo da forma como o indivíduo percebe sua enfermidade ele ativará mecanismos para satisfazer as necessidades e fará isto em relação com seu poder de compra, sua cultura e sua personalidade (ARREDONDO e MELENDEZ, 1991).

Características individuais devem merecer especial atenção no tratamento da hipertensão arterial e também para ajudarem a identificar as causas do insucesso terapêutico tantas vezes apresentado.

\subsection{1 - O Uso dos Serviços de Saúde como Forma de Controle sobre a Doença}

A variável municipio de residência não mostrou significância na associação com o uso dos serviços de saúde. A acessibilidade aos serviços não parece ser um fator de importância na análise de busca por assistência pelo hipertenso. Devem existir outros fatores que provocam ou impedem esta busca. KROEGER e col. (1988) encontraram uma correlação inversa entre a acessibilidade aos serviços e os seus usos, na medida em que aumentava a distância dos serviços, diminuía sua utilização.

Neste estudo a principal justificativa para não procurar os serviços de saúde foi o fato de "não achar preciso". 
Os indivíduos hipertensos que mais procuram pela assistência são as mulheres. Segundo MEDICI (1990) as mulheres parecem ter uma percepção mais acurada de sua condição de saúde e também desenvolvem maiores relações com os serviços de saúde em razão de seus atributos e funções reprodutivas. Deve ser lembrado neste ponto que são também as mulheres que apresentaram o modelo etiológico endógeno para a percepção sobre a origem da doença. Pode-se inferir de tais informações que, entre elas, 0 sentimento de interioridade, culpa e responsabilidade assume uma função motivadora na busca por assistência.

Além disso a forma que as mulheres se encontram inseridas no mercado de trabalho não é muito rígida e permite maior flexibilidade de tempo para buscar assistência aos seus problemas de saúde.

Outro dado curioso foi a identificação de que os mais novos não buscam assistência, mas na medida em que a idade vai avançando aumenta. As principais razões para os mais novos não buscarem assistência é porque não acham necessário ou não têm tempo. A própria concepção de estar doente e poder estar doente apresenta-se de forma diferente segundo a faixa etária. Existe entre os mais jovens o senso comum de que a juventude Ihes confere poderes de invulnerabilidade. Aqui não se trata tanto da forma de perceber a doença e assumir responsabilidades individuais sobre o seu controle, mas a ausência do sentimento de necessidade de assistência ou ajuda (ANDERSEN e ADAY, 1978; ARREDONDO e MELENDEZ, 1991).

Observou-se que o proletariado não típico é a condição de classe que menos busca assistência. Segundo MEDICI (1990), quanto maior o nível de renda familiar maior será a procura por assistência a saúde. $O$ autor discute que pessoas que possuem maiores rendimentos, geralmente tem maior nível de escolaridade e isto influencia positivamente sobre a forma da percepção da doença, além de terem mais recursos para o acesso aos serviços.

A escolaridade tem, pois, associação com a busca pela assistência. Indivíduos com melhores níveis de escolaridade usam mais os serviços de saúde. Isto é justamente por terem acesso facilitado e horários de trabalho 
mais flexíveis. Ressalta-se que as maiores prevalências são encontradas entre os analfabetos. Desta forma, os grupos populacionais mais necessitados da assistência são os que estão mais distantes dela.

A informação tem despertado a consciência da importância dos problemas de saúde e, desta forma, determinado a percepção da morbidade. É possivel também que o aumento do número de casos crônicos de morbidades esteja associado ao agravamento dos problemas econômicos e mesmo emocionais e que fazem que as pessoas percebam e sintam de forma diferente os problemas de saúde (MEDINA e col.,1987).

A questão do custo do acesso aos serviços de saúde foi principalmente relacionado pelos homens. Isto é coerente com o modelo etiológico que apresentaram, onde prevaleceu a percepção exógena e com evidências de mais respostas relacionando à situação de trabalho. Para os homens portanto, o custo de uma visita médica é motivo suficiente para não buscar assistência.

Ressalta-se aqui o fato de que os indivíduos masculinos nesta população do estudo pertenciam a condição de classe de proletariado, o que os caracteriza como trabalhadores submetidos a uma situação de exploração e assalariados. Discute-se a possibilidade de que tais indivíduos, ao estarem inseridos nas relações de produção, também tivessem o acesso mais facilitado aos serviços de saúde, pois em muitos casos, as próprias empresas empregadoras cuidam em oferecer tais assistências. No entanto, MECHANIC (1976) encontrou que, mesmo os individuos inseridos no mercado de trabalho, quando mulheres, buscavam mais assistência do que os homens e que, portanto, a condição de trabalho não poderia ser usada como determinante para este comportamento (CORDEIRO, 1993).

\subsection{2 - O Uso de Medicamento Específico como Forma de Controle sobre a Doença}

Quase a metade dos individuos hipertensos da região do estudo informou não fazer uso de medicação específica para o controle da pressão 
alta. A principal justificativa para não usar medicação foi a ausência de sintomas da doença.

O município que apresentou a maior freqüência de uso de medicamentos foi Juquitiba e foi também onde houve a maior proporção de idosos. Para confirmar estas inferências observou-se que os mais jovens são também aqueles que menos usam medicamento.

Os individuos nas condições de classe do subproletariado e proletariado também são os que menos usam hipotensores e alegam a falta de efeito e o custo da droga.

As mulheres foram as que mais afirmaram fazer uso de medicação específica e, aparentemente, assumem mais o controle da hipertensão arterial. O não uso de medicamentos devido a presença de complicações foi referido exclusivamente por mulheres. MECHANIC (1976) encontrou resultados semelhantes em seu estudo, onde as mulheres usavam mais medicação do que os homens e principalmente drogas psicotrópicas.

Quando relacionadas as duas ações de controle (visita ao médico e uso de drogas) observou-se que a ingestão do medicamento está associada ao uso dos serviços de saúde. Aqueles que tem como rotina a visita aos serviços de saúde para buscar assistência para o problema da pressão alta, também tem o hábito do uso das medicações. A procura pela assistência não é certificado de adesão ao tratamento, mas a forma como é ofertada faz a diferença no sucesso terapêutico. Serviços multiprofissionais apresentam indices de adesão mais altos $e$, consequentemente melhor controle sobre a morbidade (LEVINE e col. 1979; SOUSA e col., 1992; VI JOINT, 1997).

Observou-se que, mesmo não buscando assistência, alguns indivíduos fazem uso regular da medicação. $E$ isto aconteceu com maior predomínio entre aqueles com menor grau de escolaridade. Estes indivíduos tanto podem estar fazendo uso de medicação prescrita em dado momento de consulta médica, como podem ter assumido o tratamento por conta própria e estarem se auto medicando. $O$ fato disto acontecer entre aqueles com menor escolaridade, remete a discussão sobre os principais elementos para se conseguir a melhor adesão ao tratamento. 
A escolaridade não mostrou associação com o uso da medicação. As pessoas procuram os serviços de saúde, mas a adesão ao tratamento passa por mudanças comportamentais que envolvem ações educativas, em que o nivel de instrução é peça chave para o seu desenvolvimento. O nível de escolaridade é fator fundamental para que as informações sobre a doença e seu tratamento sejam recebidas da forma correta e assim, funcionem como facilitadores para o sucesso terapêutico (JARDIM, 1998).

O modelo etiológico predominante foi o endógeno e a partir da sua categoria (D) Causas Naturais, foram identificadas respostas que associavam a origem da hipertensão com outras doenças ou mesmo com sintomas. Se o indivíduo entende que sua doença está relacionada a determinados sinais, e em dado momento estes sinais não existem mais, ele não encontrará motivação e estímulo para qualquer ação sobre a morbidade. Daí a não adesão ao uso do medicamento.

Na verdade, sua percepção é sobre algo que não existe de fato, a não ser quando sua presença é sentida. $O$ fato de não acharem necessário a busca de assistência é coerente com a justificativa de não usarem medicamento por não sentirem a presença de sintomas.

\section{4 - Os Modelos Etiológicos e as Formas de Controle sobre a Hipertensão Arterial}

A utilização do modelo de regressão logística permitiu verificar o efeito conjunto das variáveis e dos modelos de percepção e formas de controle. Este efeito conjunto mostrou:

- modo de perceber a morbidade influencia a busca por assistência, mas não o uso de medicamentos;

- sexo, faixa etária e escolaridade também foram associadas ao uso dos serviços

- o uso de medicamentos específicos esteve associado com o sexo e faixa etária. 
A forma como a hipertensão é percebida pelos indivíduos influencia na freqüência da busca por assistência, mas não influencia o uso de medicamentos específicos.

$\dot{E}$ interessante observar que o modelo etiológico predominante (endógeno) contribui muito para explicar as ações de controle do indivíduos sobre a doença. $O$ fato do hipertenso perceber a doença como algo intrinseco ao seu ser, faz dele responsável pela condução dos movimentos de controle.

A identificação do modelo endógeno entre os indivíduos que mais procuram por assistência confere este caracter de relação entre a forma de perceber a morbidade e a forma de assumir seu controle. $O$ indivíduo é motivado a buscar assistência não em razão da presença de sinais e sintomas - ausentes no caso da hipertensão arterial, mas muito mais pelo sentimento da necessidade individual de cuidado. Ele se vê como o responsável, direto ou não pela doença que Ihe aflige. Poderia se dizer que existe mesmo um sentimento de culpa que estabelece o movimento do hipertenso na direção do tratamento. Afinal, ao sentir-se "nervoso", ao ter se permitido acolher outras doenças, ao interiorizar os problemas da família e ao receber a doença como herança familiar o indivíduo se vê diante de um fato intransponivel em que ele não pode culpar o outro ou modificar algo externo. Então conduz a si mesmo na busca das respostas.

"... a condição de saúde sentida ou percebida pela população de uma área e suas interações com a estrutura de serviços assistenciais oferecidos, é uma realidade complexa que deve ser analisada em função das características próprias da população que influenciam sobre a utilização dos serviços oferecidos, e da estrutura assistencial que condiciona a população na utilização dos mesmos, de certa forma regulando a demanda." (ARREDONDO e MELENDEZ, 1991: 48)

O modo de perceber a doença mostrou influenciar sobre a busca de serviços, assim como o sexo, a idade e a condição de classe. 
Já no caso do controle através do uso de medicação específica, o modo de perceber a doença e a escolaridade não apresentaram influência.

Neste estudo o modelo exógeno não predominou. Identifica-se com isto que fatores externos, sejam sociais ou do ambiente, não foram considerados pelos indivíduos nas respostas sobre a origem da doença. Se tais fatores não são identificados como perturbadores, eles também não funcionam como motivadores para o tratamento. De que forma seria possível modificar o comportamento de tais individuos se, no seu modelo de crenças, isto não é necessário ?

A experiência individual com a morbidade deve ser respeitada e utilizada como motivação na busca da melhor abordagem terapêutica.

A questão da adesão ao tratamento extrapola a freqüência aos serviços de saúde. O fato do indivíduo hipertenso buscar assistência e não usar os medicamentos prescritos está refletindo justamente a forma de percepção que traz sobre a doença. Ao buscar assistência nos serviços de saúde o hipertenso pode estar transferindo a idéia da responsabilidade. $E$ ao recusar o uso de medicamentos evidencia-se que a presença da morbidade não foi assumida em sua totalidade.

Alcançar melhores niveis de controle sobre a hipertensão arterial é um problema que tem desafiado os profissionais de saúde. Entender melhor a forma como os indivíduos hipertensos vêem a doença pode ser útil no planejamento dos serviços de saúde e nos modelos de assistência, garantindo assim, maior sucesso.

O tratamento da hipertensão arterial inclui mudanças de comportamento, hábitos de vida e incorporação de novas rotinas, como o uso de drogas hipotensoras. Estas drogas têm papel importante nesta terapêutica, mas sem as mudanças comportamentais sua influência fica quase nula. As ações educativas devem ser parte integrante no planejamento da assistência ofertada, pois será através destas atividades que se conseguirá melhores taxas de adesão. 


\section{CONCLUSÕES}

Concluímos que a prevalência encontrada reflete a taxa de detecção dos casos de hipertensão pelos serviços de saúde da região. Em relação a prevalência real trata-se de um dado subestimado, mas que pode ter sua utilidade no planejamento da assistência e na abordagem ao paciente hipertenso.

Verificamos que a percepção que a população hipertensa tem sobre a origem desta morbidade foi predominantemente dentro do modelo etiológico endógeno. Pelo fato das mulheres perceberem a doença de forma diferente dos homens, a forma de abordagem para o tratamento da hipertensão não deve ser semelhante para ambos os sexos. A motivação para o tratamento entre as mulheres deve ser identificada dentro delas mesmas e trabalhando com a responsabilidade pessoal sobre a morbidade. Já entre os homens, as questões de comportamento, questões sócio econômicas e relações de trabalho deveriam ser melhor exploradas na abordagem terapêutica. Além disso, as mulheres tendem mais à subjetividade e isto deve ser lembrado pelos profissionais ao prescreverem e orientarem sobre o controle da doença.

Há necessidade de ampliar o conhecimento sobre o uso dos serviços de saúde pela população portadora de morbidade crônica e do impacto desses serviços sobre as áreas onde estão situados e diretamente sobre morbidades específicas. Os resultados indicam que a estrutura dos serviços de saúde da região não correspondem às necessidades da população no que diz respeito ao diagnóstico e tratamento de doenças crônicas. O sexo, a condição de classe social e a idade foram variáveis associadas à busca pela assistência.

Os serviços de saúde permanecem no modelo tradicional de atendimento de demanda, e os usuários adaptam suas necessidades às condições que the são oferecidas. No caso da hipertensão arterial, muitos não procuram assistência simplesmente por não julgarem necessário. Por 
que enfrentar tantos obstáculos para uma consulta e para buscar uma ajuda que não é sentida como necessária ?

Os dados sugerem que novos horários e maior flexibilidade na oferta dos serviços ajudariam alcançar melhor cobertura da assistência. Os serviços de saúde não deveriam insistir na oferta de assistência indiscriminada, sem atentar para necessidades e características individuais.

Quanto à medicação específica para o tratamento da doença, verificamos que não é utilizada porque o individuo hipertenso não identifica sua necessidade. A ausência de sintomas é motivo para não usar o medicamento. Os profissionais que atuam na área devem conduzir suas orientações e prescrições sob a lembrança de que as ações educativas devem conseguir maior sucesso na terapêutica.

O modo de perceber a doença atua como um estímulo para o uso dos serviços, mas não para o uso da medicação. Esta percepção popular deveria ser mais explorada pelos profissionais e incorporada a sua prática e aplicação terapêutica. O modelo etiológico encontrado no presente estudo sugere que deveria haver maior colaboração dos profissionais e serviços de saúde na direção de atender a necessidade sentida pela população. Permanecer com um discurso técnico sobre a gravidade da doença, o uso dos hipotensores, o estímulo as mudanças comportamentais, sem entender, ou pelo menos tentar, de que forma esta doença é vista pelo indivíduo, vai continuar representando grande dispêndio de energia com baixo retorno nos resultados.

Outros estudos que façam uma abordagem sobre a construção de concepções sobre doenças, que não seja essencialmente técnica, deveriam ser estimulados, na busca pelo conhecimento mais amplo sobre as melhores formas de assistência. Tais estudos poderiam também influenciar o julgamento dos administradores em saúde pública a favor de cuidados de saúde que caminhem na direção da necessidade sentida pela população. 


\section{REFERÊNCIAS BIBLIOGRÁFICAS}

1. Amand $S$, Rosenthal $T$, Grossman $E$. The prevalence and awareness of hypertension among Israel Arabs. J Hum Hypertens 1996; 10 (Supl. 3): 31-3.

2. Andersen R, Aday LA. Acess to medical care in the US: realized and potential. Medical Care 1978; 16(7): 533- 546.

3. Antonovsky A. Social class and the major cardiovascular disease. $J$ Chronic Disease 1968; 21: 65 - 106.

4. Arredondo A e Melendez V. Modelos explicativos sobre la utilizacion de servicios de salud: revision y analisis. Salud Pública de México 1991; 34 (1): $36-49$.

5. Ayres JEM. Prevalência da hipertensão arterial na cidade de Piracicaba. Arq Bras Cardiol 1991; 57(1):33-36.

6. Azevedo ES. Peculiaridades da distinção racial no Brasil. HiperAtivo 1996; 3(3): $146-152$.

7. Bastos HD, Macedo CS, Riyuzo MC. Pressão Arterial: conceito de normalidade na infância. Pediatr Mod 1993; 29(3) :223 - 4.

8. Berlinguer G. A doença. São Paulo: Hucitec-CEBES; 1988.

9. Berquó ES, Souza JMP, Gotlieb SLD. Bioestatística. $2^{a}$ ed. São Paulo: EPU; 1981.

10. Blackwell B. Drug therapy - patient compliance. The New Engl J Med 1973; 289(5) 249-52.

11. Bloch KV, Coutinho ESF, Lobo MSC, Oliveira JEP, Milech A. Pressão arterial, glicemia capilar e medidas antropométricas em uma população yanomami. Cad Saúde Pública 1993; 9 (4): 428 - 38.

12. Blumhagen D. Hyper-tension: a folk illness with a medical name. Culture Medicine and Psychiatry 1980; 4:197 - 227.

13. Boltanski L. As classes sociais e o corpo. Rio de Janeiro: Graal; 1979. 
14. Borrel C. Métodos utilizados no estudo das desigualdades sociais em saúde. In: Barata RB, organizador. Condições de vida e situação de saúde. Saúde e Movimento. Rio de Janeiro: ABRASCO; 1997. p.167195.

15. Bowlin SJ, Morril BD, Nafziger NA, Jenkins PL, Lewis C, Pearson TA. Validity of cardiovascular disease risk factors assessed by telephone survey : the behavioral risk factor survey. J Clin Epidemiol 1993; 46 (6): $561-571$.

16. Braithwaite JD e Morton BG. Patient eduation for blood pressure control. Nursin Clinics of North America 1981 (2): 321 - 329.

17. Breilh J. Epidemiologia: economia, política e saúde. São Paulo:UNESP - HUCITEC; 1991.

18. Brigagão JIM. A construção de significados de uma doença crônica: a artrite reumatóide. São Paulo; 1994. [Dissertação de Mestrado Pontifícia Universidade Católica].

19. Burt VL, Cutler JA, Higgins M, Horan MJ, Labarthe D, Whelthon P, Brown C, Rocclea E.J. Trends in the prevalence, awareness, treatment and control of hypertension in the adult US population. Data from the health examination surveys, 1960 to 1991. Hypertension 1995a; 26 (1): $60-69$.

20. Burt VL, Whelthon P, Roccela EJ, Brown C, Cutler JÁ, Higgins M, Horan MJ, Labarthe D. Prevalence of hypertension in the US adult population. Results from the third national health and nutrition examination survey, 1988 - 1991. Hypertension 1995b; 25(3): $305-313$.

21. Cadlwell DR, Coob S, Dowling MD, Dejnhg D. The dopout problem in antihypertensive treatment. A pilot study of social and emotional factors influencig a patient's ability to flow antihypertensive treatment. $J$ Chron Dis 1970; 22: 579 - 592.

22. Canguilhem G. O normal e o patológico. $2^{2}$ ed. Rio de Janeiro: Forense Universitária; 1982.

23. Carandina L, Sanches O, Carvalheiro JR. Análise das condiçòes de saúde e de vida da população urbana de Botucatú - SP. I Descrição do 
plano amostral e avaliação da amostra. Rev Saúde Pública 1986; 20(6): $465-74$.

24. Carneiro O, Jardim PCV. Pressão arterial em Tribo Xavante. Comparação 15 anos depois. Arq Bras Cardiol 1993; 61 (5): 279-282.

25. Carvalheiro JR, Carvalheiro CDG, Almeida MCP. Levantamento de condições de saúde por entrevistas domiciliárias. VI - Vila Lobato: caracteristicas individuais e morbidade referida. Medicina 1982; 15 (3): $139-153$.

26. Carvalho FM, Silvany Neto AM, Paim JS, Melo AMC, Azaro MGA. Morbidade referida e utilização de consulta médica em cinco populações do Estado da Bahia. Ciência e Cultura 1988; 40 (9): 853 - 858.

27. Carvalho JJM, Silva NAS, Oliveira JM, Arguelles E, Silva JAF. Pressão Arterial e grupos sociais. Estudo epidemiológico. Arq Bras Cardiol 1983; 40 (2): 115-120.

28. César CLG \& Tanaka OY. Inquérito domiciliar como instrumento de avaliação de serviços de saúde: um estudo de caso na região sudoeste da área metropolitana de São Paulo, 1989 -1990. Cad Saúde Pública 1996; 12 (Supl.2): 59-70.

29. César LGC, Figueiredo GM, Westphal MF, Cardoso MRA, Costa MZA, Gattás VL. Morbidade referida e utilização de serviços de saúde em localidades urbanas brasileiras: metodologia. Rev Saúde Pública 1996; 30(2): $153-60$.

30. Chor D, Fonseca MJM, Andrade CR. Doenças cardiovasculares. Comentários sobre a mortalidade precoce no Brasil. Arq Bras Cardiol 1995; 64 (1): 15- 19.

31. Chor D. Dora. Perfil de risco cardiovascular de funcionários de banco estatal. São Paulo; 1997. [Tese de Doutorado - Faculdade de Saúde Pública da USP]

32. Consenso Brasileiro de Hipertensão (III). Sociedade Brasileira de Hipertensão; Sociedade de Nefrologia; Sociedade Brasileira de cardiologia. Relatório. Campos do Jordão - SP, 12 a 15 de fevereiro de 1998. 
33. Costa EA, Rose GA, Kelin CH, Leal MC, Szwarcwald CL, Bassanesi SL, Achutti AC, Fischam A. Salt and Blood pressure in Rio Grande do Sul. Brazil. Bulletin of PAHO 1990; 24 (2): 159 - 176.

34. Costa EA. Hipertensão arterial como problema de massa no Brasil. Magnitude da hipertensão arterial no Brasil. Ciência e Cultura 1983; 35 (11): $1636-37$.

35. Costa WG, Araújo GM, Chaves Al. Prevalência da hipertensão arterial sistêmica na região de Uberlândia - MG. Rev Goiana Med 1984; 30:55 60.

36. Curb DJ, Borhani NA, Blaszkowski TP, Zimbaldi N, Fotiu S, Williams W. Long term surveillance for adverse effects of antihypertensive drugs. JAMA 1985; 253(22): 3263-68.

37. Degoulet P, Menard J, Godmard JL, Devries C, Chetellier G, Plouin PF. Factors predicting attendance at clinic and blood pressure control in hypertnesive patients. Br Med [Clin Res] 1983; 287: 88-93.

38. Delena SM, Cingolani HE, Almiron MA, Echeveria RF. Prevalência de la hipertension arterial en una poblacion rural bonaerense. Medicina B. Aires 1995; 55(3): 225 - 30.

39. Drizd T, Dannenber AL, Engel A. Blood pressure levels in persons 18 74 years of age in $1976-80$, and trends in Blood pressure from 1960 to 1980 in the United States. Vital hlth Statisc Ser 1986; 11, (234): 1- 29.

40. Duarte LFD. Da vida nervosa, nas classe trabalhadoras urbanas. $2^{a}$ ed. Rio de Janeiro: Jorge Zahar ; 1986.

41. Duncan BB, Schmidt MI, Polanczyk CA, Homrich CS, Rosa RS, Achutti AC. Fatores de risco para doenças não transmissiveis em área metropolitana na região sul do Brasil. Prevalência e simultaneidade. Rev Saúde Pública 1993; 27(1): 143-8.

42. Equipe das Comunidades de Base e de Agentes de Diocese de Goiás. O Meio Grito: um estudo sobre as condições, os direitos, o valor e o trabalho popular associados ao problema da saúde em Goiás. In: Brandão CR, organizador. Pesquisa Participante. $4^{\mathrm{a}}$ ed. São Paulo: Brasiliense; 1984. p. $130-198$. 
43. Eyer J. Hypertension as a disease of modern society. International Journal of Health Services 1975; 5(4): $539-558$.

44. Facci Júnior C, Carvalho JJM, Facci AM, Borges AM, Souza EC, Bilich F, Oliveira OB, Barbosa ET. Prevalência da Hipertensão arterial nos funcionários de um Hospital Geral. Arq Bras Cardiol 1986; 46_(3): 195 198.

45. Fang J, Madhavann S, Alderman M. The association between birthplace and mortlity from cardiovascular causes among black and white residents of new york city. The New England J Medicine 1996; 335 (21): 1545 1551.

46. Ferreira CS. Concepção popular da hipertensão arterial: contribuição à relação médico paciente. Rev da SOCERJ 1991; 4(3): 180184.

47. Freeman V, Fraser $H$, Forrester $T$, Wilks $R$, Cruickshank J, Rotimi C, Cooper R. A comparative study of Hypertension prevalence, awareness, treatment and control rates in St Lucia, Jamaica and Barbados. J Hypertension 1996; 14 (4): 495 - 501.

48. Freeman V, Rotimi C, Cooper R. Hypertension, Prevalence, Awareness, Treatment, and control Among African Americans in the 1990s: estimates from the Maywood Cardiovascular Survey. Am J Preventive Medicine 1996; 12 (3) 177 - 185.

49. Fuchs FD, Moreira LB, Moraes RS, Bredemeir M, Cardozo SC. Prevalence of systemic and associated risk factors in the Porto Alegre metropolitan area. Populational-based study. Arq Bras Cardiol 1994; 63(6): 473-9.

50. Fundação IBGE . Pesquisa Nacional por Amostra de Domicilio (PNAD). Rio de Janeiro; 1990.v. 14.

51. Fundação IBGE .Censo demográfico 1991. São Paulo. Rio de Janeiro; 1994. v. 21. (10 Recenseamento Geral do Brasil)

52. Fundação Nacional de Saúde - Ministério da Saúde (FNS/MS) DATASUS. Disponível em http://datasus.fns.gov.br [1998 Dez 28] 
53. Fundação Sistema Estadual de Análise de Dados (SEADE) O novo retrato de São Paulo. Avaliação dos primeiros resultados do Censo demográfico de 1991. 2ed. São Paulo; 1993.

54. Gattas VL. Avaliação da cobertura vacinal e do uso de serviços de saúde para vacinação na região sudoeste da Grande São Paulo , 1989-1990. São Paulo; 1996. [Dissertação de Mestrado - Faculdade de Saúde Pública da USP].

55. Geiger HJ, Scotch NA. The Epidemiology of essential Hypertension. A review with special attention to psychologic and sociocultural factors. J Chron Dis 1963; 16: 1151-1182.

56. Ginter E. Cardiovascular risk factors in the former communist countries. Analysis of 40 European MONICA populations. European $\mathbf{J}$ Epidemiology 1995; 11: 199-205.

57. Gupta R, Alodatt NA, Gupta UP. Hypertension epidemiology in India: meta analysis of 50 year prevalence rates and blood pressure trends. $\mathbf{J}$ Human Hypertension 1996; 10 (7): $465-72$.

58. Habermann F. Nivel pressórico e prevalêencia de Hipertensão Arterial em amostra da população urbana de Botucatu (SP). Relatório Projeto FINEP. Botucatú ; 199? (mimeo)

59. Hasson L, Zanchetti A. O estudo do tratamento ótimo da hipertensão arterial (HOT): dados de 12 meses sobre o controle da pressão arterial e tolerabilidade. Com enfoque especial à idade e sexo. Blood Pressure 1995; 4 : $313-319$.

60. He J, Klang MJ, Whelton PK, Chen JY, Mo JP, Qian MC, Mo PS, He GQ. Migration, blood pressure pattern and hypertension: The Yi Migrant Study_Am J Epidemiology 1991; 134(10): 1085 - 1101.

61. Herzlich C, Pierret J. De ayer a hoy: construcción social del enfermo. Cuadernos Médico Sociales 1988; 43: 21 - 30.

62. Herzlich C. L'Origine de la Maladie. L'Hygiene Mentale. Supplement de L'encephale 1968; LVII (1): 1-24. 
63. Hoffmeister $\mathrm{H}$, Mensik GBM, Stolzenberg $\mathrm{H}$. National trends in risk factors for cardiovascular disease in Germany. Preventive Medicine 1994; 23 : $197-205$.

64. Hunt L, Irwin S. Views of whats wrong: diagnosis and patients. Concepts of illness. Soc Sci Med 1989; 28 (9): 945 - 956

65. Hypertension Detection and Follow-up Program Cooperative Group (HDFPCG) .Five year findings of the Hypertension Detection and Followup Program. 1. Reduction in mortality of persons with high blood pressure, incluiding mild hypertension. JAMA 1979;242: 2562 - 2571.

66. Hypertension Detection and Follow-up Program Cooperative Group (HDFPCG) Blood pressure studies in 14 communities. A two- stage screen for hypertension. JAMA 1977; 237 (2): 2385 - 2391.

67. Ibrahim MM, Rizk H, Appel U, El-Aroussy W, Helmy S, Sharaf Y, Shour Z, Kandili H, Roccella E, Whelton PK. Hypertension prevalence, awareness, treatment and control in Egypt. Results from the Egyptian National Hypertension Project (NHP) . Hypertension 1995; 26 (6 Pt 1): 886 - 90.

68. Jaddou HV, Batiehah Am, Ajlouni KM. Prevalence and associated factors of hypertension: results from a three community-based survey, Jordan. $\mathbf{J}$ Hum Hypertension 1996; 10(12): 815 - 21.

69. Jardim PCBV, Sousa ALL, Alves TM, Garcia MA, Martins RC. Evaluation of compliance to treatment of patient with hypertension in multiprofessionalactivities [abstract]. Am J Hypert 1992a; 5(5- II): $134 \mathrm{~A}$.

70. Jardim PCBV, Carneiro O, Carneiro SB, Baiocchi MN. Pressão arterial em comunidade negra isolada remanescente de quilombo - Norte de Goiás - Kalunga. Arq Bras Cardiol 1992b; 58(4): 289 - 293.

71. Jardim PCBV. Educação em Saúde e controle da pressão arterial São Paulo; 1998.[Tese de Doutorado - Faculdade de Medicina da USP]

72. Joint National Committee on Detection, Evaluation and Treatment of High Blood Pressure (JNC). The V Report of The Joint National Committee on Detection, Evaluation, and Treatment of High Blood Pressure. Arch Intern Med 1993; 153: 154 - 183. 
73. Joint National Committee on Detection, Evaluation and Treatment of High Blood Pressure (JNC). VI Relatório do Joint National Committee. Prevenção, detecção, avaliação, tratamento da pressão arterial elevada. Publicação NIH n. 98-4080 nov. 1997.

74. Junqueira LAP. Descentralização e intersetorialidade: a construção de um modelo de gestào municipal. RAP Rio de Janeiro 1998; 32(2): 11 22.

75. Kannel WB. Blood pressure as a cardiovascular risk factor. JAMA 1996; 275 (20): 1571-15776.

76. Kannel WB. Hypertension as a risk factors for cardiac events epidemiologic results of long term studies. J Cardiovascular Pharmacology 1993; 21(Suppl. 2): S27 - S37.

77. Kaplan NM. Clinical Hypertension. $5^{\text {th }}$ ed. Baltimore - EUA: Williams \& Wilkins; 1990. p.1-25.

78. Kaufman JS, Rotimi CN, Brieger WR, Olandokum MA, Kadiri S, Osotimehin BO, Cooper RS. The mortality risk associated with hypertension: preliminary results of a prospective study in rural Nigeria. $\mathbf{J}$ Hum Hypertens 1996; 10(7): 461-4.

79. Klein $\mathrm{CH}$ et al. Variação da pressão arterial em trabalhadores de uma siderúrgica. Cad Saúde Pública 1986; 2: 212 - 26.

80. Klein CH, Araújo JWG, Leal MC. Inquérito epidemiológico sobre hipertensão arterial em Volta Redonda - RJ. Cad Saúde Pública 1985; $1: 58-70$.

81. Klein $\mathrm{CH}$. Hipertensão Arterial em estratos geoeconómicos do Rio Grande do Sul. Rio de Janeiro; 1981. [Dissertação de Mestrado - Escola Nacional de Saúde Pública/ FIOCCRUZ].

82. Klein CH, Silva NAS, Nogueira A, Campos LH, Bloch KV. Estudo multicêntrico sobre hipertensão arterial no Brasil. Relatório da pesquisa HÁ na llha do Governador, RJ, 1992 apresentado ao Ministério da Saúde e ao Conselho Nacional de Desenvolvimento Científico e Tecnológico. 
83. Kochar MS, Woods KD. Controle da Hipertensão para enfermeiras e demais profissionais de saúde. $2^{a}$ ed. São Paulo: Organização Andrei; 1990.

84. Kohn R, \& White KL. Health Care: an international study. Oxford University Press. London, 1976.

85. Kroeger A . Errores de respuesta y otros problemas de las encuestas de salud mediante entrevista en los paises en desarrolo. Bol Of Sanit Panam 1986; 100(3): $253-282$.

86. Kroeger A. Health interview surveys in developing countries: a review of the methods and results. International J Epidemiology 1983; 12(4): 465 -481 .

87. Landers R, Riccobene A, Beyreuther M, Neusy AJ. Predictors of longterm compliance in attending a worksite hypertension programme. J Hum Hypertens 1993; 7(6): 577-9.

88. Laplantine F. Antropologia da doença. São Paulo: Martins Fontes; 1991.

89. Laurenti R e Fonseca LAM. A mortalidade por doenças cardiovasculares no município de São Paulo em um período de 30 anos (1940 - 1969). Arq Bras Cardiol 1976; 29(2): 85-88.

90. Laurenti R, Jorge MHPM, Lebrão ML, Gotlieb SLD. Estatísticas de Saúde. São Paulo:EDUSP;1985.

91. Lebrão ML, Carandina L, Magaldi C. Análise das condições de vida da população urbana de Botucatu, São Paulo (Brasil). IV - Morbidade referida em entrevistas domiciliárias, 1983 - 1984. Rev Saúde Pública $1991 ; 25$ (6): $452-60$.

92. Lebrão ML. Estudos de Morbidade. São Paulo: EDUSP; 1997.

93. Lescura Y, Mamede MV. Educação em saúde: abordagem para o enfermeiro. São Paulo: Sarvier ; 1990.

94. Lessa I, Fonseca J. Raça, aderência ao tratamento e/ou consulta e controle da hipertensão arterial. Arq Bras Cardiol 1997; 68(6):443-9. 
95. Lessa I. Epidemiologia da hipertensão arterial. In: $\mathbf{O}$ adulto brasileiro e as doenças da modernidade. São Paulo - Rio de Janeiro: HUCITECABRASCO; 1998. P. 77-96.

96. Levine DM, Cohen JD, Dustan HP, Falkner B, Flora JÁ, Lefebvre C, Morisky DE, Oberman A, Pickering TG, Roccella EJ, Saunders E, Whelthon PK. Behavior changes and prevention of high blood pressure. Circulation 1993; 88 (3) 1387 - 90.

97. Lólio CA. Prevalência da hipertensão arterial em Araraquara. Arq Bras Cardiol 1990a; 55 (3):167-73.

98. Lólio CA . Epidemiologia da Hipertensão Arterial. Rev Saúde Pública $1990 \mathrm{~b} ; 24(5): 425-32$.

99. Lólio CA, Laurenti R. Mortalidade por doença isquêmica do coração no município de SP. Evolução de 1950 a 1981 e mudanças recentes na tendência. Arq Bras Cardiol 1986;46: 153-6.

100. Lólio CA, Pereira JCR, Lotufo PA, Souza JMP. Hipertensão arterial e possiveis fatores de risco. Rev Saúde Pública 1993; 27 (5): 357 - 62.

101. Lombardi C, Bronfman M, Facchini LA, Victoria CG, Barros FC, Béria JU, Teixeira AMB. Operacionalização do conceito de classe social em estudos epidemiológicos. Rev Saúde Pública 1988; 22(4): $253-65$.

102. Lopes AA. Raça e hipertensão arterial. HiperAtivo 1996; 3(3): 153172.

103. Lotufo PA, Lólio CA. Tendências de evolução da mortalidade por doenças cardiovasculares: o caso do Estado de São Paulo. In: Monteiro CA. (org) Velhos e novos males da saúde no Brasil. São Paulo: HUCITEC - NUPES/USP; 1995. p.279- 288.

104. Lowenstein FW. Blood pressure in relation to age and sex in the tropics and subtropic. The Lancet 1961; 389 - 392.

105. Mackenbach JP, Kunst AE, Cavelaars A, Groenhof F, Geurts JJM. Socioeconomic inequalities in morbidity and mortality in western Europe. The Lancet 1997; 349: 1655 - 1659.

106. Maddocks I. Possible absence of essential hyperytension in two complete pacific island population. The Lancet 1961; 396 - 399. 
107. Marques VP e Tuomiletho J. Hypertension awareness, treatment and control in the community : is the "rule of halves"still valid ? J Hum Hypertens 1997; 11(4); 213-20.

108. Mechanic D. Sex, Illness, IIness Behavior and The use of health services. Soc Sci \& Med 1978; 12B: $207-14$.

109. Medici AC. Aspectos sócio - econômicos da morbidade no Brasil.

Uma contribuição aos Estudos sobre População e Saúde ( $O$ caso do Nordeste). Saúde em Debate 1990; 30: 40 - 81.

110. Medina E, Kaepffer AM, Cumsille F, Medina RR. Encuesta de morbilidad y atencion medica como método de analisis de situacion de salud. Bol Of Sanit Panam 1987; 102 (6): $594-605$.

111. Minayo MCS. $O$ desafio do conhecimento - pesquisa qualitativa em saúde. São Paulo / Rio de Janeiro: HUCITEC/ABRASCO; 1992.

112. Minayo MCS. Saúde-doença: uma concepção popular da etiologia Cad Saúde Pública 1988; 4(4): $363-381$.

113. Ministério da Saúde (MS). Secretaria de assistência a Saúde. Departamento de Programas de Saúde. Coordenação de Doenças Cardiovasculares. Doenças Cardiovasculares no Brasil. Sistema Único de Saúde - SUS - dados epidemiológicos. Assistência Médica. Brasília; 1993.

114. Mion Jr D. Aderência do paciente hipertenso ao tratamento. Palestra proferida durante o XLIII Congresso da Sociedade Brasileira de Cardiologia. Brasília, 1987.

115. Monego ET. Saúde e trabalho na história de vida da mulher. Goiânia;1995. [Dissertação de Mestrado - Faculdade de Educação da Universidade Federal de Goiás]

116. Moura MF, Tiago EL, Ramos L, Regis C, Rezende V, Sousa ALL, Jardim PCBV. Arterial hypertension in na urban community of the interior of Brazil [abstract]. Am J Hypert 1995; 8 (4-11): 146A .

117. Ngokwey N. Pluralistic Etiological Systems in their social context: a brazilian case study. Soc Sci Med 1988; 26 (8): $793-802$. 
118. Nobre F, Lima NKC, Moura Jr LA. Hipertensão arterial essencial .In: Porto CC organizador. Doenças do coração. Prevenção e tratamento. Rio de Janeiro: Guanabara Koogan; 1998. p 461 - 475.

119. Oliveira FJA. Concepções de doença: o que os serviços de saúde têm a ver com isso ? In: Duarte LFD e Leal OF (org.). Doença, sofrimento, perturbação: perspectivas etnográficas. Rio de Janeiro: Fiocruz; 1998.p. $81-94$.

120. Oliveira LAP e Simões CCS. Morbidade: níveis de percepção. In: Fundação Instituto Brasileiro de Geografia e Estatística. Perfil estatístico de crianças e mães no Brasil: situação de saúde - 1981. IBGE 1984. p. 151-74.

121. Page LB. Epidemiologic evidnece on the etiology of human hypertension and its possible prevention. In: Appraisal and reappraisal of cardiac therapy. Am Heart J 1976; 91 (4): 527-534.

122. Patton MQ. Qualitative evaluation methods. Beverly Hill Lodon: Sage; 1980.

123. Pavlik VN, Hyman DJ, valbona C, Toronjo C, Louis K. Hypertension awareness and control in a inner-city african-American sample. J Hum Hypertens 1997; 11(5): $277-83$.

124. Piccini RX, Victoria CG. Hipertensão arterial em área urbana no sul do Brasil: prevalência e fatores de risco. Rev Saúde Pública 1994; 28(4): 261-7.

125. Pickering SG. Hypertension, Pathophysiology, Diagnoses and Management. Vol.1 New York : Raven Press JH Laragh and BM Brenner; 1990.

126. Possas Cristina. Epidemiologia e Sociedade - Heterogeneidade estrutural e saúde no Brasil. São Paulo: HUCITEC; 1989. p 44- 49.

127. Puras A, Sanchis C, Artigão LM, Division JÁ. Prevalence, awareness, treatment and control of hypertension in a Spanish population. European J Epidemiology 1998;14:31 - 36 . 
128. Queiroz MS, Canesqui AM. Famílias trabalhadoras e representações sobre saúde, doença e aspectos institucionais da medicina "oficial" e "popular". Cadernos de Pesquisa 1989; $n^{\circ}$ 7. UNICAMP.

129. Queiroz MS, Canesqui AM. Representações sobre saúde e doença. Agentes de cura e pacientes no contexto do SUDS. Campinas: UNICAMP; 1991.

130. Rachid J, Lima MP, Rachid MBF. Rastreamento da hipertensão arterial sistêmica na infância. J Bras Med 1996; 70 (3): 16, 19- 22.

131. Rego RA, Berardo FAN, Rodrigues SSR, Oliveira ZMA, Oliveira MB, Vasconcelos C, Aventurato LVO, Monacau JEC, Ramos LR. Fatores de risco para doenças crônicas não transmissíveis: inquérito domiciliar no município de São Paulo, SP (Brasil). Metodologia e resultados preliminares. Rev Saúde Pública 1990; 24 (4): 277-85.

132. Ribeiro MBD, Ribeiro AB, Stabile Neto $C$, Chaves $C C$, Kater $C E$, Lunes M, Saragoça MAS, Zanella MT, Anção MS, Marson O, Kohlmann O, Franco RJS, Nunes SF, Ramos OL. Hypertension and economic activities in São Paulo, Brazil. Hypertension 1981; 3(Supl II): 233- 237.

133. Roberts $\mathrm{J}$ e Rowland $\mathrm{M}$. Hypertension in adults $25-74$ of age. United States, 1971 - 1975. Data from the national Health Survey. DHHS Publication (PHS) 1981; $\mathrm{n}^{\circ} 221$ (séries 11): 1-38 11.

134. Sanson-Fischer PW, Clover K. Compliance in the treatment of hypertension. A need for action. Am J Hypertens 1995 ; 8(10PTs): 82S$88 \mathrm{~s}$.

135. Simonatto DMM, Dias MD, Machado RL, Abensur H, Cruz J. Hipertensão Arterial em escolares da grande São Paulo. AMB 1991; 37 (3): $109-14$

136. Siqueira-Batista $R$, Siqueira-Batista $R$, Batista $O L$, quintas $E M$, Fernandes RS, Chiga ALV. Estudo epidemiológico da hipertensão arterial e dos fatores de risco cardiovascular em Bangú, Rio de janeiro, Brasil. RBM 1994; 51(4): 345 - 52.

137. Sontag S. A doença como metáfora. Rio de Janeiro: Edições Graal, 1984. 
138. Sousa All, Jardim PCBV, Monego ET. Uma experiência multiprofissional na abordagem ao paciente hipertenso. Arq Bras Cardiol 1992; 1 (59): $31-5$.

139. Stamler J. The INTERSALT Study: background, methods, findings and implications. Am J Clin Nutr 1997; 65 (Supl. 3): 626 - 642.

140. Stamler R, Stamler J, Grimm R, Dyer A, Gosch FC, Berman R, Elmer P, Fischman J, Heel NV, Civinelli J, Hoesema R. Nonpharmacological control of Hypertension. Prev Med 1985; 14: 336 - 345.

141. StatSoft, Inc. Statistica for windows [Computer program manual]. Tulsa, 1998.

142. Suarez AR Epidemiologia de la hipertensión arterial. Salud Uninorte, Barranquilla 1985 , 2(2): 95-102.

143. Suarez MA. Utilização dos serviços de saúde materno-infantil na região sudoeste da Grande São Paulo - SP 1989 - 90. São Paulo; 1996. [Dissertação de Mestrado - Faculdade de Saúde Pública da USP]

144. Syndenstricker E. A study of illnes in a general population group. Pub Health Report 1925;40: $279-291$.

145. Tao S, Wu X, Duan X, Fang W, Hao J, Fan D, Wang W, Li Y. Hypertension prevalence and status of awareness, treatment and control in China. Chin Med J England 1995; 108(7): 483 - 9.

146. Tormo MJ, Navarro C, Chirlaque MD, Perez-Flores D. Prevalence and control of arterial hypertension in the south-east of Spain: a radical but still insufficient improvement. Eur J Epidemiol 1997,13 (3): 301 - 8.

147. Vaitsman J. Saúde, Cultura e Necessidades. In: Fleury S. organizadora. Saúde Coletiva ? Questionando a onipotência do Social. Rio de Janeiro: Relume - Dumará; 1992. p.157 - 173.

148. Valles M, Mate G, Bronsoms J, Campins M, Rosello J, Torguet $P$, Mauri JM. Prevalence of arterial hypertension and other cardiovascular rixk factors among hospital workers. Med Clin Barc 1997; 108 (16): 604 7. 
149. Vargas CM, Burt VL, Gillum RF, Pamuk ER. Validity of self-reported Hypertension in the national Health and Nutrition Examination Survey III, 1988 - 1991. Preventive Medicine 1997; 26: 678 - 685.

150. Whelton PK. Epidemiology of Hypertension. The Lancet 1994; 344 : 101-106.

151. World Health Organization. Experts Commmittee on Arterial Hypertension. Report. Geneva; 1978. (WHO - Tecnical Report Series, 628). Disponibilidade em www. who.gov

152. World Health Organization. Experts Commmittee on Arterial Hypertension. Report. Geneva; 1997. (WHO - Tecnical Report).

Disponibilidade em wuw. who.gov

153. World Health Organization. The world Health Organization MONICA Project. (MONItoring trends and determinants in CArdiovascular disease): a major international collaboration. J Clin Epidemiol 1988; 128 : $105-14$.

154. World Health Organization. International Society of Hypertension Guidelines for the Management of Hypertension. J Hypertension 1999; 17:151 - 183. (WHO - Guidelines 151).

155. Zweifler AJ, Kaunisto $\mathrm{Ca}$. Education of the hypertensive patient: the Ann Arbor approach. J Hypertension 1989; 7(suppl 3): S89-S91.

156. Interamerican Association Socity of Hypertension. Muita Hipertensão, pouco diagnóstico. Updating 1996; 1 (1): 2 -3. 
ANEXO 


\section{UNIVERSIDADE DE SĀO PAULO SECRETARIA DE EST. DA SAUUDE}

2000008

(n)

\section{PROJETO MORBIDADE}

CONJUNTO A

BLOCO 1

RELAÇAOO DOS MORADORES DOS DOMICILIOS SORTEADOS

Nome do entrevistador Ne

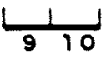

RESULTADO DAS VISITAS

1 a $\quad 2 \stackrel{a}{a}$

1. $\bigcirc \bigcirc$ kealizada em ... $\ldots 1 \ldots 1 \ldots$

2. $\bigcirc \bigcirc$ Recusa

3. $\bigcirc \bigcirc$ Domicilio de uso ocasional

4. $\bigcirc \bigcirc$ Domicilio vago

5. $\bigcirc \bigcirc$ Domicilio techado

$6 . \bigcirc$ prédio de uso comercial

7. $\bigcirc \bigcirc$ Não pertence à população er estudo

8. $\bigcirc \bigcirc$ outros. Especificar

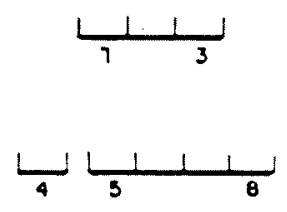

1. Trpo de domicilio:

1. particular

2. coletivo

2. Melhoramento público:
1. calfamento na rua
Oesr Onic
2. 1luminaçòo elétraca
Osin $\bigcirc$ nào 
4. Quadro samiliart jdentifjque os moradores do domzejlio por tamilia, em eguida arrole os membros du cada lamilia do equinte manejrat primed ro o chefe, depols os homens mas velhos sequidos dos mass novos, em seguida as mulheres na mesme ordem de jade.

Assinale com un circulo o n? correspondente a cada chefe de lamiliat

\begin{tabular}{|c|c|c|c|c|}
\hline $\begin{array}{c}\text { No } \\
\text { Ordem }\end{array}$ & NE & Nome & Sexo & $\begin{array}{l}\text { Idade ou data } \\
\text { de riase imento } \\
\text { lulemo andver } \\
\text { sariol }\end{array}$ \\
\hline & 2 & & & \\
\hline & 2 & & & ' \\
\hline & 3 & & & \\
\hline & 4 & & & \\
\hline & 5 & & & \\
\hline & 6 & & & \\
\hline & 7 & & & \\
\hline & 8 & & & \\
\hline & 9 & & & \\
\hline & 10 & & & \\
\hline & 12 & & & \\
\hline & 12 & & & \\
\hline & 13 & & & \\
\hline & 24 & & & \\
\hline & 25 & & & \\
\hline & 16 & & & \\
\hline & 27 & & & \\
\hline & 18 & & & \\
\hline & 19 & & & \\
\hline & 20 & & & \\
\hline
\end{tabular}

觌. VERIFIQUE:

- SE OISI CHEFEISI DE FALILIA ESTRIXOO DEVIDANENTE aSSTNAGADOISI.

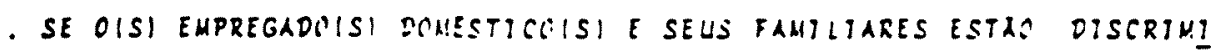
NADOS ICONDIGAO NO DOMTCIIIII.

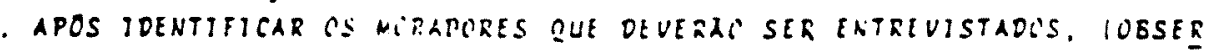

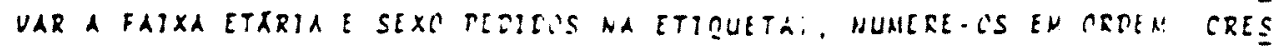

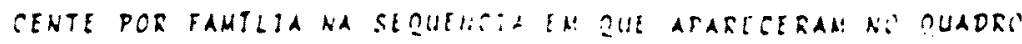




\section{UNIVERSIDADE DE SAO PAULO SECRETARIA DE EST. DA SAUUDE}

0000000 $\therefore 0080 \%$

\section{PROJETO MORBIDADE}

CONJUNTO B

BLOCO 2

FOLHA DE CONTROLE

Mundeiplo

No Quest

No Donste.

Setor

Quarteirão

Estrato

Pous

No

Apto

Ba1rro

Nome do Entrevistado

No Ordem

sexo $\bigcirc$ masc. Drem. do waseimento: $\bigcirc$ rata..........

Nome do Entrevistador

NP

RESUITADO DAS VISITAS

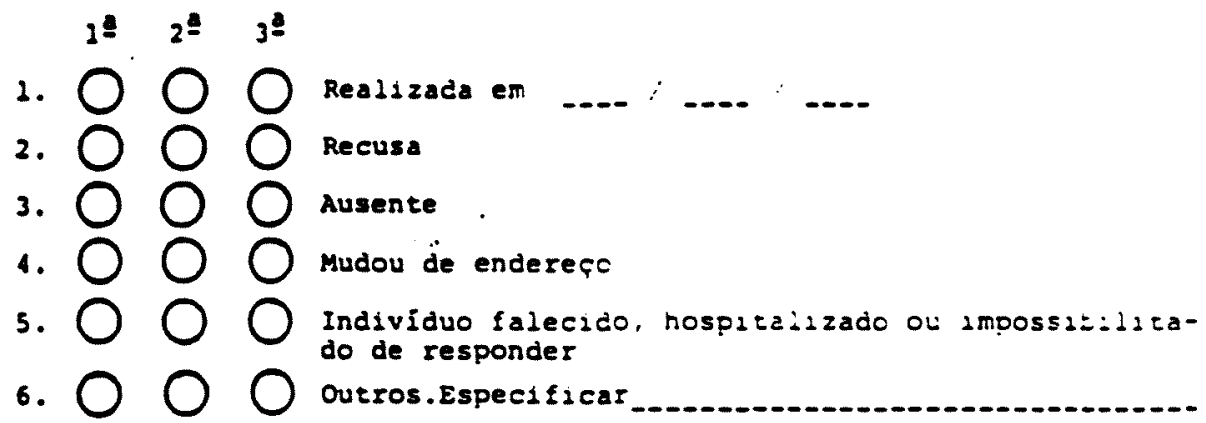

085.

2829

$\frac{1}{3031}$

USO EXCLUSIUO dA COORDENAÇKO

CODIPICAclo

Evisxo 
BLOCO 3

MORBIDADE - PROBLEMAS NOS ULTIMOS 15 DIAS

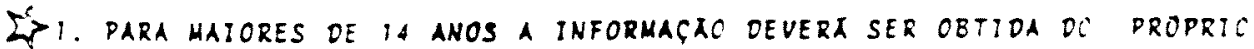
:NOIVIOUO.

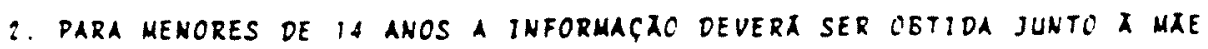
S!! RESPONSAUEL.

×. O Sr(a) teve un ou mals problemas de saúde nos ujtimos is dias?

1. nāo... (passe pare a questāo 3 )

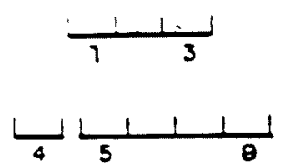

2. 10

9. NS/NR

2. Ousil(15) fol (Iam)?

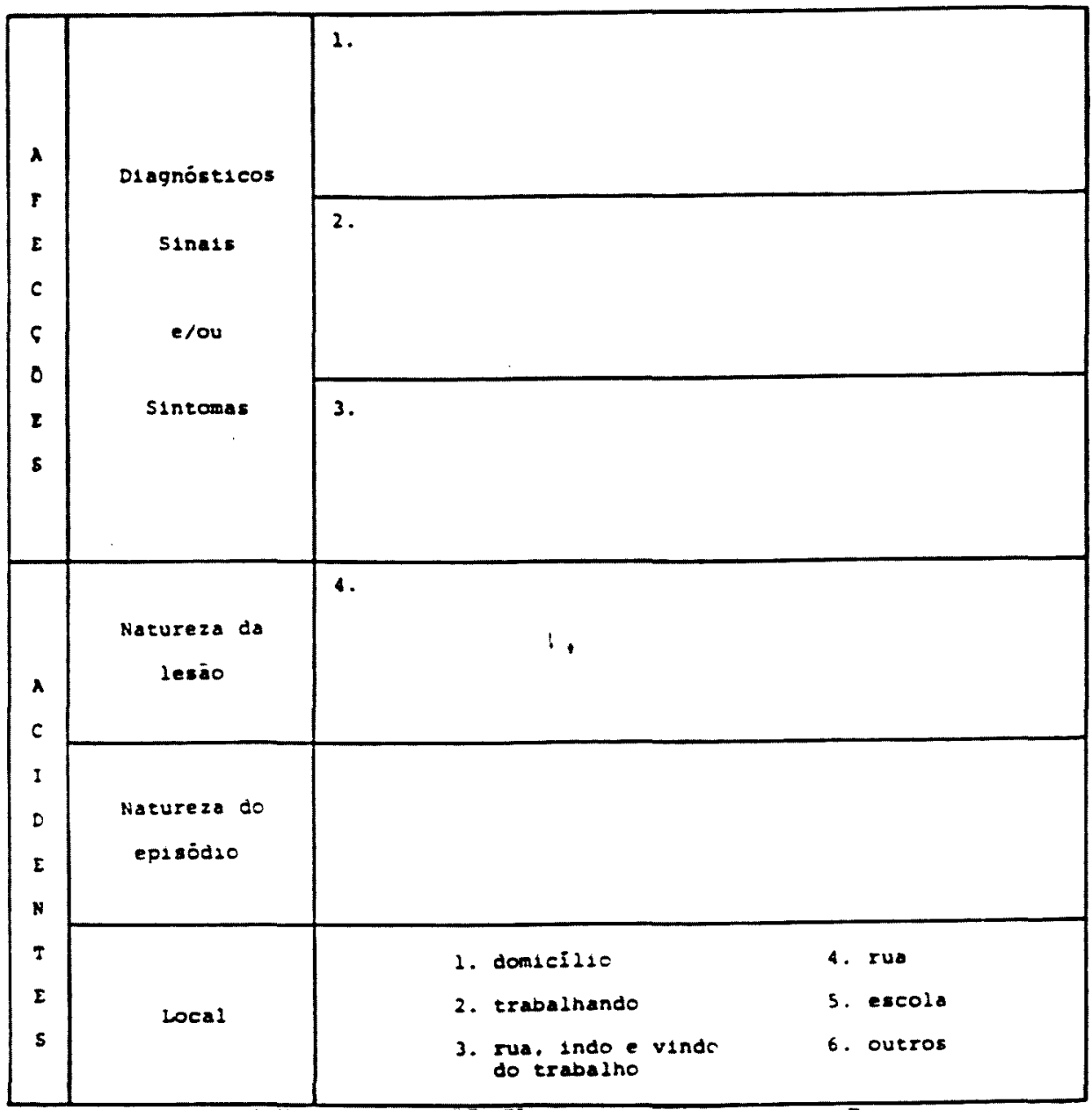

- escreve exatamente come a pessoa relatou q quando hónven mais de um probleme anozer os 3 primeiros.

3. E problemas de nervos o $\mathrm{Sr}$ (a) teve?

1. nāo. - Iveja inotrucōeol

2. sin. Especificar:

\section{NS/NR}

\section{INTRUCOES:}

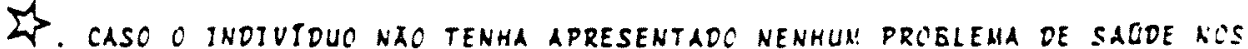
OLTIMOS IS DIAS, ENCERRE O BLCCC E PASSE PARA O CCNJUNTC D.

- Caso o indiviouo tenha apresentado algun problema de sacoe ncs ulti MOS 15 DIAS, PASSE A REGISTRA-LOS NO CONJUNTC $C$. 
Municipio No Domic.

Entrevistado NP Ordem

BLOCO 3.01:3.02:3.03:3.04:3.05

PROBLEMAS E PROCURAS

Problema no

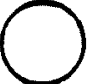

4. Ouando começou este problema?

dias meses anos

9. NS NR

5. Por que o Sr(a) acha que este problema aparecau?

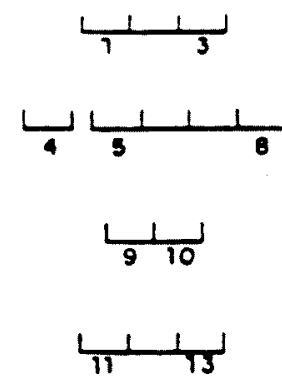

9. NS/NR

4 6. Este problema de saúde $11 m i t o u$ as suas atividades habituals?

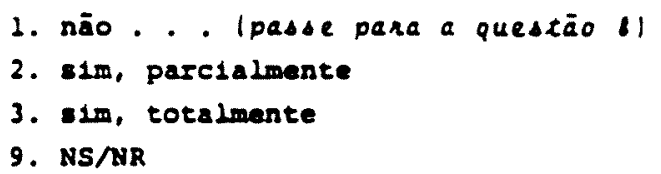

7. Este problema lmpediu o Sr(a) de 15 à escola ou ao trabalho?
0 . não se apllea
1. nāo
2. 1 10
9. NS/NR

8. O Sr(a) procurou algupa ajuda ou conversou com alguém para resolver este problem de saüde nestes ültimos 15 dias?

1. não. - Ipasse para a questāo 33 - bloco 3.11 a 3.15 I

2. $12 \mathrm{~m}$

9. ouanto tempo demorou entre o $S r(a)$ perceber o problema e decidir pro curar ajuda?

dias ou horas

9. NS/NR

10. Quem o Sr(a) procurou? lquando de regerin a senvico indagan qual pro bissional tencionava encontrarl.

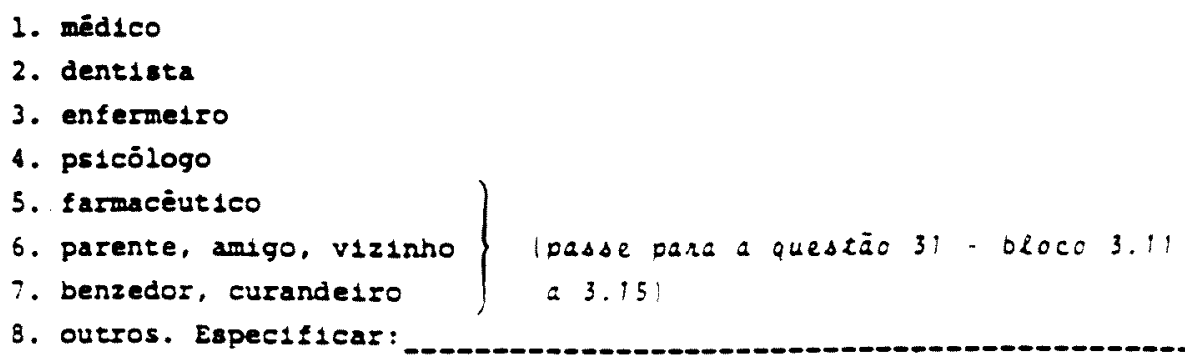

2. dentista

3. enfermetro

4. psicōlogo

5. farmacèut ico

6. parente, arigo, vizinho $\{$ |passe pare a questāo 31 - bloco 3.11

7 . benzedor, curandelro 23.15

8. outros. Especiflear: 
A. Cade o $S x(i)$ pr urou essa ajuda?

ipo de servigo.

Nowe.

Endereço $R$.

Ba1r50 Mun1eiplo

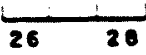

12 Como o srlal chegou a esse cervico?

1 sasaupão próprla

4. pé

3. \& arsbus

4. $t$ de 1 insmut

5. cax:

6. Mibulánela

7. outros

9. us/NR

?33. O Sr(a) to1 atendido nesse institutpio?

2. nōo. . |paste paka a quescão 32 . bloce 3.11 a 3.15 |

2. 1 .

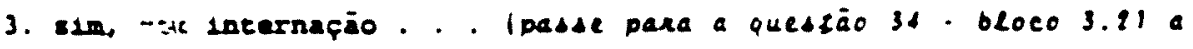
3. 251

4. imnāo, fol encaminhado para:

rıpo de serviço

Nome

enderepo $R$. MP.

Besrro Mun1elp1o.

-e bos internado, paste para a questão 34 . bloco 3.21 a 3. 25; be não concinue neste bloco.

14. O que o $s r(a)$ achou do servipo?

lleca as alternatrvas de questāo pare o entrivestado

1. musto bom

2. bow

3. La1s ou medos

4. ruim

9. NSNR

Por que?

15. O qu o $5 r(a)$ achou do atendimento do profiasional?

Iteia as alternativas da questäo pare o entrevistado|
1. mesto bon
2. $\mathrm{bec}$
3. ante ov anos
4. 200
9. $48 / 2 \mathrm{a}$
par cre?

16. O Sr (a) pagou por esee atandtmento?

․ Dão. - Ipasse para a questão 181

2. sim, parcialmente

3. 15m, integralmente. . Liga para a questāo 17 é pule a 181

S. HSNRR . . (passe pare a queszāo 19 )

17. Gannto o $5 x(a)$ pagou?

xos 
\$ 18. Por que o $S r$ (a) näo pagou ou pagou parcialmence?

2. Seguro saūde privado

2. Convènso empreso

3. Sindicato, associaçöes de caregorias

4. INAMPS, Prefeitura, Estado, Furrural

5. outros. Espec1flcar

9. NS/AR

(pode haver mais de una resposta)

19. To1 receltado algum medicamento?

1. nāo. - Ipasbe para a questāo 21 - bloco 3.11 a 3.131

2. 810

9. Ns/Mr. - (passe para a questão 21 - bloco 3.11 a 3.15 )

20. Camo fol obt1do esae medicamento?

1. gratulto, no próprio serviço

2. Fratu1to, em outra inetitulcāo. . Municlpio

3. comprou. NCs

4. nio obteve. Especificar o motivo:

5. outros. Especificar:

9. NS/NR

(pode haver mais de ume resposta)

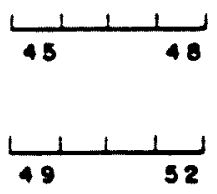

\section{BLOCO 3.11: 3.12: 3.13: 3.14: 3.15}

\section{PROBLEMAS TRATAMENTO}

Problema no

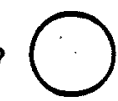

21. Pol Indicado algum outro t1po de tratamento?

1. nāo: - (passe para a questāo 26)

2. sim. Especte1car

9. nShar - . (passe para a questāo 26)

22. Onde fol real1zado esse tratamento?

1. no próprio serviço

2. outro local. Especificar

İpo de Serviço

Nome

Endereço $R$. No

Batrro Munieipio

23. O Sr(a) pagou por esse tratamento recebido?

1. não. - (passe para questāo 25 )

2. sim, parcialmente

3. sim, integralmente. . (siga para a questāo 24 e pule a 25 )

9. HShIR. . Ipasde para a questāo 26 )

24. Quanto pagou por esse tratamento?

Ness

9. NSNRR

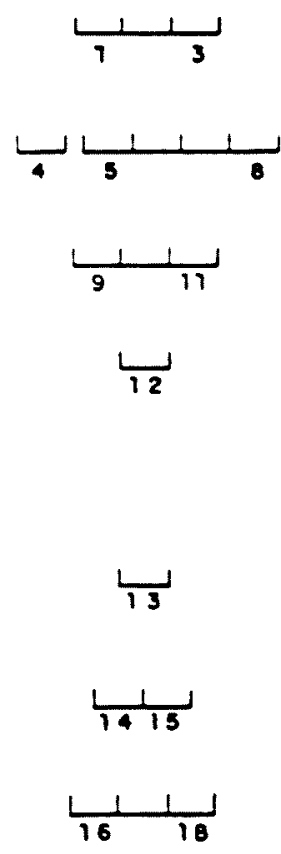

19 
E. Po: que o SFla, nao pagou ou pagou parciajmule:

i. seguro saüde privado

2. convénto empresa

3. Sindiesto, associaçöes de categoria

4. INMMPS, Prefeltura, Estado, Furrural

5. outros. Espec1ficar

9. NS/NR

(pode haver mais de una respobta)

26. Fol pedido algum exame?

1. nēo. - (passe para a questāo 31 )

2. 810

9. NShR . . Ipasse para a questāo 31 )

27. Prencha o quadro aba1xo em correspondêncla cos os exames pedidos:

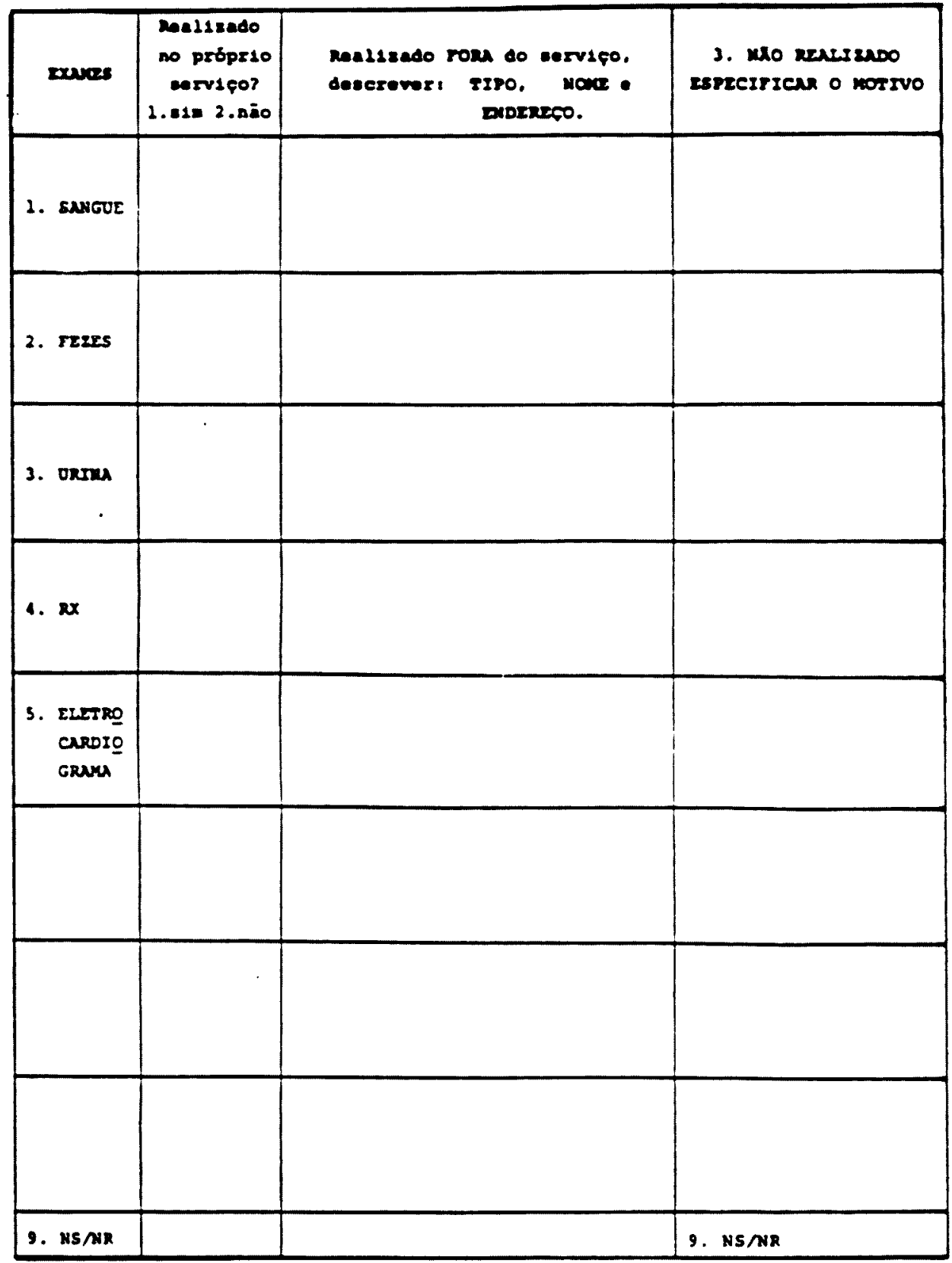

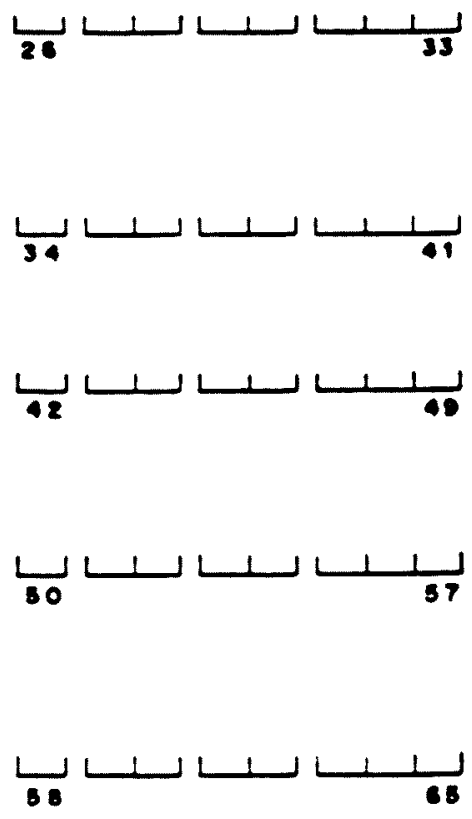

28. O Br(a) pagou por esse(s) exame (s)?

1. año. . (passe pare a questão 30 )

2. In, parcialmente

3.'IIm, Integralmente. . Isiga para a quedtāo 29 e pule a 30 )

9. ushaR . . Ipasse pare a questäo 3 )

29. ganto pagou?

nos

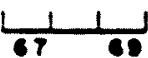

9. $18 / \mathrm{NR}$ 
30. Por que o $S r(a)$ não pagou ou pagou parcialmente?

1. Seguro a aüde privado

2. Convênio empresa

3. Sindicato, astociaçöes de categorias

4. INAMPS, Prefeitura, Estado, Funrural

5. outros. Especiflcar

9. NS/NR

(pode haven nais de uma respostal

31. Esse problema de saūde fol resolvido?
1. sim. Ouanto tempo ele durou?
lencerre o bloco

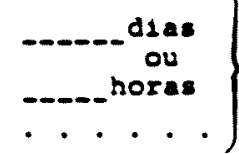 leia a chamada do binall
2. está en tratamento . . . . . . . . . . .
3. sim, parcialmente
4. nāo, fol encaminhado para especial1sta
I pegue outro conjunto $c$. preencha a identubcacá.
5. nāo inicie pela questáo 10 as

32. o Sr(a) procurou outro t1po de ajuda?

1. nāo

2. sin. - Ipegue ousro conjunto $C$, preencha a identificacäo e ine. cie pela questäo 101

33. Cano o SI(a) resolveu este problema?
1. continua com o problema
2: cura espontanea
3. auto medicaçāo
4. Eratamento caseiro
5. outros. Especificar

27. volte para O bloco 3. RUESTTO z E z E verifique se todos os proble

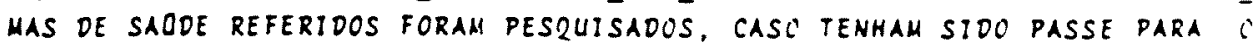
CONJUNTO $\stackrel{0}{0}$

BLOCO 3.21: 3.22: 3.23; 3.24; 3.25 HOSPITALIZAÇÃO NOS ÚLTIMOS 15 DIAS

Problema no

* 34. Quantas noites o $S r(a)$ permaneceu incernado? horas ou noites

9. NS/NR

35. O que o $S r(a)$ achou do serviço?

(Leia as alternativas da questão para o entrevistado)

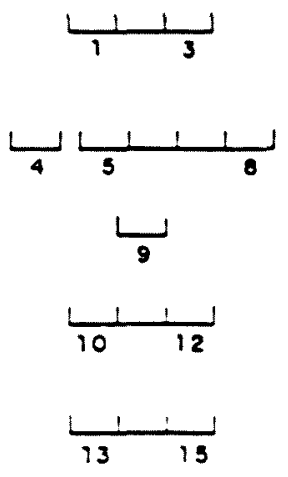

1. mutto bor

2. bar

3. mass ou menos

4. IU⿴囗十

9. NS/NR 
36. O que o $s r(a)$ achou do atendimento mēdico?

lleia as alzrnnazivas da questäo para o entrevesiadol

1. mito bom

2. bom

3. mass ou menos

4. 5 rus

9. NSNR

Por que?

37. Cono o Sr(a) chegou a esee serviço?
1. condução própr 1 a
2. p
3. 1 ondbus
4. + de 1 ónlbua
5. taxt
6. ambulincia
7. outros
9. NS/NR

38. C Sr (a) pagou por esea internação?
1. não. . (pasbe para a questāo 40)
2. eim, pareialmente
3. eim, integralmente. - loiga para a questāo 39 e pule a 401
9. NSARR . . Ipaste para a questäo il)

39. Ounto o SI (a) pagou por esea internaçāo?

scas

9. NSNR

10. Por que o Sr(a) não pagou ou pagou parclalmente?

1. Seguro saúde privado

2. Convènto empresa

3. Sindlcato, associaçōes de categoorias

4. INMups, Prefestura, Estado, Funrural

5. oueros. Especificar.

9. NSANR

(pode haver mais de una resposia)

11. Este fol a unica internaçoo ocorrida nos íltimos is dias por causa deste problema?

1. nāo

2. sis.. (encerre o blocol

42. Onde fol a segunda internagão?

ripo de serviço.

Nome:

Endereço $R$.

Basro Munteipto

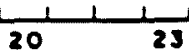


Municipio NQ Domic.

Entrevistado No Ordem

CONJUNTO D

BLOCO 4

1. não... |encerre o blocol

2 . sim. Quantas vezes? vezes

44. Oual fol o motivo?
1. atestado
2. pré-natal
3. puericultura
4. check-up
5. vacinação
6. outros . . Especificar

(pode haver mais de uma resposta)

45. Qual fol o serviço?

Motivo no

Tipo de serviço

Nome

Endereço $R$. NP

Bairro Municipio

43. Nesses ültimos 15 dias o(a) $\mathrm{Sr}$ (a) procurou algum serviço de saúde por motivos que nāo fosse doença?

saúde

\section{OUTROS MOTIVOS PARA USO DE SERVIÇO NOS ULLTIMOS 15 DIAS}

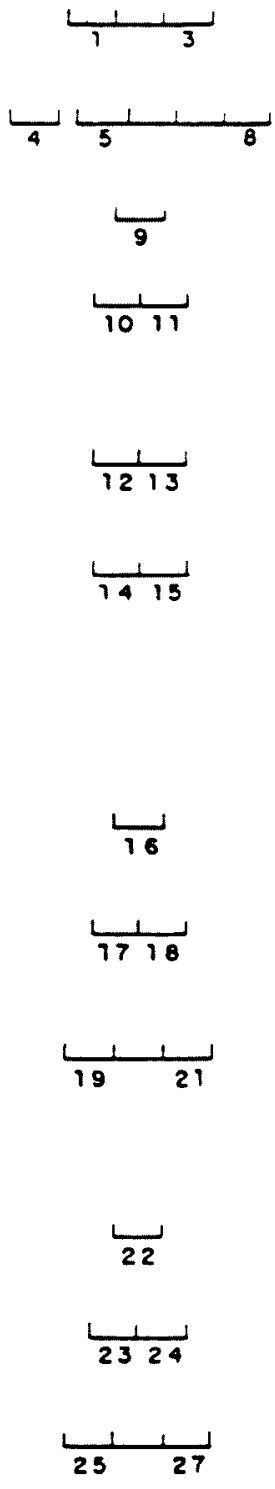

- Se houver mais de um servifo, anotar o Nạ correspondente do motivo para cada um.

Mottvo ne

İpo de serviço

Nome

Endereco R.

- No

Municipio

\section{BLOCO 5}

CONSUMO DE MEDICAMENTOS NOS ÚLTIMOS 3 DIAS

46. O SI(a) consumiu algum medicamento nos ültimos 3 dias?

2. não... (encerre o bloco)

2. Sim. Qual(is)?. . (preencie o quadro seguanie

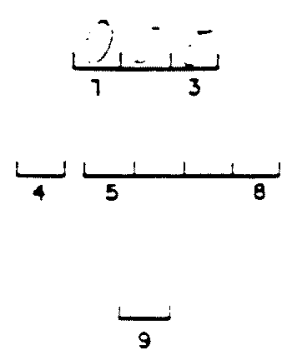




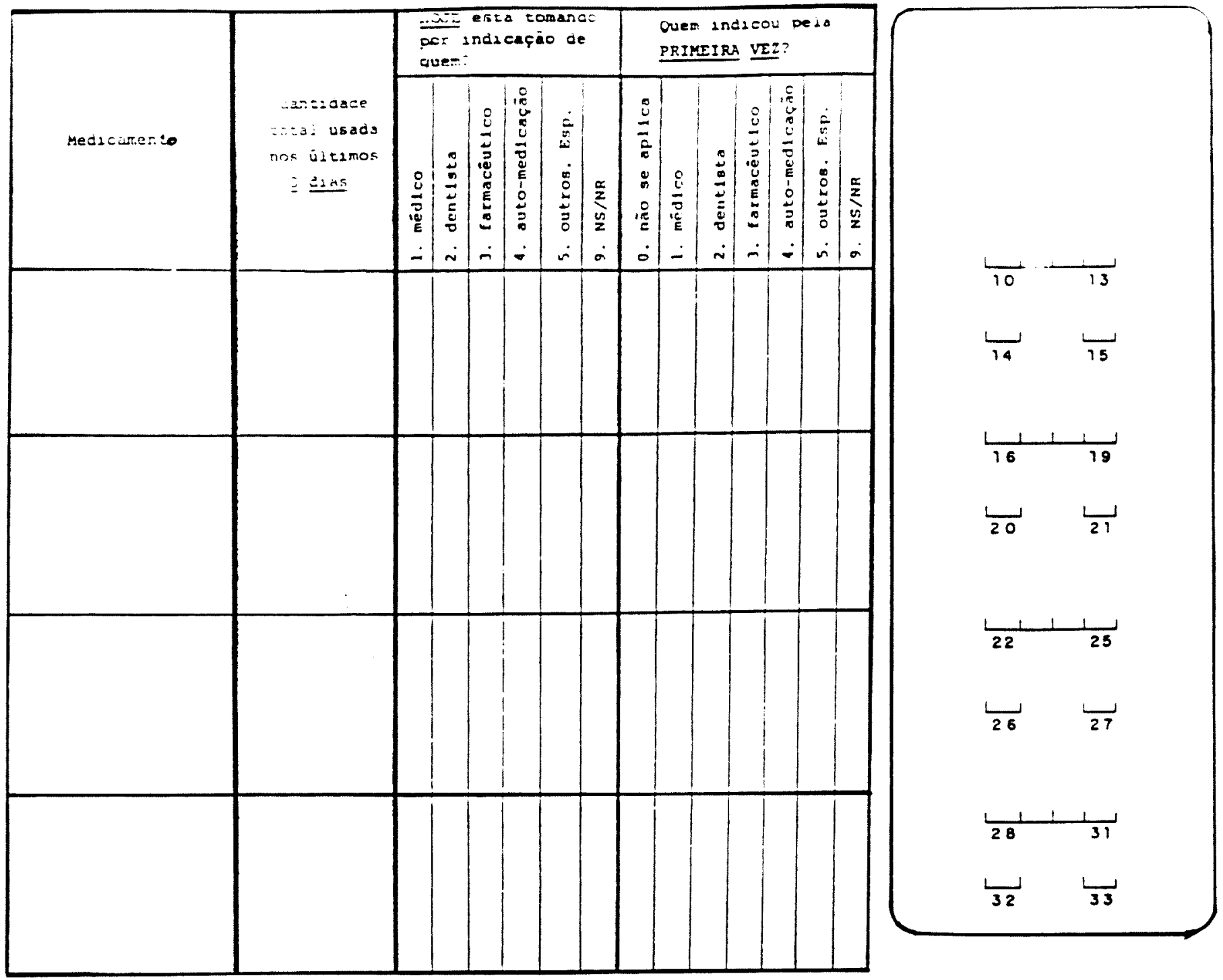

BLOCO 6

HOSPITALIZACAAO NOS ÚLTIMOS 12 MESES

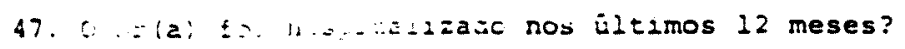

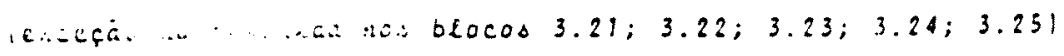

2. não.. i irncensc o bloco)

2. sim. Quartzs vezes?

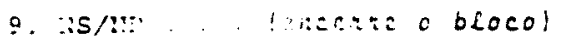

48. Quanto =ting: : j:ia) es:eve internado(a)?
1. na Liternagăo mais zecente
noites
2. Ma incersujio ancezicr
nottes
3. na internacāo anterior
noites
4. ha mec:rajac areeric=
noltes

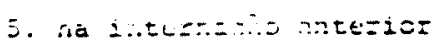
noites

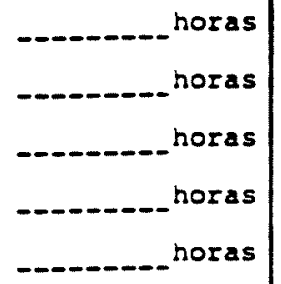
9. NS/lit.
$\because \because$
(2) 3
(4) 5

49. Quendo fo: a insezajạàc mals recente?

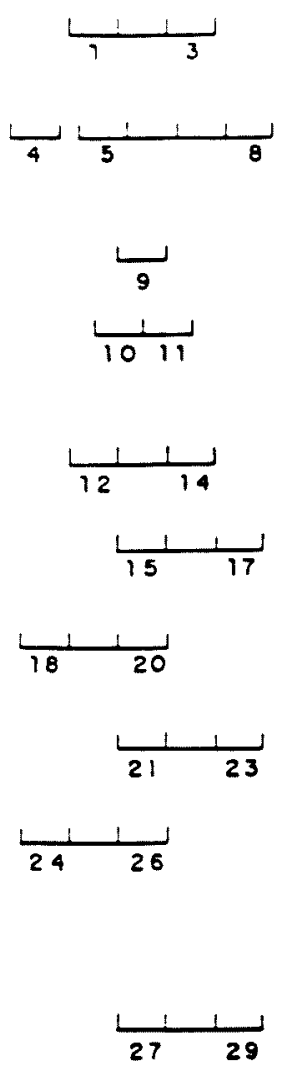

Hä -2..'

9. NSANE 
50. qual é o nome e endereço do hospltal?

Nome

Enderefo $R$.

Munderpio

Ba1rIo

\section{NS/NR}

51. Oual foi a causa da internaçäo mais recente?

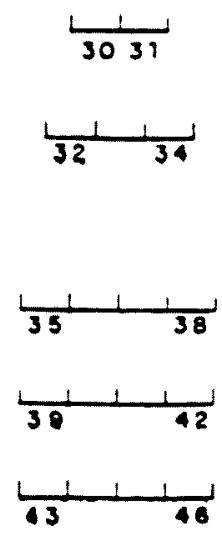

52. O que o $5 r$ (a) achou do serviço?

lleia as alternativas da questäo para o entrevistadol

1. musto bom

2. bom

3. ma1s ou menos

4. ruim

9. NS/NR

por que?

53. O que $\circ \mathrm{SI}(\mathrm{a})$ achou do atendimento médico?

lleia as alternativas da questäo para o entrevistadol

1. muito bom

2. bam

3. ma1s ou menos

4. Iuim

9. NS/NR

Por que?

54. Como o Sr(a) chegou a esse servico?

1. condução própria

2. a pé

3. 1 ōn1bus

4. + de 1 ônibus

5. taxi

6. ambulancia

7. outros

9. NS/MR

55. Camo o Sr(a) fol admitido(a) no hospital?

1 por conta própria

2. por encaminhamento. Especificar o serviço que encaninhou. Tıpo de serviço

Endereço $R$. No Batrro Munieipio

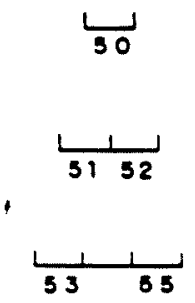

9. NS/NR

56. Ouanto tempo o Sr(a) demorou para conseguir a internaçāo?

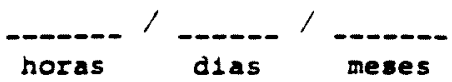

9. NS/NR 
57. O Sr(a) pagou por essa internaçäo?

1. não. . Ipassc para a questāo 59 |

2. sim, parcialmente

3. sim, integralmente. . isiga para a questär st c cncisic c bls col

9. NS/NR . Ipasse para a questác 60 - bloci:

58. Guanto pagou por essa internação?

NCzs

9. NS/NR

59. Por que o SI (a) nāo pagou ou pagou parcialmente?

1. Seguro saúde privado

2. Convènio empresa

3. Sindicato, associaçōes de categorias

4. INAMPS, Prefeitura, Estado, Funrural

5. outros. Espezificar

9. NS/NR

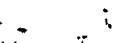

Ipode haver mais de uma respesial.:

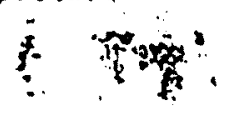
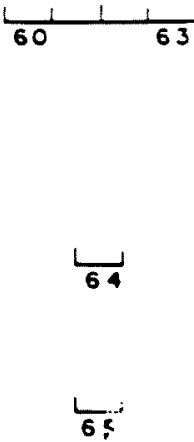

BLOCO 7

\section{PROBLEMAS CRONNICOS E DEFICIENCIA FISICA}

60. O $5 r(a)$ tem algum destes problemas?

leeca as altcrnatevas da quesiāc para o cnerelistade

1. cegueira

2. dificuldade de enxergar

3. surdez

4. surdo-mudez

5. parallsia toral ou parcial de membros Especificar

6. perda de membros ou parte deles Especificar

7. กล̃o

9. NS/NR

Ipode haver mais de uma resposta!

61. Com exceção dos referidos acima, O $\mathrm{Sr}(a)$ tem alguma outra defielén cia fisica?

1. näo. - (caso has questöes $60 \mathrm{c} 6$ ) a respesta scja när. pasdc pana a questäo 661

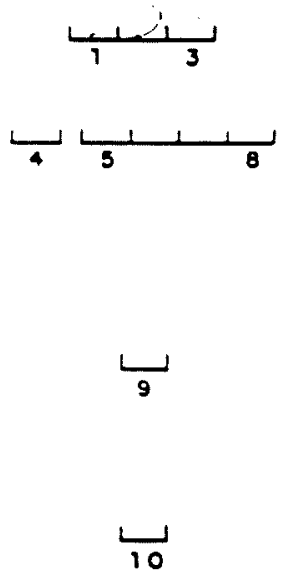

2. sim. Especificar

62. O sr(a) usa algum tipo de aparelho corretivo por causa desse(s) pro blema(s). inclusive óculos?

1. กล̄o

2. sim, óculos e/ou lentes de contato

3. sim, outros. Especificar 
63. C $S=(a)$ recebe alguma assistèncla espect 1 lca em decorrèncla desse(s) E=oblema (s)?

1. 510

2. não precisa, não acha necessário

3. nāo sabe quem procurar ou onde if

4. não tem recursos (convènios, dinheiro, etc...) (passe pana a

5. sāo tem tempo

6. não gosta de ir ao médico

7. cutros. Especificar

lpote haver mait do uma respodra)

64. Que tipo de assistêncla recebe?
1. mëdica
2. reabilitaçāo
3. habilitaçāo profissional
4. outros. Especilicar

(pode haver mais de uma resposta)

65. Oual o serviço?

$$
\text { T1po }
$$

Endereço $R$. No

Tipo.

Nome

Endereço $R$. NP

Batrro Municipio

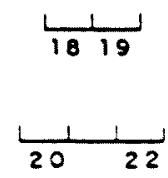

66. O Sr(a) tem algum desses problemas de saüde?

(Leia as alternativas da questāo para o entrevistado)

2. pressāo alta

2. drabetes

3. ataque ou convulsão

4. coração. Especificar

5. doença resplratöria. Especificar

6. problemas dos nervos. Especificar

o. nāo

67. O Sr(a) tem algum outro problema de saúde alēm dos jä citados?
1. nāo
2. sim. Especificar

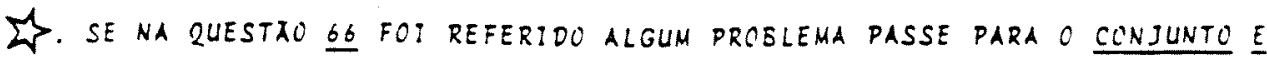
E RESPONDA UM CONJURTO PARA CADA PROBLEMA. CASO TENHA RESPONDIOC QUE NAO SIGA AS INSTRLCOES ABAIXO:

\footnotetext{
pARA CRINCAS MENCRES OE, aNO, PASSE PARA O CONJUNTC

$\therefore$ para indiviouos de? a 19 anOS, passe para C CONJUNTO $g$.

E. FARA iNOIVIDUOS DE 20 anOS OU MATS. PASSE PARA O CONJUNTC F.
}

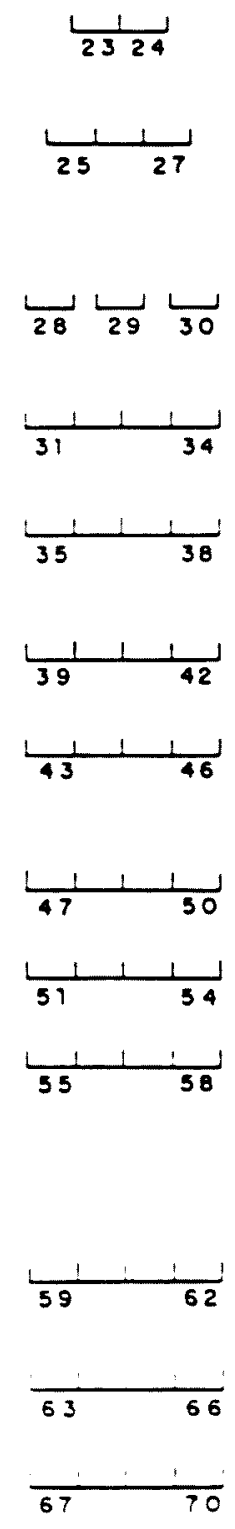


Município N8 Domic.

Entrevistado NP Ordem

CONJUNTO E

BLOCO 7.01; 7.02: 7.03: 7.04: 7.05: 7.06. DOENÇAS CRŌNICAS

Problema no

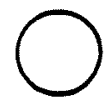

68. Fo1 algum mëd1co quem disse que o $\mathrm{Sr}(\mathrm{a})$ tem essa donģa?

1. มāo

2. $81 \mathrm{~m}$

69. Por que O SI(a) acha que esse problems apareceu?

9. NS/NR

70. O Sr(a) visita o médico ou serviço de saúde perlodicamente por causa deste problema?

1. nāo

2. não, só quando tem problema

3. sid, de rotina. . (pasde para a questão $7 ?$ )

71. Por que nāo val perlodicamente?

1. não acha preciso

2. è musto longe

3. não gosta de 15 ao médico

4. não tem tempo

5. é caro

6. acha que sāo resolve

7. outros. Especillcar

9. NS/NR

(pode haver mais de uma resposta)

72. Qual fol a ültima ver que o Sr(a) consultou um mädico ou visitou um serviço de saúde por causa deste problema?

1. Há

2. nunca - . lencerre o bloco e leia a chamada no binall

9. NS/NR

73. Algua vez the foram receitados medicamentos de rotina para este pro blema?

1. sāo.. (encerre o bloco e leia a chamada no final)

2. $\sin$

9. NS/NR

74. O Sr(a) tomou algum(s) medicamento(s) zegularmente para esse proble ma ros últimos 30 dias?

$\therefore$ nāo. . loasse para a questão ib

2. Sis. . Isiga para a questäo 75 e pule a questäo 76 )

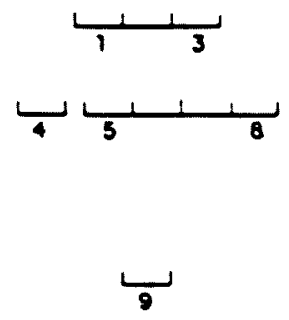




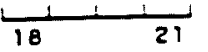

9. NSMR

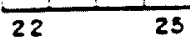

76. Por que o $\mathrm{SI}$ (a) nāo tomou?

1. näo teve sintomas

2. os remédlos eram caros

3. resolveu däo tomar

4. o remēdio nāo estava fazendo efejto

5. teve complicaçōes

6. 0 mádsco suspendeu

7. outros. Espec1E1car

9. XSMR

(pode haver mais de una resposta).

lencerre o bloce e leia a chamada no binal)

77. Camo fol obtido esee madicamento?

1. gratu1to, no próprio serviço

2. gratu1to, em cutra Institulgāo . . Municipio

3. comprov

9. NS/NR

(pode haver mais de una resposta)

73. para crianças henores de 1 ano, passe para i conjunte h.

2. para individuOS de 1 a 19 anOS, PASSE PARA C CONJUNTO G.

3. PARA INDIVIOUOS OE 20 ANOS OU MAIS, PASSE PARA $'$ CONJUNTE E.
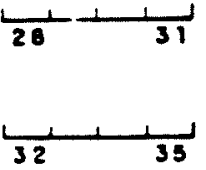


\section{Oula a beblda de sua preferincia?}

lo referir bebida alcoolica, passe para a questão iol

\$ 79 . Entre as bebldas alcobllcas, qual pretere?

1. Especlesear.

2. nunca bebeu beblda alcoóllea lencerse o blocol

3. bebla, mas não bebe há mals de 1 ano

4. beb1a, tendo parado de beber há menos de 1 ano

80. De modo geral as pesuoas o incomodam porque criticam o seu modo de beber?
1. nōo
2. 10
9. NSMR

81. Alguma vez o $S r(a)$ entiu que deveria dininuis a quantidade de bebI da ou parar de beber?
1. não
2. $.1 \mathrm{~m}$
9. NS/NR

82. O Sr (a) costuma beber pela mana para diminulr o nervosismo ou ressa ca?
1. não
2. $1 \mathrm{~m}$
9. NS/NR

83. O Sr(a) Elca chateado(a) ou se sente culpado(a) pela maneira que cos tum beber?

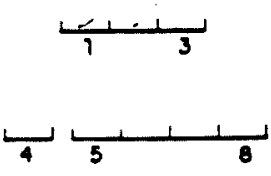
1. ño
2.
9. NS/NR

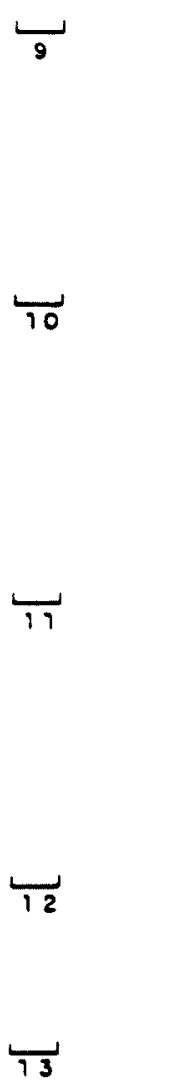




\section{BLOCO 9}

\section{ODONTOLOGIA ISOMENTE PARA MAIORES de, anO;}

84. O Sr(a) consultor algum dentista nos últimos i2 meses?

1. sim, quantas vezes? veres

2. não, não teve problemas

3. não, nào tinha dinheiro

4. não, tem medo

5. não, não tem mass dentes

lencerti, aecos

6. não, asrida é pequeno

7. não, näo acha preciso

6. não, outros. Espectficar

9. NSARR

ipode haic: mass or uma icspcsica

85. Quando foi a ültima consulta?

Ba dias meses

9. NS/NR

86. Oual fol o motivo da consulta?

1. problemas com dentes, gengivas ou próteses

2. exume odontológico periódico ou ilmpeza des dentes

3. atestado odontológico para trabalho

4. outros. Especificar

9. NS/NR

87. Onde O Sr(a) fez essa consulta?

Tlpo de Serviço

Nome No

Endereço $R$.

Balrso Municipio
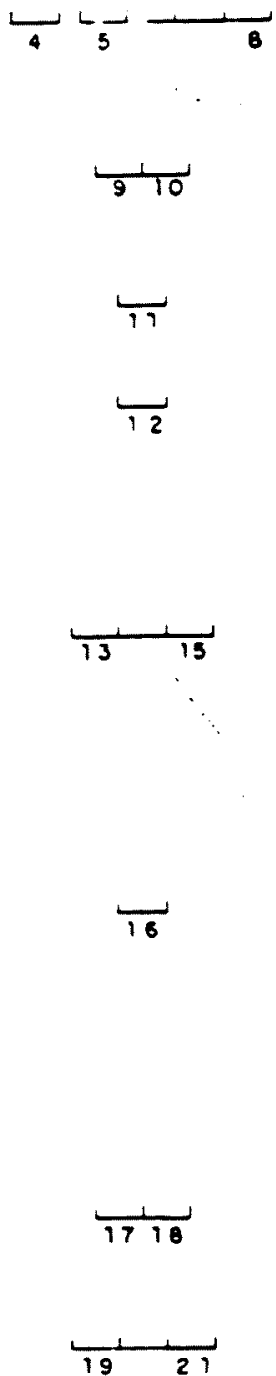

88. O SI (a) pagou por esse tratamento?

1. Däo... (passe para a questāo 90 )

2. sim, parcialmente

3. sim, Integralmente. . (siga para a qucstāo 89 e encerre o bloco)

9. NS/NR. . Ipesse para a questão 91 :

89. Quanto pagou?

Nezs

9. NS/NR 
90. Por que o $\mathrm{Sr}$ (a) nīo pagou ou pagou parcialmente?

1. seguro saúde privado

2. Convinio ampresa

3. S1ndicatos, asuociaçōes de categorias

4. Ixuss, Prefestura, Eatado, Funrusal

5. Servico odontológico escolar

6. outros. Espec1f1car

9. $\mathrm{HBNR}$

lpode haver mais de ume resposta)

I. para criancas nenores oe, ano. passe para o conjunto h.

2. PARA criangas de 1 a 4 anos, 11 meses e 29 dias. passe rara $c$ con. JUNTO 1 .

3. PARA CRIANGAS OE 5 a 6 ANOS VERIFICAR O SEU NG DE ORDEM: SE FOR 1 PASSE PARA O CONJUNTO K; SE FOR DIFERENTE DE 1 ENCERRE O RUESTIONXRIC.

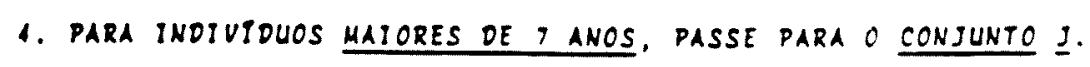


Municipio NQ Danic.

Entrevistado NQ Ordem

Nome da Mãe

CONJUNTO H

BLOCO 10

MATERNO-INFANTIL (SOMENTE PARA CRIANCAS MENORES DE I ANO)

I PARA SER RESPONDIDO SOMENTE PELA MAE DA CRIANÇA

Data do nasermanco do mie:

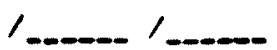

91. Até que ano da escola a Sra. frequantou?

0.1 nunca frequentou e sabe ler e escrover

0.2 nunca frequentou e nāo sabe ler e excrovar

1. - primario ou 18 grau

2. - gilniaso ou 18 grau ano/sárte

3.- colegial ou 28 grau ano/abirle

ano/sērle

3.5 cursos técnlcos de nivel nedio completo

3.6 cursas técnicos de nivel mödlo incompleto

4.0 unsversidade complete

4.1 undversidade incospleta

\$92. A 5ra. fez alguma consulte médica para acompanhar a gravidez do -.$-7$

1. hảo. Por que?

Ipasse para a questäo 961

2. 815

93. Em que mìs de gestação a Sra. tez a primeira consulta mëdica? (em meses gestacionaisl

9. NS/NR

94. Quantas coneultas foram Leltas?
1. apenas 1
2. de 2 a consultas
3. de 5 a 8 consultas
1. 9 ou mals consultas
9. NSNR

95. Onde a (s) consulta (s) fol (ram) feste(s)?

1. Iipo de Serviço

2. Nome

3. Enderofo 2. N9

Bairro Mundelp1o

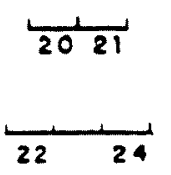

1. Itpo de Serviço

2. Nome

3. Indereço $R$. No

Basrro Munsciplo

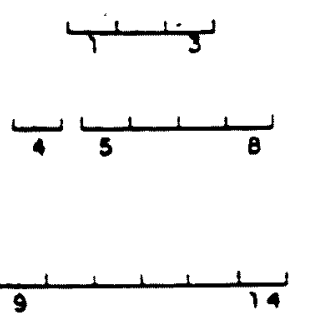

ل15 
96. A $s:$ (a) pagou por essas consuleas?

i. näo

2. 81m, parcialmente

3. Sim, Lntegralmente

9. NSNR

97. Por que a sra. nīo pagou ou pagou parelalmente?

1. Seguro saüde privado

2. Convínio empreas

3. Sind1eato, associaçōes de categorias

4. INAMSS, Prefeltura, Estado, Funrural

5. outros. Especificar

9. HS/RR

(pode haver nais de una resposta)

98. Onde a criança nasceu?

1. dontcl110. . Ipasse para a questāo 104 I

2. hosp1tal. Espec1f1que:

Nome

Tipo de serviço

Endereço R. No Muncipio

3. outros. Espec1f1cax

99. Por que a sra. procurou este hospltal?

9. NS/NR

200. Oual tol o tipo de parto?
1. normal
2. cesárea
3. förceps
9. NS/NR

101. A Sra. pagou por esse parto?

1. año. - (passe para a questä́ 103)

2. im, parcialmante

3. sim, integralmente. . (siga para a questāo 102 e pule a 103 )

9. ushr. . Ipasse para a questāo 104 )

102. Guanto a Sra. pagou por esse parto?

Rezs

9. NS/NR

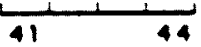

103. Por que o(a) Sr (a) nāo pagou ou pagou parcialmente?

1. Seguro saúde privado

2. Convento empresa

3. Sindscato, assoclaçōes de categorlas

4. InNus, Prefeltura, Estado, Funrural

5. oueros. Especiflear

9. NS/RR

(pode haver mais de una resposta) 
廿 104. A sra. procurou alguma orlentaçdo em serviço de saúde para culdar da crlanca Independentemante dela estar doente?

1. מāo procurou orlentaçāo. Por que?
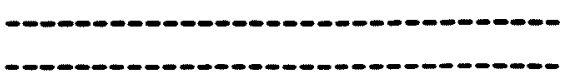

lencerre o bloco

2. 18. Especif1que:

TIpo de Serviço

Nome

Enderę̧o $\mathrm{R}$.

NP

Basro Mun1eIp10

Tipo de serviço

Nowe

Endereco $R$.

Basro Municipto

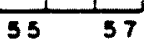

9. NS/NR

105. Qual era a ldade da erlança quando a Sra. procurou essa orlentação? meses

9. NS/HR

206. A Sra. pagou por essas consultas?
2. مח
2. sim, parcialmente
3. sim, integralmente
9. NS/NR

107. Por que a Sra. näo pagou ou pagou parcialmente?
1. Segrizo saüde privado
2. Convinio empresa
3. Sindicato, associaçōes de categorias
4. INAMPS, Prefeltura, Estado, Funrural
5. outros. Espectflcar
9. NS/NR
(pode haver mais de ume resposta)

27. passe para O conjunto 1 . 
Município

No Domic.

Entrevistado

No Ordem

CONJUNTO I

BLOCO 11

IMUNIZAÇĀO (SOMENTE PARA CRIANÇAS MENORES DE 5 ANOS)

DATA DE NASCIMENTO DA CRIANÇA -..- '

VACINACCAO DE ROTINA

\$ para preenchimenti deste iten solictte a caderneta de vacinactí da criança

* 108. Quais as vacinas que $O(a)$

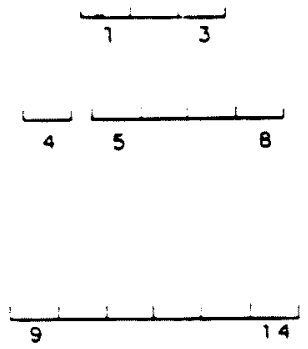

Copie no quadio abaixo as vacinas anotadas a tinie na cadernete de vacinaçä ou proceda segundo as instruçócs do manuai peia as inars maçös veroass.

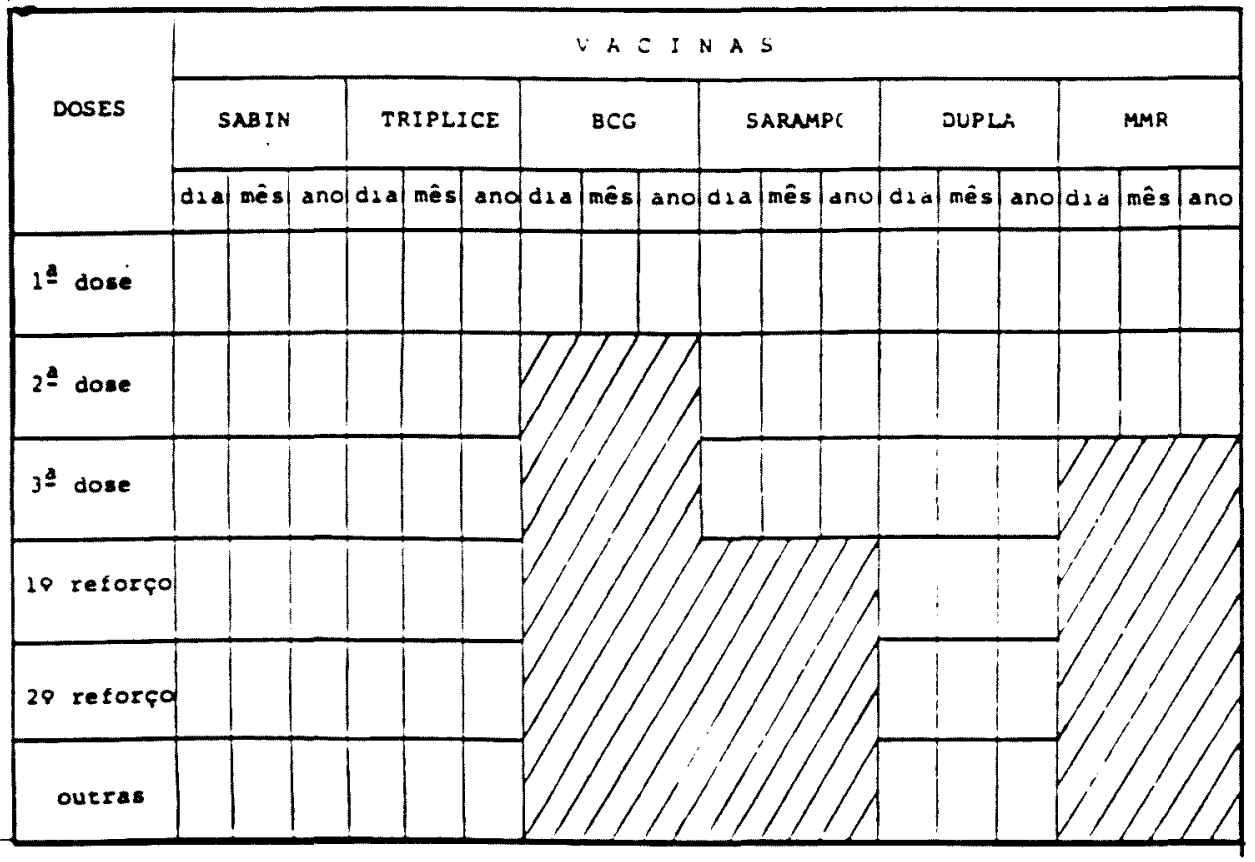

\section{Onde a criança fol vacinada?}

Tipo de Servizo

Nome Código

Endereço R.

Batrro Municipio

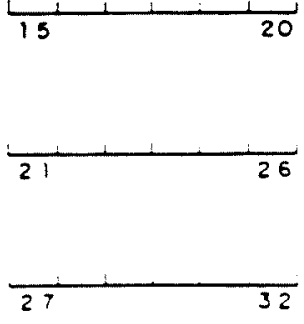

9. NS/NR

Tipo de Serviço

Nome cödigo

Endereço $R$. Munieiple

\section{NS/NR}

Ba: $=0$ 
110. Ut111ze o quadro abalxo quando a crlança tiver mass de una ta de vacinação.

lvide manual do entreviszadorl.

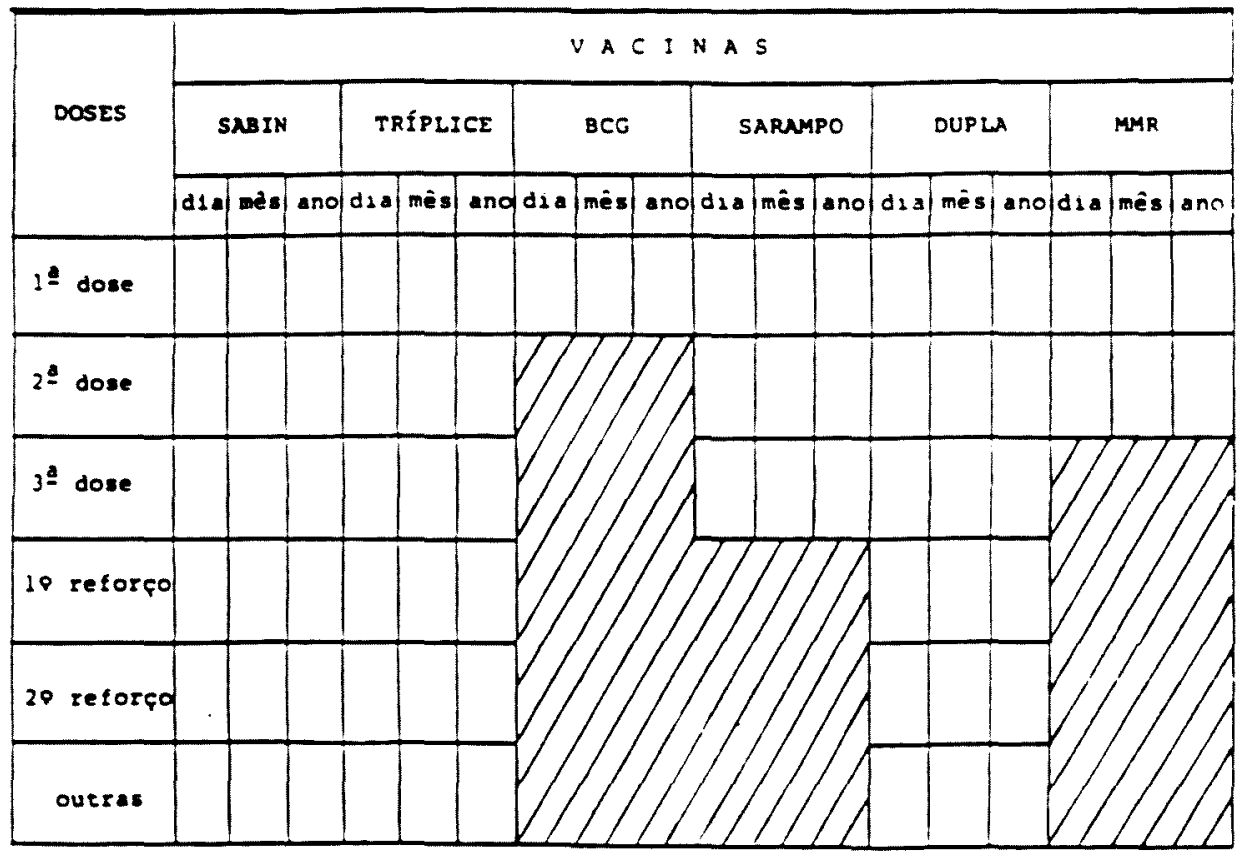

121. Onde a criança foi vacinada?

Tıpo de Serviço

Nome

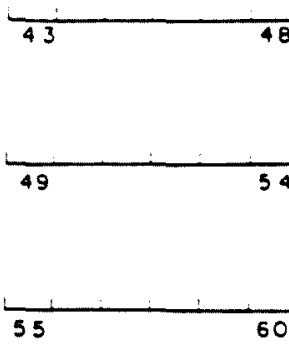

Endereço R.

Ba15ro

Munzelp1o

9. NS/NR

Anote aqui os dados necessärios a complementacār do quad: da cucotär

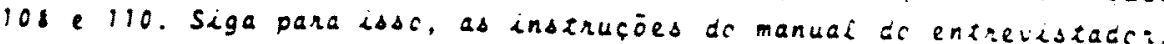

112. Informaçōes obtidas de:

1. caderneta de vacinaçāo

2. verbalmente (através da māe ou responsável)

3. caderneta de vacinaçāo + informaçōes verbais da māe ou responsä vel

CAMPANEAS

113. $C(a)$

recebeu vacinas quando forar

realizadas as campanhas de vacınaçäo das seguintes datas?

Solicite os comprovantes

\begin{tabular}{|c|c|c|c|c|c|}
\hline ano & VACINADO & $\begin{array}{c}52 \mathrm{~m} \\
\text { No dose }\end{array}$ & nāo & NS NR & $\begin{array}{l}\text { não } \\
\text { se } \\
\text { aol1ca }\end{array}$ \\
\hline 86 & Campö110 & & & & \\
\hline \multirow{2}{*}{87} & Canpólio & & & & \\
\hline & Sarampo & & & & \\
\hline \multirow[t]{2}{*}{$8 B$} & Campö110 & & & & \\
\hline & Sarampo & & & & \\
\hline
\end{tabular}

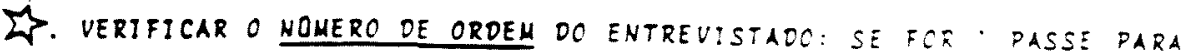
CONJUNTO K, CASO CONTRIRIO ENCERRE C RUESTIONAR? 
NirEXO Do :LOCO 11

CODIFICACRO DAS

aDERNETAS DE VACINAGAG

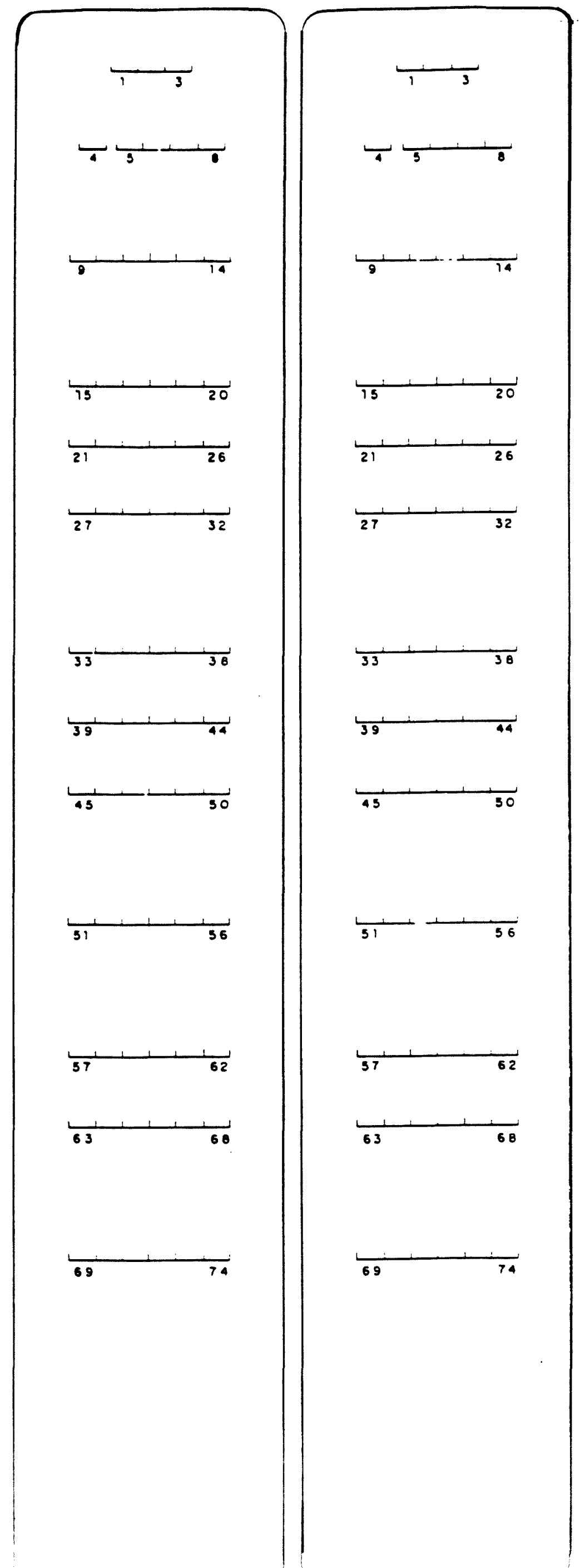


BLOCO 12

\section{CONDIÇAO SÓCIO-ECONŌMICA IPARA TODOS OS INDIVIDUUS ACIMA DE 7 ANOS - EX} CETO CHEFES DE FAMILIAI

214. Aef que ano da escola o $S z$ (a) freqdentou?

0.1 nunca freqdentou sabe ler e escrever

0.2 nunca frequnatou nāo sabe ler e eszrever

1. - primirlo ou 18 grau

2.- glnielo ou 19 grau

3. - coleglal ou 29 grau

3.5 cureos técnlcos de nivel mädo completo

3.6 cureos céenlcos de nivel mîdio incompleto

4.0 undvarsidada completa

5.0 \% iveraldade incompleta

\$ 113. A:iuimante O Sr(a) exerce alguma atividade (seja ela remunerada ou nio remunerada) de trabalho?
1. Sin, an atividade
2. Im, afastado por motivo de doença
3. 81m, - tamber aposentado
1. ñ̄o, desempregado
5. sāo, uposentado
6. nĩo, dons de casa
7. nīo, só entudante
(encerre o blocol
8. nāo, outros Pare os undividuos de 7 a 16
inos. siga pare a questio 116 .
Para os macores de is anus. pu le a questár 116 e passe para a 119

If SOMEnTE para as crianças de, a li anos

116. Descreva o local onde vocé trabalha o que faz lá. (t1po de traba lho desenvolvido, e que produz ou vende a empresal
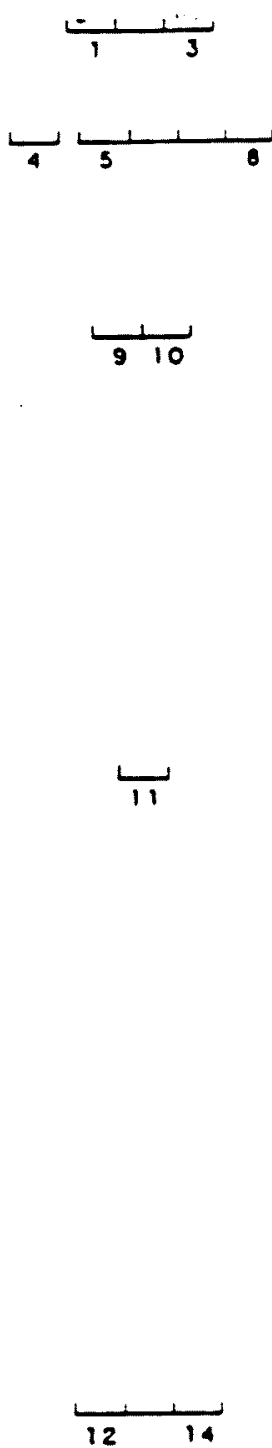

9. NSMR

(Encerre o blaco)

Z SOMEnTE para matores de 14 anos

117. Oual a/era o seu cargo/ocupação ou função em seu trabalho princ1 eipal? Descreva as enrefas mals frequentes que desenvolve em seu trabalho.

loescrever detalhadamenze o que o individuo ia: 1 
\$ 118. No neu =rabulho prineipal o $\mathrm{sr}(\mathrm{a})$ é/eraplleie as alternatevas da

1. enprugado asulariado com carteira profissional assinada

2. ampegeu. insterlado sem cartelra profissional assinada

3. empregado fimiliar não remunerado

4. contr. própria nu autónomo com estabelecimento

5. ronta própria ou autónomo sem estabelecimento

6. erprejador con até funcionãrios flxos

7. ... : : ec. 5 ou mals fuscionärios fixos

8. para $t$ ibilnador rural que nà se encaixe nas aiternativas acima descraver detalhadamente sua situaçāo

9. is. ik

119. Descreva qual é/era a atividade to estabelecimento, empresa, negó clo su instituiçàs em que trabalha/trabalhou.

$93 / \mathrm{NR}$

120. im que Municiplo tlca o lugar onde o $5 r(a)$ Erabalha/trabalhou?

1. no próprio Munielplo

2. outro Municiplo:

$$
\text { Rus : }
$$
No

Balrso Municipio

1. salário 11quido. NCz\$

9. NS/NR

122. Ném deste trabalho o $\mathrm{Sr}(\mathrm{a})$ tem algum outro tipo de trabalho remune rado? ( $f$ ixo ou eventual).

1. nāo.. (passe para a questão 124 )

2. $1 \mathrm{x}$

9. NSANR

123. Qunnto o $\mathrm{Sr}$ (a) ganhou com este trabalho no més passado?

1. Salizio 1Iquido. NCzs

9. NSMR

124. O Sr(a) tem algur outro rendimento além do(s) declazado(s) anterzog mante?

1. nāo

2. sim. Quanto? NCzs

9. NS/NR

CONDICAO DE CLASSE SOcIal (PARe uso de codificaçäo)
$1.1 \cdot$ NPB
$2.1-\mathrm{NPB}$
3.2 - NPB
$\therefore .2-\mathrm{PT}$
$2.2-P T$
2.3 - SP
$2.3-5 P$
$2.4-\mathrm{PBZ}$
$3.5-P B:$
$3.6-3$ 
BLOCO 13

125. Caracterização do domicfl120:
1. casa
2. apartamento
3. barraco
4. casa de cómodos (cabeça de porco/cort1̧̧o)
5. outros. Especificar

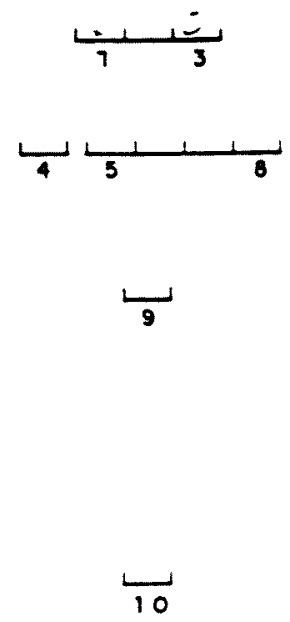

127. Quantas pessoas moram nesta casa?

$$
\text { pessoss }
$$

9. NS/NR

128. Quantos cōmodos tem en sua casa, tirando o banhelro? cômodos
9. NS/MR

129. IIpo de parede dominante
1. t1jolo
2. madelra
3. tíbua
4. bloco
5. outros. Espectelcar
9. MS/NR

130. Revestimento das paredes externas
1. total
2. parcial
3. Inexistante
9. NS/NR

131. Revestimanto das paredes intermas
1. total
2. parcial
3. Inexistente
9.'NS/NR 
132. Time du piso doninante
1. terra batida
2. t1jolo ou cimento
3. Ladr 1 ho
4. assoalho, taco, carpete
5. Outros. Especiflear
9. NS/NR

133. T1po de cobertura tominante
1. telha de cerainlca
2. Elbra-cimento
3. Laje
1. out $=0$. Especificar
9. NS/NR

134. Tlpo de forro dominante
1. estuque ou laje
2. madeira
3. outros. Espec1flcar
4. Inextstente
9. $\because$ NR

135. -1po de 1nstalaçāo sanitäria
1. Inexistente
2. externa e coletivo
3. externa e unifamiliar
4. Interna e coletiva
5. Interns e unifamiliar
9. Ns/NR
(ppde haver maid de uma respobta)

136. Destino dos dejetos
1. S1stema püblico de esgoto
2. esgoto a cẻu aberto
3. Lossa séptica e seca
4. Eossa negra
5. Outros. Especificar

9. NS/NR

(pode haver mais de uma resposta)

137. Abastecimento de água (11gação de água)
1. rede püblica Interna
2. reae püblica externa
3. poço artesiano interno
1. popo artesiano externo
5. poço comum Interno
6. poço comum externo
9. IS/AR
(pode haver nais de uma resposta)

138. Destino de $11 \times 0$
1. enterra
2. joga em terreno baldio
3. queima
4, coleta diaria
5. coleta en dias alternados
6. coleta una vez por semana
7. coleta irregular
8. outros. Especificar
9. NS/NR

loode haver mats ic uma resposta 


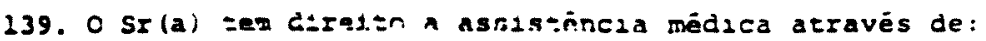

1. Seçuz. raita =zinadc

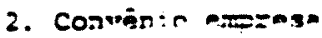

3. Sincicatrs anociacōes de categorias

4. IAMSPE

5. INRYPS

6. outros

7. กão tan c1re1:o

9. NS/NR

(pode haven mais de uma resposta)

140. Até que ann da exsola o Sr(a) completou?

0.1 nunca freqüntos abe ler e escrever

0.2 nunca frnctentou não sabe ler e escrever

1.- primairio ou 19 grau ano/série

2. - ginásio ou 10 grau _..._... ano/séxie

3. - colegial ou 20 grau _...... ano/sérle

3.5 curaos técnicos de nivel médio completo

3.6 cursos técnicon de nivel méd1o incompleto

4.0 universitade completa

4:1 undversidade incompleta

141. Atualmente a $S r(a)$ exezce alguma atividade (seja ela remunerada ou nāo remuneradal de trabalho?

1. sim, en esividade

2. sin, afastado por motivo de doenca

3. sim, e Embeim aposentado

4. nāo, dnceroregaco

5. näo, apcrentado

6. não, dona de casa

7. näo, só extudante lpassc para a questāo 150 |

8. nāo, outros

112. Qual ë/era a sau eargo/ocupação ou funçào em seu trabalho principal? Descreva as tarefas mals frequentes que desenvolve em seu trabalho. 1Descrever dezalhadamenze o que o indiviauo bazl 
143. Liv een trabelho frincipal o $\mathrm{sr}$ (a) Ë/era?

leeia as uternatuves de questāo para o entrevistadol

1. empregudo assalariado com carteira profissional aselnada

2. empregado assalariado sem carteira profissional assinada

3. emorẹado familiar nào remunezado

4. conts própria ou autōnomo com estabelecimento

5. conta prépria ou autōnomo sem eatabelecimento

6. empreç dór con até 4 sunclonárlos fixos

7. emprecador con 5 ou mals funcionários fixos

8. para trabalhador rural que nāo se encaixe nas alternativas acl ma. descrever detalhadamente sua situaçāo.

9. HSNR

144. Descreva zual E/era at1vidade do estabelecimento, empresa, neg\$ clo ol snstituş̧̄o en que trabalha/trabalhou.

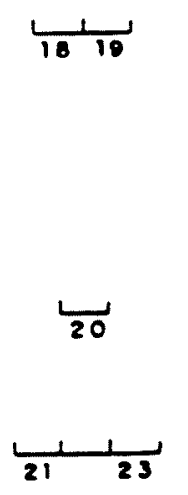

9. NS NR

Municipio

Ipara os desempregados passe para a questāo 149 )

146. quanto o Sr(a) ganhou com esse trabal ho ou aposentadoria no més pas

1. Salärio liqquido. NCzs

sado?

9. NS/NR

147. Além deste trabalho $\circ \mathrm{Sr}(\mathrm{a})$ ter algun outro tipo de trabalho remune rado? ( $\$ 1 \times 0$ ou eventual)

1. nāo.. . |passe para a questão 149 |

2. sim

9. NS/NR

148. Ouasto o $S r$ (a) ganhou com este trabalho no mes passado?

1. salário 1Iquido. NCzs

2. NS/NR

149. O SI(a) tem algum outro rendimento além do(s) declarado(s) anterlog mante?

1. nāo

2. sim. Quasto? NCz\$

9. NS/NR

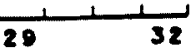

33

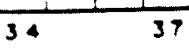


150. Qundro de composiçāo e renda famil1ar:

(Arrole todos os moradores do domicilio que posduam renda)

\begin{tabular}{|l|l|}
\hline WORE & RENDIMENTO TOTAL \\
\hline Chele & \\
\hline & \\
\hline & \\
\hline & \\
\hline & \\
\hline & \\
\hline & \\
\hline & \\
\hline & \\
\hline RENOA ENMILIAR & \\
\hline
\end{tabular}

CODIFICACAO DE CIASSE SOCjAL (Para uso da codificaçāo)
1.1 - NPB
$2.1-$ NPB
$2.2-P T$
$1.2-P T$
$2.3-S P$
$3.1-$ NPB
$1.3-S P$
$2.5-$ PBI
$3.5-$ PBT
$1.4-$ PNT
$3.6-B$

151. Quanto o $5 r(a)$ gastou no ủltimo mès com energia elétrica: sces
9. NS/NR
0. não se aplica

152. O Sr(a) tem algur tipo de plantaçāo ou de crlacāo que contribul no:
1. orcamento famlilar
$O_{s i m}$
Oñ̄o
2. al1mentaçāo
não

153. O $5 x(a)$ possui?

Ileia as alternativas da questāo para o entrevistado!
$3 \int 1$. enceradelra
2. refrigerador
6 4. televisor
5. toca-discos
$9 \int$ 7. asplzador de pó
8. miquina de lavar roupa
10. telefone
12 11. veículo auto-motor
13. video-cassete
$1 5 \longdiv { 1 4 . ~ f r e e z e r }$
16. Fidio
99. NS/NR 
154. Onde o Sr(a) masceu?

1. no próprio Muricipio

2. outro Municiplo do Estado de São Palto. Oual?

3. outro Eatado do PaIs. Oual? oue muileipio?

1. outro Pals. oual?

9. NSAR
$20 \mathrm{NA}$
(1) urbana
(2) rural

155. Há quanto tempo o Sr(a) mora neste Municiplo?

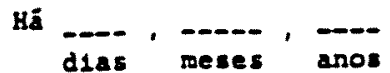

Ha

156. Cansiderando os ültimos 10 anos, quais foram as cidades en que morou. secs -wapectivos estados, zona e cempo de permanéncia en cada uma? incicie pela uleinal

\begin{tabular}{|c|c|c|c|}
\hline CIDNDE & ESTNDO & \begin{tabular}{|c|c|} 
20NA \\
1. urbana \\
2. rouros
\end{tabular} & IRYPO \\
\hline & & & \\
\hline & & & \\
\hline & & & \\
\hline & & & \\
\hline & & & \\
\hline & & & \\
\hline & & & \\
\hline & & & \\
\hline & & & \\
\hline & & & \\
\hline
\end{tabular}

157. O Sr(a) estä associado cu fll1ado a algran Associaç̄o, S1ndlcato ou partido pollesco?

(Leia as alzennazivas para o enerevisladol

1. nāo

2. II e frequenta as reuniōes

3. 1. e näo frequerea as reuniōes

9. NS/NR

Especificar o(s) nome (s) da(s) Associagāo(öes), Sindicato(s) ou Par t1do(s) PolIt1co(s) ao(s) qual(is) está associado ou f1llado:

9. NSAR

-

258. O SI (a) costum lez jozal?

1. - nāo

2.. s1m. Especticar gand (1s)

9. NS/UR 